UNIVERSIDADE DE SÃO PAULO

ESCOLA DE ENFERMAGEM

DANIELA BRAGA LIMA

ANEMIA E DEFICIÊNCIA DE VITAMINA A EM CRIANÇAS

BRASILEIRAS

SÃO PAULO

2014 
DANIELA BRAGA LIMA

\section{ANEMIA E DEFICIÊNCIA DE VITAMINA A EM CRIANÇAS BRASILEIRAS}

Tese corrigida apresentada ao Programa de Pós-Graduação em Enfermagem da Escola de Enfermagem da Universidade de São Paulo para obtenção do título de Doutora em Ciências. A versão original se encontra disponível na Biblioteca da EEUSP.

Área de concentração: Cuidado em Saúde.

Orientadora: Prof. ${ }^{\mathrm{a}}$ Dr. ${ }^{\mathrm{a}}$ Elizabeth Fujimori.

\section{SÃO PAULO}


AUTORIZO A REPRODUÇÃO E DIVULGAÇÃO TOTAL OU PARCIAL DESTE TRABALHO, POR QUALQUER MEIO CONVENCIONAL OU ELETRÔNICO, PARA FINS DE ESTUDO E PESQUISA, DESDE QUE CITADA A FONTE.

Assinatura:

Data:

Lima, Daniela Braga

Anemia e deficiência de vitamina A em crianças brasileiras /

Daniela Braga Lima. -- São Paulo, 2014.

$125 \mathrm{p}$.

Tese (Doutorado) - Escola de Enfermagem da Universidade de São Paulo.

Orientadora: Prof. ${ }^{a}$ Dr. ${ }^{a}$ Elizabeth Fujimori.

Área de concentração: Cuidado em Saúde

1. Anemia. 2. Vitamina A - Deficiência. 3. Saúde da criança. 4. Epidemiologia. 5. Nutrição. 6. Enfermagem em Saúde Pública. I. Título. 
Nome: Daniela Braga Lima

Titulo: Anemia e deficiência de vitamina A em crianças brasileiras.

Tese apresentada ao Programa de Pós-Graduação em Enfermagem da Escola de Enfermagem da Universidade de São Paulo para obtenção do título de Doutora em Ciências.

Aprovado em: _______

\section{Banca Examinadora}

Prof. Dr. Instituição:

Julgamento: Assinatura:

Prof. Dr. Instituição: Julgamento: Assinatura:

Prof. Dr. Instituição:

Julgamento: Assinatura:

Prof. Dr. Instituição: Julgamento: Assinatura:

Prof. Dr. Instituição:

Julgamento: Assinatura: 


\section{DEDICATÓRIA}

Dedico este trabalho a Deus, presença constante, equilíbrio e força, iluminando meu caminho nessa trajetória.

Aos meus pais, Maria Perpétuo e Severino, e aos meus irmãos Murilo e Luiz, que já não se encontram entre nós, mas deixaram seu espectro de luz, amor e exemplo.

À minha família, pelo carinho, a confiança, o apoio incondicional e por compartilhar comigo, mesmo distante, todas as emoções, alegrias e dificuldades dessa fase.

Ao Carlos, por suas palavras de ânimo nos momentos mais difíceis e por suportar, pacientemente, minhas ausências. 


\section{AGRADECIMENTOS}

A Deus, minha fortaleza, meu sustento e refúgio.

À professora e orientadora Dr. ${ }^{a}$ Elizabeth Fujimori, que me ensinou, com humildade e grandeza, o caminho a ser percorrido, por sua competência, dedicação constante e ensinamentos ofertados ao longo dessa trajetória. Sua sabedoria, confiança e amizade acrescentaram valores imprescindíveis à minha evolução.

Ao Lucas Petri Damiani a amizade, contribuição e aprendizado na aplicação das técnicas de estatística e na análise dos dados.

Aos integrantes do grupo de pesquisa Núcleo de Estudos Epidemiológicos na Perspectiva da Enfermagem em Saúde Coletiva (Nepesc) o convívio e as experiências compartilhadas. Em especial, à professora Dr. ${ }^{a}$ Ana Luiza Vilela Borges as contribuições e palavras incentivadoras.

A todos os professores e funcionários do Departamento de Saúde Coletiva da Escola de Enfermagem da USP, que me atenderam em diferentes momentos e de diversas formas, possibilitando-me desenvolver este estudo.

Aos professores integrantes da banca de defesa pública, por aceitarem o convite e pelas valiosas contribuições, que permitiram o aprimoramento deste trabalho.

Às amigas Ana Rute, Maria Marta, Maysa, Micheline, Simone Albino e Simone Assis a generosidade e o apoio, solidificando nossa amizade e crescimento.

Agradeço, enfim, a todos que, de forma direta ou indireta, contribuíram para meu crescimento pessoal e profissional. 
Não há saber mais ou saber menos: Há saberes diferentes.

(Freire, 1987) 
Lima DB. Anemia e deficiência de vitamina A em crianças brasileiras [tese]. São

Paulo: Escola de Enfermagem, Universidade de São Paulo; 2014.

\section{RESUMO}

Introdução: Dentre as carências nutricionais de maior relevância destacam-se, neste estudo, anemia e deficiência de vitamina A, que constituem as principais preocupações das políticas públicas, na área de alimentação e nutrição. Apesar de medidas de prevenção e controle já terem sido implantadas no Brasil há algum tempo, suas prevalências continuam elevadas, com profundas repercussões na saúde infantil. Assim, embora reconhecidos como problemas de saúde pública e bastante explorados, politicamente, ainda há espectros de interesse epidemiológico a serem investigados. Objetivo: Analisar os determinantes da anemia e da deficiência de vitamina A (DVA), bem como a presença concomitante dessas duas carências nutricionais em crianças brasileiras. Métodos: Reanálise dos dados da Pesquisa Nacional de Demografia e Saúde da Criança e da Mulher (PNDS) de 2006, abrangente inquérito das condições de saúde de mulheres e crianças brasileiras cuja $3^{a}$ edição incorporou a avaliação dos níveis de hemoglobina e vitamina A. Essa reanálise baseou-se numa amostra probabilística complexa com representação nacional, o que permitiu descrever a situação de anemia e DVA nas macrorregiões brasileiras e suas áreas urbanas e rurais. $\mathrm{O}$ presente estudo incluiu a análise de 3.417 crianças de 6 a 59 meses. Anemia foi definida como hemoglobina $(\mathrm{Hb})<11 \mathrm{~g} / \mathrm{dL}$, determinada pelo método da cianometa-hemoglobina. DVA foi definida como retinol sérico $<0,7 \mu \mathrm{mol} / \mathrm{L}$, avaliado por cromatografia líquida de alta eficiência. Para expansão da amostra utilizaram-se critérios adotados pela PNDS. As variáveis respostas foram presença de anemia, de DVA e carência concomitante de DVA e anemia, enquanto as explanatórias, analisadas considerando-se três dimensões, foram vinculação aos processos estruturais da sociedade (variáveis socioeconômicas e ambientais); ao ambiente imediato da criança (variáveis maternas, de segurança e consumo alimentar); e individual (características biológicas da criança). A força de associação entre as variáveis respostas e as explanatórias foi avaliada pelo odds ratio (OR), tanto na análise univariada (OR bruta) quanto na múltipla (OR ajustada), com nível de significância de 5\%. Resultados: Determinantes da anemia: A prevalência de anemia no País foi de $20,5 \%$. Na análise múltipla, permaneceram associadas à anemia residir no Nordeste [OR: 3,45; IC: 2,21-5,40] Sudeste [OR: 2,55; IC: 1,60-4,06] e Sul [OR: 2,22; IC: 1,39-3,55]; na zona urbana [OR: 2,01; IC: 1,35-3,00]; e ter insegurança alimentar grave [OR: 1,78; IC: 1,003,16 ], destacando-se como proteção ter mãe com 5 a 8 anos de estudo [OR: 0,62; IC: $0,41-0,92]$ e consumir carne pelo menos uma vez na semana [OR: 0,45; IC: 0,22-0,93]. Determinantes da DVA: A prevalência de DVA no País foi de 17,5\%. Após ajuste para as variáveis de confusão, permaneceram associadas ao DVA residir no Nordeste [OR: 1,77; IC: 1,16-2,77] e Sudeste [OR: 1,74; IC: 1,16-2,72]; na zona urbana [OR: 1,29; IC: 0,91-1,87]; e ter mãe com idade $\geq 36$ anos [OR: 3,14; IC: 1,48-7,09], considerando-se proteção consumir carne pelo menos uma vez na semana [OR: 0,19; IC: 0,09-0,40]. Determinantes da DVA e da anemia: A prevalência concomitante de DVA e anemia foi de 3,9\%, sem associação entre elas $(p>0,05)$. As variáveis estatisticamente associadas $(p<0,05)$ com DVA e 
anemia na análise múltipla foram residir no Sudeste [OR: 4,28; IC: 1,96-11,68] e Nordeste [OR: 2,92; IC: 1,31-7,96]; na zona urbana [OR: 3,66; IC: 1,46-12,30]; e ter insegurança alimentar grave [OR: 3,64; IC: 1,41-8,84]; revelando-se proteção ter idade $\geq 2$ anos de idade [OR: 0,51 ; IC: $0,26-0,99$ ]; e consumir carne pelo menos uma vez na semana [OR: 0,04; IC: 0,00-0,23]. Conclusões: Os resultados mostram redução importante na prevalência de anemia e DVA infantil no Brasil, embora, de acordo com o critério de importância epidemiológica da Organização Mundial da Saúde (OMS), continuem como problema moderado de saúde pública. Apesar das fortes evidências de que a DVA contribui para o desenvolvimento da anemia, constatou-se baixa prevalência concomitante dessas duas carências nutricionais entre as crianças brasileiras, e sem associação entre elas. Entretanto, anemia e DVA apresentam determinantes comuns (residir em macrorregiões menos e mais desenvolvidas e em área urbana), que reiteram o caráter trans-social dessas carências estudadas. $\mathrm{O}$ fato de terem como determinante a insegurança alimentar e como proteção consumir carne pelo menos uma vez por semana reforça a determinação social dessas deficiências nutricionais, embora a insegurança alimentar não tenha se associado à DVA. Os resultados evidenciaram como principais determinantes da anemia e da DVA aqueles relacionados aos processos estruturais da sociedade e do ambiente imediato da criança e não os individuais. Constatou-se, também, que as estratégias governamentais têm contribuído para a prevenção e controle dessas carências nutricionais no País, porém, sinaliza-se a necessidade de expansão da estratégia governamental no sentido de prevenção e controle da DVA, até então restrita a áreas de risco (região Nordeste e áreas pobres da região Sudeste).

Palavras-chave: Anemia. Deficiência de vitamina A. Saúde da criança. Fatores epidemiológicos. Nutrição em saúde publica. Enfermagem em saúde pública. 
Lima DB. Anemia and vitamin A deficiency in Brazilian children [thesis]. São

Paulo: Escola de Enfermagem, Universidade de São Paulo; 2014.

\begin{abstract}
Introduction: Among the most relevant nutritional deficiencies, anemia and vitamin A deficiency stand out, constituting the main concerns of public policy in food and nutrition area. Even though prevention and control measures have already been implemented in Brazil some time ago, their prevalence remains high, with profound effects on child health. Thus, in spite of recognized as problems of public health and plenty explored, politically, there are still spectra of epidemiological interest to be investigated. Objective: To analyze the determinants of anemia, vitamin A deficiency (VAD), as well as these two concomitant nutritional deficiencies in Brazilian children. Methods: Reanalysis of data from the National Survey on Demography and Health of Women and Children (PNDS) of 2006, comprehensive survey of health of women and children in Brazil, whose 3rd edition incorporated the evaluation of hemoglobin and vitamin A levels. This reanalysis was based on a complex random sampling with national representation, which allowed describing the situation of VAD and anemia in Brazilian regions and their urban and rural areas. This study included analysis of 3.417 children aged from 6 to 59 months. Anemia was defined as hemoglobin $(\mathrm{Hb})<11 \mathrm{~g} / \mathrm{dL}$, determined by cyanometahemoglobin method. VAD was set as serum retinol $<0.7 \mu \mathrm{mol} / \mathrm{L}$, evaluated by high performance liquid chromatography. To expand the sample, the criteria adopted by PNDS were used. The variable responses were presence of anemia, VAD and concomitant deficiency of VAD and anemia, while the explanatory, analyzed considering three dimensions, were link to the structural processes of society (socioeconomic and environmental variables), to the immediate environment of the child (maternal variables, of safety and food consumption); and individual (biological characteristics of the child). The strength of association between the response and the explanatory variables was evaluated by odds ratio (OR), both in univariate (crude OR) and in multiple analysis (adjusted OR), with a significance level of 5\%. Results: Determinants of anemia: The prevalence of anemia in the Country was $20.5 \%$. In multiple analysis, remained associated with anemia living in the Northeast [OR: 3,45, CI; 2,21-5,40], Southeast [OR: 2,55; CI: 1,60-4,06] and South [OR:2,22;IC:1,39-3,55]; in urban area [OR: 2,01; CI: 1,35-3,00], and having severe food insecurity [OR: 1,78; CI :1,00-3,16], highlighting as protection having a mother with 5 to 8 years of study [OR: 0,62; CI: 0,41-0,92] and consuming meat at least once a week [OR: 0,45; CI: 0,22-0,93]. Determinants of VAD: The prevalence of VAD in the Country was $17.5 \%$. After adjustment for confounding variables, remained associated with DVA living in the Northeast [OR: 1,77; CI: 1,16-2,77] and Southeast [OR: 1,74; CI: 1,16-2,72]; in urban area [OR: 1,29; CI: 0,91-1,87]; and having a mother aged $\geq 36$ years [OR: 3,14; CI $: 1,48-7,09]$, considering protection to consume meat at least once a week [OR: 0,19; CI: 0,09-0,40]. Determinants of anemia and VAD: The concomitant prevalence of VAD and anemia was $3.9 \%$, with no association between them $(\mathrm{p}>0,05)$. Variables statistically associated $(\mathrm{p}<0.05)$ with VAD and anemia in
\end{abstract}


multiple analysis were living in the Southeast [OR: 4,28; CI: 1,96-11,68] and Northeast [OR: 2,92; IC: 1,31-7,96]; in urban area [OR: 3,66; CI: 1,46-12,30], and having severe food insecurity [OR: 3,64; CI: 1,41-8,84]; revealing protection being $\geq 2$ years old [OR: 0,51 ; CI: $0,26-0,99$ ] and consuming meat at least once a week [OR: 0,04; CI: 0,00-0,23]. Conclusions: The results show a significant reduction in the prevalence of child anemia and VAD in Brazil, although according to the criterion of epidemiological importance of the World Health Organization (WHO), they continue as a moderate public health problem. Despite strong evidences that VAD contributes to the development of anemia, it was verified a low prevalence of these two concomitant nutritional deficiencies among Brazilian children, and no association between them. However, anemia and VAD present common determinants (living in macro-regions less and more developed and in urban areas), reaffirming the transocial character of these nutritional deficiencies. The fact they have as a determinant food insecurity and as protection consuming meat at least once a week reinforce the social determination of these nutritional deficiencies, although food insecurity was not associated with VAD. The results showed as major determinants of anemia and VAD, those related to structural processes of society and the immediate environment of the child and not the individuals. It was also verified that government strategies have contributed to the prevention and control of these nutritional deficiencies in the Country, but it is signalized the need for expansion of the government's strategy for prevention and control of VAD, so far restricted to high-risk areas (Northeast and poor areas of the Southeast).

Keywords: Anemia. Vitamin A deficiency. Child health. Epidemiologic factors. Public health nutrition. Public health nursing. 


\section{LISTA DE ILUSTRAÇÕES}

\section{FIGURAS}

Figura 1 - Diagrama conceitual da relação entre deficiência de ferro e anemia em uma população hipotética

Figura 2 - Modelo hierárquico dos fatores determinantes da anemia............

Figura 3 - Modelo causal de determinação da deficiência de vitamina A em menores de cinco anos

Figura 4 - Fluxograma para seleção da amostra de crianças com análise de retinol sérico e hemoglobina.

Figura 5 - Modelo hierárquico proposto para a análise dos determinantes da anemia, DVA e ocorrência concomitante de DVA e anemia........

Figura 6 - Prevalência de DVA, anemia e DVA e anemia concomitantes em crianças de 6 a 59 meses de idade por macrorregiões de residência. Brasil, PNDS/2006

Figura 7 - Correlação entre os níveis de retinol sérico e as concentrações de hemoglobina em crianças de 6 a 59 meses de idade. Brasil, PNDS/2006.

Figura 8 - Modelo hierárquico para a análise dos determinantes das carências nutricionais. 


\section{QUADROS}

Quadro 1 - Estudos nacionais de prevalência de anemia infantil por macrorregião, analisados em duas Revisões de Literatura..............

Quadro 2 - Estudos nacionais de prevalência de anemia infantil por macrorregião.

Quadro 3 - Estudos nacionais de prevalência de DVA infantil por macrorregião, analisados em sete Revisões de Literatura............ 35

Quadro 4-Estudos nacionais de prevalência de DVA infantil por

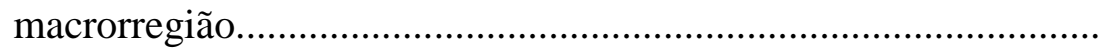

Quadro 5 - Caracterização da condição socioeconômica e ambiental do estudo. 60

Quadro 6 - Descrição das variáveis biológicas das crianças do estudo. 61 


\section{TABELAS}

Tabela 1 - Prevalência de anemia em crianças de 6 a 59 meses de idade, segundo as variáveis dos Blocos 1 e 2. Brasil, PNDS/2006.

Tabela 2 - Proporção de crianças com 6 a 59 meses de idade com anemia, segundo o consumo alimentar dos grupos de alimentos nos últimos sete dias (Bloco 2). Brasil, PNDS/2006

Tabela 3 - Prevalência da anemia em crianças de 6 a 59 meses de idade, segundo as variáveis biológicas (Bloco 3). Brasil, PNDS/2006... 70

Tabela 4 - Modelo múltiplo final dos determinantes associados à anemia em crianças de 6 a 59 meses de idade. Brasil, PNDS/2006

Tabela 5 - Prevalência de DVA em crianças de 6 a 59 meses de idade, segundo as variáveis dos Blocos 1 e 2. Brasil, PNDS/2006

Tabela 6 - Proporção de crianças com 6 a 59 meses de idade com DVA, segundo o consumo alimentar dos grupos de alimentos nos últimos sete dias (Bloco 2). Brasil, PNDS/2006

Tabela 7 - Prevalência de DVA em crianças de 6 a 59 meses de idade, segundo as variáveis biológicas (Bloco 3). Brasil, PNDS/2006.... 75

Tabela 8 - Modelo múltiplo final dos determinantes associados à DVA em crianças de 6 a 59 meses de idade. Brasil, PNDS/2006

Tabela 9 - Associação entre níveis de retinol sérico e concentrações de hemoglobina em crianças de 6 a 59 meses de idade. Brasil, PNDS/2006.

Tabela 10 - Prevalência concomitante de DVA e anemia em crianças de 6 a 59 meses de idade, segundo variáveis dos Blocos 1 e 2. Brasil, PNDS/2006.

Tabela 11 - Prevalência concomitante de DVA e anemia em crianças de 6 a 59 meses de idade, segundo o consumo alimentar dos grupos de alimentos nos últimos sete dias (Bloco 2). Brasil, PNDS/2006.....

Tabela 12 - Prevalência concomitante de DVA e anemia em crianças de 6 a 59 meses de idade, segundo variáveis das crianças (Bloco 3). Brasil, PNDS/2006 
Tabela 13 - Modelo múltiplo final dos determinantes associados à ocorrência concomitante de DVA e anemia em crianças de 6 a 59 meses de idade. Brasil, PNDS/2006. 


\section{LISTA DE SIGLAS}

\begin{tabular}{|c|c|}
\hline ABEP & Associação Brasileira de Empresas de Pesquisa \\
\hline Aids & Síndrome da Imunodeficiência Adquirida \\
\hline EAR & $\begin{array}{l}\text { Estimated Average Requirement (Em Português, Necessidade } \\
\text { Média Estimada) }\end{array}$ \\
\hline Deff & Design effects (Em Português, Efeito do desenho) \\
\hline DST & Doença Sexualmente Transmissível \\
\hline DVA & Deficiência de Vitamina A \\
\hline EBIA & Escala Brasileira de Insegurança Alimentar \\
\hline ESF & Estratégia Saúde da Família \\
\hline $\mathrm{Hb}$ & Hemoglobina \\
\hline HPLC & $\begin{array}{l}\text { High Performance/Pressure Liquide Chromatography (Em } \\
\text { Português, Cromatografia Líquida de Alta Eficiência-Clae) }\end{array}$ \\
\hline IA & Insegurança Alimentar \\
\hline IC & Intervalo de confiança \\
\hline IMC/Idade & Índice de massa corporal-para-idade \\
\hline MS & Ministério da Saúde \\
\hline Nepesc & $\begin{array}{l}\text { Núcleo de Estudos Epidemiológicos na Perspectiva da } \\
\text { Enfermagem em Saúde Coletiva }\end{array}$ \\
\hline OMS & Organização Mundial da Saúde \\
\hline OR & Odds Ratio \\
\hline PBF & Programa Bolsa Família \\
\hline PNAD & Pesquisa Nacional por Amostra de Domicílio \\
\hline PNAN & Política Nacional de Alimentação e Nutrição \\
\hline PNDS & Pesquisa Nacional de Demografia e Saúde \\
\hline SAN & Segurança Alimentar e Nutricional \\
\hline Sedex & Serviço de Encomenda Expressa \\
\hline TCLE & Termo de Consentimento Livre e Esclarecido \\
\hline UNICEF & Fundo das Nações Unidas para a Infância \\
\hline WHO & World Health Organization \\
\hline
\end{tabular}




\section{SUMÁRIO}

APRESENTAÇÃO........................................................................................... 19

1 INTRODUÇÃO

1.1Justificativa....................................................................................................... 21

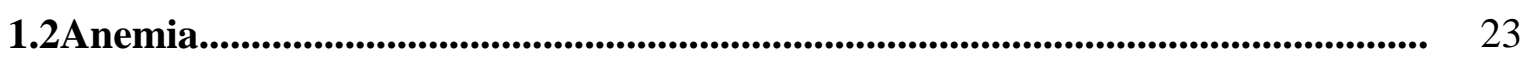

1.2.1 Aspectos gerais.......................................................................................... 23

1.2.2 Prevalência da anemia em crianças............................................................................ 26

1.3 Deficiência de vitamina A.................................................................................... $\quad 30$

1.3.1 Aspectos gerais..................................................................................................... 30

1.3.2 Prevalência da deficiência de vitamina A em crianças............................................ 31

1.4 Interações entre anemia e deficiência de vitamina $\mathbf{A}$........................................... 38

1.5 Determinantes da anemia e da deficiência de vitamina A..................................... 41

2 QUESTÕES DE PESQUISA..................................................... 50

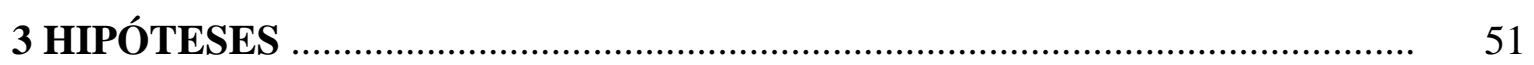

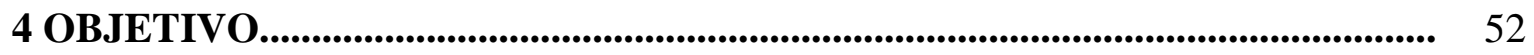

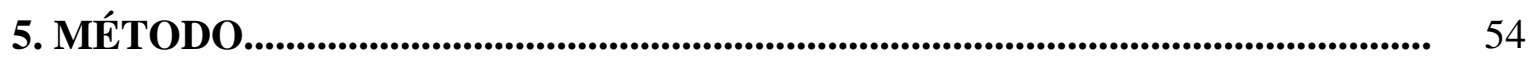

5.1 Delineamento do estudo............................................................................................ 54

5.2 Pesquisa Nacional de Demografia e Saúde da Mulher e da Criança-

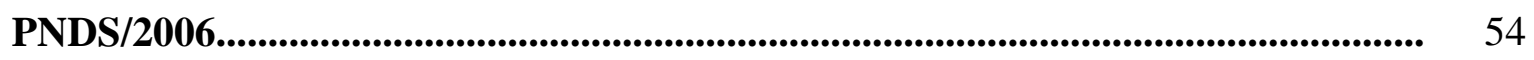

5.2.1 Amostragem da PNDS/2006................................................................................. 55

5.2.2 Processo de expansão da amostra da PNDS/2006.................................................. 56

5.2.3 Aspectos metodológicos da coleta de dados da PNDS/2006 ............................... 56

5.2.4 Dosagens de hemoglobina e retinol sérico ……………................................... 58

5.3 Amostras do presente estudo...................................................................................... 58

5.4 Variáveis do estudo................................................................................................ 59

5.4.1 Variáveis respostas.............................................................................................. 59

5.4.2 Variáveis explanatórias ............................................................................................ 60

5.5 Processamento e análise dos dados......................................................................... 62

6 RESULTADOS............................................................................................................ 66

6.1 Determinantes da anemia ........................................................................................ 66

6.2 Determinantes da deficiência de vitamina A........................................................ $\quad 72$

6.3 Determinantes da ocorrência concomitante de deficiência de vitamina A e 
anemia .................................................................................................................................. 78

7 DISCUSSÃO................................................................................................... 87

8 CONSIDERAÇÕES FINAIS ................................................................................... 107

REFERÊNCIAS............................................................................................... 110 


\begin{abstract}
APRESENTAÇÃO
Desde o início da graduação desta pesquisadora em Nutrição, cursada na Universidade Federal de Ouro Preto, MG, o tema "distúrbios nutricionais em crianças" surgiu de inquietações, observações e vivências, que se mantiveram durante sua trajetória profissional, como nutricionista e docente, atualmente, na Universidade Federal de Alfenas, MG. No mestrado em Ciência da Nutrição, na Universidade Federal de Viçosa, MG, teve a oportunidade de aprofundar seus conhecimentos sobre o perfil nutricional de crianças nos dois primeiros anos de vida. Os resultados do estudo revelaram baixa prevalência de déficits nutricionais, com exceção dos relativos à estatura/idade. Verificou-se que o estado nutricional das crianças foi afetado por algumas condições, a saber: habitação, peso ao nascer, tipo de aleitamento recebido no momento da entrevista, curta duração do aleitamento materno exclusivo e introdução precoce de novos alimentos no primeiro mês de vida. Do ponto de vista nutricional, as dietas se mostraram desbalanceadas e apontou-se o ferro como o nutriente de maior carência no primeiro ano de vida.

O entendimento de que os distúrbios do estado nutricional na criança produzem consequências deletérias para a saúde não só infantil, mas de toda a vida do indivíduo, direcionaram seu interesse à melhor compreensão dos determinantes do processo saúde-doença no grupo infantil, visto que a alimentação e a nutrição da criança representam as maiores demandas nos atendimentos realizados na atenção básica. Assim, motivou a pesquisadora buscar por um doutorado na área do cuidado em saúde que tratasse dos determinantes das condições de saúde das crianças, principalmente em relação às deficiências nutricionais mais prevalentes.
\end{abstract}


Introdução 


\section{INTRODUÇÃO}

\subsection{Justificativa}

Os distúrbios do estado nutricional durante a infância podem ser ocasionados por múltiplas condições, tais como carências nutricionais, e produzem consequências sérias que tornam imperativo seu controle, principalmente nos países em desenvolvimento. Ao longo das últimas décadas, o Brasil sofreu marcantes modificações políticas, econômicas e sociais que contribuíram consideravelmente para beneficiar o perfil nutricional da população infantil, bem como melhorar suas condições de saúde (Batista Filho, Souza, Bresani, 2008; Victora et al., 2011a,b). Com o declínio da prevalência da desnutrição energético-proteica, as deficiências de micronutrientes adquiriram maior relevância enquanto problema de saúde pública, com destaque para a deficiência de ferro e a de vitamina A, que, mesmo com melhoras isoladas, constituem as principais preocupações das políticas públicas na área de alimentação e nutrição infantil (Paiva et al., 2011; Gondim et al., 2012a, Brasil, $2012 \mathrm{a}, \mathrm{b})$.

Apesar de as medidas de prevenção e controle da anemia e da deficiência de vitamina A (DVA) já terem sido implantadas no Brasil há algum tempo, as prevalências dessas deficiências nutricionais continuam elevadas, com profundas repercussões na saúde infantil, que se refletem nas taxas de morbimortalidade desse grupo. Ademais, há estudos que mostram associação entre ocorrência de anemia e DVA, indicando que a DVA contribui para o desenvolvimento da anemia (Semba, Bloem, 2002).

Assim, embora reconhecidas como problemas relevantes e bastante exploradas, ainda apresentam espectros de interesse epidemiológico a serem investigados, a exemplo de seus determinantes e cartografia, referentes à sua distribuição nas macrorregiões brasileiras e à situação urbana e rural. Além disso, poucos estudos analisam a segurança alimentar e o consumo alimentar infantil como determinantes importantes da anemia, da DVA e da carência concomitante de DVA e anemia. 
Justifica-se, com base nessa assertiva, o desenvolvimento deste estudo, consistente em uma reanálise dos dados da Pesquisa Nacional de Demografia e Saúde (PNDS), de 2006 (Brasil, 2009), considerando tratar-se de um abrangente inquérito sobre as condições de saúde de mulheres e crianças brasileiras, cuja terceira edição incorporou a avaliação dos níveis de hemoglobina e vitamina A, além da avaliação da segurança e consumo alimentar, conduzida em amostra representativa da população, que permite descrever a situação da anemia e da DVA nas macrorregiões brasileiras e suas áreas urbanas e rurais. Dessa forma, ampliar também a compreensão dos determinantes da anemia e da DVA na criança e subsidiar propostas de promoção da saúde e prevenção dessas carências, pois essas só podem ser estipuladas a partir do conhecimento prévio do quadro situacional do grupo ou da comunidade na qual a criança se insere, a fim de propor estratégias que possibilitem melhorias das condições de vida. 


\subsection{Anemia}

\subsubsection{Aspectos gerais}

A Organização Mundial da Saúde (OMS) define anemia como um estado em que a hemoglobina sanguínea encontra-se abaixo de valores considerados normais para a idade, sexo e situação fisiológica devido à carência de um ou mais nutrientes, independentemente da sua origem. Assim, a medida da concentração de hemoglobina $[\mathrm{Hb}]$ é o indicador bioquímico mais utilizado em saúde pública para definir essa deficiência nutricional, de maior prevalência nos países em desenvolvimento (WHO, 2004).

A anemia tem como principais causas a carência de um ou mais nutrientes essenciais, necessários para a formação de hemoglobina, tais como ferro, ácido fólico, vitaminas B6, B12, C e proteínas; a hemólise produzida por doenças infecciosas como a malária e parasitoses (esquistossomose, ancilostomíase); ou mesmo as doenças hereditárias que afetam a produção dos glóbulos vermelhos, como a talassemia (WHO, 2001; 2004).

Um diagrama conceitual da relação entre deficiência de ferro, anemia e anemia ferropriva em uma população hipotética é apresentado na Figura 1 (WHO, 2001).

Figura 1- Diagrama conceitual da relação entre deficiência de ferro e anemia em uma população hipotética

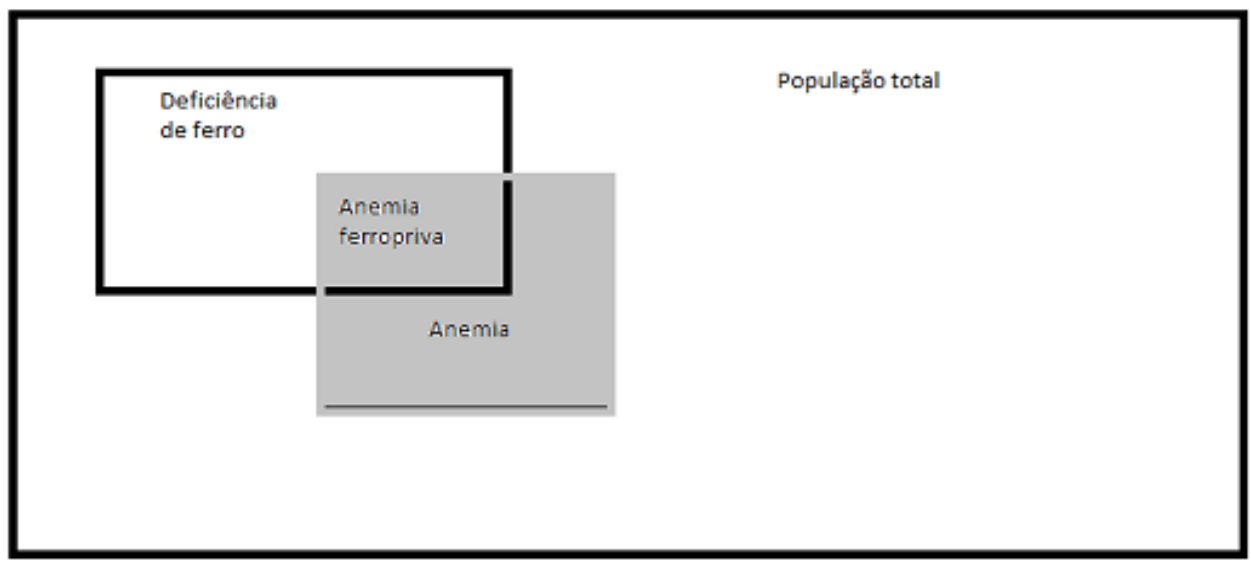

Fonte: WHO, 2001 
A estimativa mais atual é a de que $30 \%$ a $50 \%$ das anemias são causadas por carência alimentar de ferro (WHO, 2007; Miller, 2013), uma vez que a deficiência do mineral tem sido responsabilizada por grande parte das anemias diagnosticadas (WHO, 2001; WHO, 2004).

A anemia por carência de ferro resulta de uma disparidade entre a disponibilidade alimentar e a demanda do nutriente, de forma que dentre as populações em risco para a anemia ferropriva, destacam-se as crianças. A susceptibilidade desse grupo se deve à sua maior necessidade de ferro decorrente da rápida expansão dos tecidos, proporcional à velocidade de crescimento e aumento da massa eritrocitária (Osório, 2002; WHO, 2008; Miller, 2013; Pasricha et al., 2013).

Além disso, a partir dos 6 meses de vida, com o esgotamento das reservas de ferro adquiridas intraútero, a alimentação se torna fundamental para o aporte de ferro. Sabe-se que o abandono precoce do aleitamento materno e a dieta de transição inadequada, somados à elevada velocidade de crescimento, torna as crianças menores de 2 anos de idade o grupo de maior risco para anemia na faixa etária pediátrica (WHO, 2001; Miller, 2013; Pasricha et al., 2013).

Entre os 2 e 6 anos de idade, observa-se um maior equilíbrio entre a demanda do organismo e a oferta dietética de ferro, porém, especialmente nos países em desenvolvimento, as condições de vida adversas e a composição inadequada da alimentação fazem com que a deficiência de ferro continue a ser um problema comum também nessa faixa etária (WHO 2001; Brasil, 2007; Pasricha et al., 2013).

Ademais, nos países em desenvolvimento, além da ingestão inadequada de alimentos fontes de ferro, há que se considerar os problemas decorrentes da interação dos constituintes da dieta com a forma como o mineral se encontra presente nos alimentos (WHO 2001; Brasil 2007; Pasricha et al., 2013).

O ferro está presente naturalmente nos alimentos de origem animal (carnes e ovos) na forma ferrosa $\left(\mathrm{Fe}^{2+}\right)$, também conhecida como ferro-heme, e também nos alimentos de origem vegetal (hortaliças de coloração verde escura e leguminosas como feijão e soja) na forma férrica $\left(\mathrm{Fe}^{3+}\right)$, conhecida como ferro não-heme. A forma ferrosa é mais biodisponível que a férrica, pois esta precisa ser reduzida na presença de ácido clorídrico ou outros agentes redutores, como o 
ácido ascórbico, para ser absorvida (Brasil, 2007). Além disso, a absorção do ferro não-heme sofre influência de outros componentes presentes na dieta, conhecidos como facilitadores ou inibidores da absorção. Ácido ascórbico e carnes são considerados facilitadores da absorção, enquanto os alimentos que contêm compostos fenólicos (chá preto, mate, café e certos refrigerantes), fitatos (cereais), sais de cálcio e fósforo, fibras e proteínas do ovo são inibidores da absorção (Queiroz, Torres, 2000; Osório, 2002).

Na infância, a anemia compromete o sistema imunológico, prejudica o crescimento e desenvolvimento psicomotor, interfere no desempenho cognitivo e aumenta a frequência de morbidades, dentre outros (Miller, 2013; Pasricha et al., 2013).

Embora se trate de "uma endemia de caráter trans-social, que se distribui em todos os continentes, blocos geoeconômicos e grupos sociais" (Batista Filho, Souza, Bresani, 2008), considera-se que a anemia mantém relação de dependência com fatores como renda, escolaridade da mãe, condições insalubres de moradia, (in)segurança alimentar, consumo alimentar inadequado, assistência à saúde insatisfatória, morbidades e algumas variáveis biológicas (Fujimori et al., 2008; Miller et al., 2009; Lynch, 2011; Miller, 2013; Pasricha et al., 2013).

Reconhecendo a deficiência de ferro como um problema de saúde pública, e considerando os efeitos prejudiciais condicionados pela anemia e os riscos dela decorrentes para a saúde dos grupos vulneráveis, principalmente as crianças, o Ministério da Saúde implementou o Programa Nacional de Suplementação de Ferro em 2005, que preconiza a suplementação semanal com xarope de sulfato ferroso (25mg de ferro) como estratégia profilática para o controle da anemia infantil (Brasil, 2005a). Outra estratégia, implementada a partir de 2004, que contempla a totalidade da população, foi a fortificação de todas as farinhas de trigo e milho com ferro e ácido fólico (Brasil, 2002). Outra forma de intervenção importante destacada na Política Nacional de Alimentação e Nutrição (PNAN) é a educação nutricional para prevenção da anemia, que inclui a promoção do aleitamento materno exclusivo até o sexto mês e o incentivo ao consumo de uma alimentação adequada e saudável, assegurando informações para ingestão de alimentos ricos em ferro (Brasil, 2012b). 


\subsubsection{Prevalência da anemia em crianças}

A OMS classifica a anemia em relação ao seu nível de importância epidemiológica em saúde pública de acordo com os seguintes critérios: grave, quando a sua prevalência em crianças menores de cinco anos é > 40\%; moderada, quando se encontra entre $20 \%$ e $39,9 \%$; leve, nos casos de prevalências entre $5 \%$ e 19,9\%; e normal, quando $<4,9 \%$ (WHO, 2001).

Em nível mundial, a anemia afeta cerca de 1,6 bilhões de pessoas, ou $24,8 \%$ da população, sendo que sua maior prevalência ocorre em crianças menores de 5 anos $(47,4 \%)$. As crianças africanas e as do sudeste da Ásia são as que mais sofrem com essa deficiência, com prevalências de até 67,6\% e 65,5\%, respectivamente. As europeias e as do Pacífico ocidental são as menos afetadas, com prevalências em torno de 20,0\%. Nas Américas, a prevalência de anemia entre os pré-escolares está em torno de 30,0\%, e no Brasil, com base no banco de dados da OMS, a anemia afeta 54,9\% das crianças nessa faixa etária, dados que justificam o seu reconhecimento como um problema grave de saúde pública (WHO, 2008).

Estudos realizados no Brasil evidenciam que a anemia apresenta altas prevalências, conforme dados de inquéritos pontuais (Jordão, Bernardi, Barros Filho, 2009; Vieira, Ferreira, 2010). Para análise da distribuição da anemia na população infantil brasileira, realizou-se um levantamento bibliográfico que buscou revisões de literatura sobre o tema. Foram identificados dois artigos de revisão de autores nacionais publicados nos últimos anos, cujos resultados são relatados a seguir.

O primeiro artigo de revisão avaliou a prevalência de anemia infantil no Brasil a partir de 53 trabalhos publicados de janeiro de 1996 a janeiro de 2007. Constatou prevalências elevadas, com mediana de 53,0\%, confirmando a estimativa da OMS. Evidenciou também que a anemia afetava principalmente crianças menores de 2 anos. A maioria dos trabalhos analisados era pontual, realizados em creches e unidades básicas de saúde, indicando a necessidade de condução de novas pesquisas, dessa feita, com amostras de base populacional (Jordão, Bernardi, Barros Filho, 2009). 
A segunda revisão de literatura analisou a prevalência de anemia infantil no Brasil com base em 35 trabalhos publicados a partir de 1996. Desses, nove foram classificados como de base populacional, oito envolveram amostras obtidas em creches ou escolas, seis foram realizados com populações em situação de iniquidade (comunidades indígenas, assentamentos rurais, favelas, clientela da Pastoral da Criança) e 12 procederam de serviços de saúde. Em escolas ou creches, a prevalência média ponderada pelo tamanho amostral foi de 52,0\% (variação de 35,0\% a 68,8\%), e, nos serviços de saúde, de 60,2\% (variação de $55,1 \%$ a $89,1 \%$ ). Na população em situação de iniquidade a prevalência média ponderada mostrou-se mais elevada, 63,5\% (variação de 47,5\% a 96,4\%) (Vieira, Ferreira, 2010).

As duas revisões praticamente analisaram os mesmos estudos, os quais são apresentados no Quadro 1, por macrorregião, indicando autoria e ano de publicação, amostra e prevalência de anemia. Observa-se uma grande variação nas prevalências encontradas, de 10,4\% a 96,4\%, e também no número de estudos por macrorregião geopolítica do Brasil, com concentração no Sudeste e no Nordeste.

Quadro 1- Estudos nacionais de prevalência de anemia infantil por macrorregião, analisados em duas Revisões de Literatura

\begin{tabular}{|l|c|c|}
\hline Estudos por Macrorregião & Tamanho amostral (n) & Prevalência da anemia (\%) \\
\hline NORTE & 75 & 22,7 \\
\hline Tuma et al., 2003 & 365 & 55,1 \\
\hline Neves, da Silva, de Morais, 2005 & 144 & 84,0 \\
\hline Orellana et al., 2006 & 677 & 30,6 \\
\hline Muniz et al,. 2007 & \multicolumn{2}{|l|}{} \\
\hline CENTRO-OESTE & 110 & 60,9 \\
\hline Hadler, Juliano, Sigulem, 2002 & 271 & 63,1 \\
\hline Brunken, Guimarães, Fisberg, 2002 & 178 & 41,0 \\
\hline Brunken, Muniz, Silva, 2004 & 167 & 62,3 \\
\hline Morais, Alves, Fagundes-Neto, 2005 & 58 & 31,0 \\
\hline Silva et al,. 2006 & \multicolumn{2}{|l|}{} \\
\hline NORDESTE & 745 & 22,2 \\
\hline Assis et al., 1997 & 75 & 60,0 \\
\hline Soares et al, 2000 & 777 & 40,9 \\
\hline Osório et al., 2001 & 135 & 35,7 \\
\hline Costa et al, 2001 & 1.287 & 36,4 \\
\hline Oliveira et al., 2002 & 137 & 96,4 \\
\hline Ferreira et al.,2002 & 293 & 77,5 \\
\hline Ferreira et al, 2003 & 603 & 46,3 \\
\hline Assis et al, 2004a & 553 & 62,8 \\
\hline Assis et al, 2004b & 402 & 89,1 \\
\hline Leal e Osório, 2005 & 746 & 40,6 \\
\hline Oliveira, Osório, Raposo, 2006 & 245 & 73,5 \\
\hline Lima et al, 2006 & \multicolumn{2}{|l|}{} \\
\hline
\end{tabular}




\begin{tabular}{|c|c|c|}
\hline Estudos por Macrorregião & Tamanho amostral (n) & Prevalência da anemia (\%) \\
\hline \multicolumn{3}{|l|}{ SUL } \\
\hline Neuman et al., 2000 & 476 & 54,0 \\
\hline Silva, Giugliani, Aerts, 2001 & 557 & 47,8 \\
\hline Uchimura et al., 2003 & 583 & 58,0 \\
\hline Santos et al., 2004 & 304 & 53,0 \\
\hline Vitolo et al., 2005 & 235 & 63,72 \\
\hline Vitolo et al., 2005 & 500 & 58,0 \\
\hline Vitolo, Bortolini, 2007 & 369 & 63,7 \\
\hline Assunção et al., 2007 & 453 & 30,2 \\
\hline \multicolumn{3}{|l|}{ SUDESTE } \\
\hline Szarfarc et al., 1996 & 371 & 42,6 \\
\hline Torres et al., 1996 & 269 & 62,3 \\
\hline Rodrigues et al., 1997 & 288 & 50,0 \\
\hline Souza, Szarfarc, de Souza, 1997 & 317 & 14,5 \\
\hline Vitolo et al., 1998 & 24 & 80,0 \\
\hline Iost et al., 1998 & 185 & 61,0 \\
\hline Fisberg et al., 1999 & 111 & 64,8 \\
\hline Monteiro, Szarfarc, Mondini, 2000 & 1.256 & 46,9 \\
\hline Lacerda e Cunha, 2001 & 288 & 50,0 \\
\hline Magalhães, Ramalho, Colli, 2001 & 135 & 10,4 \\
\hline Nogueira-de-Almeida et al., 2001 & 115 & 68,7 \\
\hline Giorgini et al., 2001 & 89 & 62,0 \\
\hline Paula e Fisberg, 2001 & 93 & 34,4 \\
\hline Silva et al., 2002a & 89 & 11,2 \\
\hline Silva et al., 2002b & 204 & 60,8 \\
\hline Hiratstuka e Ribeiro, 2002 & 63 & 77,8 \\
\hline Lessa, Devincenzi, Sigulem, 2003 & 57 & 69,5 \\
\hline Miranda et al., 2003 & 171 & 63,2 \\
\hline Spinelli et al., 2003 & 135 & 35,0 \\
\hline Castro et al., 2004 & 61 & 47,5 \\
\hline Marchi, Szarfarc, Rodrigues, 2004 & 127 & 40,6 \\
\hline Levy-Costa e Monteiro, 2004 & 584 & 45,2 \\
\hline Terão et al., 2004 & 314 & 40,7 \\
\hline Almeida et al., 2004 & 192 & 62,5 \\
\hline Castro et al., 2005 & 69 & 47,5 \\
\hline Ferraz et al., 2005 & 179 & 35,8 \\
\hline Matta et al., 2005 & 865 & 47,3 \\
\hline Torres et al., 2006 & 72 & 37,5 \\
\hline Bueno et al., 2006 & 330 & 68,8 \\
\hline Silva, Priore, Franceschini, 2007 & 205 & 57,6 \\
\hline Duarte et al., 2007 & 254 & 41,7 \\
\hline Konstantyner, Taddei, Palma, 2007 & 212 & 51,9 \\
\hline
\end{tabular}

Fonte: Adaptado de Jordão, Bernardi e Barros Filho (2009) e Vieira e Ferreira (2010)

A grande maioria dos estudos revelou que a prevalência de anemia era elevada nas crianças brasileiras, classificando-se como problema grave ou moderado em relação à importância epidemiológica em saúde pública, sendo a condição leve encontrada em apenas três estudos realizados na região Sudeste.

Todos os estudos analisados utilizaram a referência da OMS (WHO, 2001) para o diagnóstico de anemia, que recomenda $\mathrm{Hb}<11 \mathrm{mg} / \mathrm{dL}$ para crianças na faixa etária de 6 a 59 meses. O tamanho amostral e os grupos estudados foram bastante heterogêneos, incluindo crianças de creches, escolas, unidades de saúde, bem 
como de domicílio em estudos populacionais e também de inserção socioeconômica diversa, porquanto provenientes de instituições públicas, privadas e de grupos em situação de iniquidade.

Constata-se, pois, que apesar das políticas públicas já efetivadas, a anemia continua como importante problema de saúde pública com prevalências elevadas, nas macrorregiões socioeconomicamente mais ou menos desenvolvidas do País, reiterando seu caráter trans-social.

Recentemente, foram publicados, no meio acadêmico, outros estudos brasileiros não incluídos nas revisões analisadas, que são apresentados no Quadro 2. Em relação à importância epidemiológica em saúde pública, constata-se que as prevalências continuam elevadas e com ampla variação, de 13,6\% a 92,4\%, porém, produziram-se mais estudos na região Norte do País.

Quadro 2 - Estudos nacionais de prevalência de anemia infantil por macrorregião

\begin{tabular}{|c|c|c|}
\hline Estudos por Macrorregião & $\begin{array}{c}\text { Tamanho } \\
\operatorname{amostral}(\mathbf{n})\end{array}$ & Prevalência da anemia $(\%)$ \\
\hline \multicolumn{3}{|l|}{ NORTE } \\
\hline Oliveira et al., 2011 & 429 & 57,3 \\
\hline Castro et al., 2011 & 624 & 30,6 \\
\hline Cardoso et al., 2012 & 1.111 & 13,6 \\
\hline Souza et al., 2012a & 610 & 51,8 \\
\hline \multicolumn{3}{|l|}{ NORDESTE } \\
\hline Carvalho et al., 2010 & 301 & 92,4 \\
\hline Leal et al., 2011 & 1.403 & 32,8 \\
\hline Gondim et al., 2012a,b & 1.108 & 36,5 \\
\hline Paula et al., 2013 & 945 & 35,0 \\
\hline \multicolumn{3}{|l|}{ SUL } \\
\hline Bortolini, Vitolo, 2010 & 354 & $\begin{array}{l}\text { 63,7 (crianças 12-16 meses); 38,1 } \\
\text { (crianças 3-4 anos) }\end{array}$ \\
\hline Rodrigues et al., 2011 & 256 & 29,7 \\
\hline Silva et al., 2011 & 41 & 51,2 \\
\hline \multicolumn{3}{|l|}{ SUDESTE } \\
\hline Netto et al., 2011 & 104 & 26,0 \\
\hline Rocha et al., 2012 & 312 & 30,8 \\
\hline
\end{tabular}

Os resultados da PNDS/2006 apresentados no Relatório Oficial indicaram redução na prevalência de anemia infantil, com variação de 10,4\% a 25,5\% nas diferentes macrorregiões brasileiras, com média nacional de 20,9\%, o que mantém a classificação da anemia como problema de importância epidemiológica moderada (Brasil 2009). 


\subsection{Deficiência de vitamina A}

\subsubsection{Aspectos gerais}

A vitamina A é um micronutriente vital para a saúde do ser humano e essencial em muitos processos fisiológicos, tais como diferenciação celular, manutenção da integridade epitelial, visão, crescimento, reprodução e sistema imunológico. Essa última função faz com que a vitamina A seja associada à redução da morbidade e mortalidade infantil por doenças diarreicas, sarampo, tuberculose e malária (WHO, 1996; McLaren, Frigg, 2001; Ramalho, Flores, Saunders, 2002; Ferraz et al., 2005; Brasil, 2007; Sherwin et al., 2012).

O estado nutricional de vitamina A pode ser avaliado por inquérito dietético qualitativo e quantitativo (consumo alimentar); exame clínico, com avaliação de sinais e sintomas da xeroftalmia como manchas de Bitot e cegueira noturna; método citológico (citologia de impressão conjuntival); dosagem de retinol sérico; e, com menor frequência, por meio da determinação da concentração hepática de retinol (Diniz, Santos, 2000; Geraldo et al., 2003).

A deficiência de vitamina A (DVA) em crianças de 6 a 71 meses é definida quando o retinol plasmático é $<0,70 \mu \mathrm{mol} / \mathrm{L}$. A OMS classifica a relevância epidemiológica da DVA com base na sua prevalência em pré-escolares como problema grave de saúde pública quando a prevalência é superior ou igual a 20\%; moderado, quando a prevalência varia de $10 \%$ a $20 \%$; e leve, quando a prevalência encontra-se entre 2\% e 10\% (WHO, 1996).

É importante destacar que, desde a década de 1980, o Brasil tem implantado uma série de medidas intervencionistas a curto, médio e longo prazo para prevenção e controle da deficiência nutricional de vitamina A. Na ocasião, instituiu-se a estratégia de suplementação com doses maciças de vitamina A para crianças em idade pré-escolar de áreas específicas do País. Em 1994, o Ministério da Saúde criou o Programa Nacional de Controle das Deficiências de Vitamina A (Martins et al., 2007). Dez anos depois, implantou-se o Programa Nacional de Suplementação de Vitamina A, intitulado "Vitamina A Mais", com a finalidade de reduzir e controlar a deficiência da vitamina A em crianças de 6 a 59 meses de idade, residentes em áreas de risco (Nordeste, região norte de Minas Gerais, Vale 
do Jequitinhonha, Vale do Mucuri e Vale do Ribeira em São Paulo). O programa prevê suplementação a cada seis meses, com distribuição da dose de acordo com a idade: crianças de 6-11 meses (uma dose de $100.000 \mathrm{UI}$ ); crianças de 12-59 meses (uma dose de 200.000 UI a cada seis meses) (Brasil, 2004, 2012a).

Além dessas medidas específicas para o controle da DVA, na nova Caderneta de Saúde da Criança recomenda-se, como estratégia de intervenção adicional, a promoção do aleitamento materno e da alimentação saudável, com estímulo ao consumo de alimentos fontes desse micronutriente pela população infantil. Outras estratégias usadas pelo governo incluem medidas educativas que abordem a importância da vitamina $\mathrm{A}$, os benefícios da utilização de alimentos fontes e os malefícios causados pela sua deficiência no organismo. Tais ações são desenvolvidas em regiões consideradas endêmicas para a deficiência dessa vitamina (Região Nordeste, norte de Minas Gerais, Vale do Jequitinhonha, Vale do Mucuri e Vale do Ribeira em São Paulo), e devem ser realizadas na rotina dos serviços de atenção primária à saúde, bem como nas campanhas de multivacinação, pelas equipes de saúde da família (Brasil, 2004, 2007, 2012a). Os estudos evidenciam que a suplementação de vitamina A reduz cerca de $24,0 \%$ da mortalidade em crianças menores de 5 anos (Imdad et al., 2010; WHO, 2011; Mayo-Wilson et al., 2011; Sherwin et al., 2012).

\subsubsection{Prevalência da deficiência de vitamina A em crianças}

A DVA tem importância para a saúde pública em função da sua magnitude (190 milhões de crianças no mundo) e dos impactos biológicos envolvendo as conhecidas manifestações oftálmicas na sua fase clínica, que afetam 5,17 milhões de crianças no mundo, além do risco de cegueira e do aumento de morbidade e mortalidade infantil (WHO, 2009).

Com base no banco de dados da OMS, referente ao período de 1995 a 2005, estima-se que 73 e 49 países no mundo têm DVA, classificada como problema de saúde pública grave e moderado, respectivamente. No Brasil, a prevalência foi estimada em 13,3\%, afetando cerca de 2,4 milhões de crianças, o que resultou em sua classificação no País como problema moderado de saúde pública (WHO, 2009). 
Os dados existentes em nível mundial são escassos, além de serem provenientes de pesquisas realizadas com metodologias, tamanhos de amostras e tipos de indicadores diversos. Apesar disso, esses trabalhos evidenciam que a DVA é mais frequente no Sudeste da Ásia, Oriente Médio, África e Américas Central e do Sul, sobretudo em crianças, associada à desnutrição (WHO, 2009).

A África é um dos continentes mais afetado, com 44 países que apresentam DVA como problema grave de saúde pública. Também é problema nutricional de saúde pública entre crianças em idade pré-escolar de países do Sudeste da Ásia (Bangladesh, Butão, Índia, Indonésia, República Democrática Popular da Coréia, Maldivas, União do Miamar, Nepal, Sri Lanka e Tailândia). Na China, a DVA é mais comum em crianças do meio rural que do meio urbano (WHO, 2000, 2009).

A DVA também é um problema de saúde nas Américas Central e do Sul, com frequência elevada em comunidades pobres da Bolívia, algumas regiões do México e do Peru e grupos indígenas do Panamá, também constituindo problema de saúde pública no Brasil, Colômbia, Equador, El Salvador, Guatemala, Haiti, Honduras, Nicarágua e República Dominicana (Mora, Gueri, Mora, 1998).

Nos Estados Unidos da América, embora desenvolvido, há evidências de carência de vitamina A devido à ingestão inadequada de retinol e de carotenoides. A Europa, no entanto, não é um continente de risco para a DVA. Nos países mais ricos, observa-se sua presença nas populações de baixo nível socioeconômico, sujeitas à insegurança alimentar, a condições sanitárias precárias e com acesso inadequado aos serviços de saúde (Imdad et al., 2010; Sherwin et al., 2012).

A DVA encontra-se elencada entre as três grandes prioridades de carência de micronutrientes, ao lado das anemias e dos distúrbios por deficiência de iodo, que ainda permanece como problema relevante de saúde pública, especialmente nos países em desenvolvimento (Brasil, 2007, 2012a,b).

Para análise da distribuição da DVA na população infantil brasileira, realizou-se um levantamento bibliográfico que buscou revisões de literatura sobre deficiência dessa vitamina em crianças. Foram identificados sete artigos de revisão de autores nacionais publicados nos últimos anos, com resultados relatados a seguir. 
A primeira revisão de literatura analisou 85 artigos publicados em periódicos científicos, livros técnicos e publicações internacionais que evidenciaram a ocorrência de DVA nas crianças brasileiras, principalmente em bolsões de pobreza da região semiárida do Nordeste. A partir dos resultados, os autores chamaram atenção dos profissionais de saúde para os sinais e sintomas dessa deficiência, bem como para os fatores de risco associados e destacaram a importância de elaboração e implementação de políticas públicas para o controle da DVA com vistas à redução da mortalidade infantil (Diniz, Santos, 2000).

A segunda revisão traçou um panorama da DVA no Brasil a partir da análise de 50 artigos publicados no período de 1972 a 2000. Os autores constataram que a DVA estava presente em várias regiões do País, com registro em diversos grupos populacionais, principalmente nos de baixa renda; em vários estados e capitais brasileiras; em cidades grandes e pequenas e em zonas rurais; e também atingindo outras áreas não tradicionalmente pobres. Os autores concluíram que, apesar dos muitos estudos realizados no País, não era possível avaliar a magnitude e gravidade da DVA em nível nacional, uma vez que os estudos tinham como base amostras pequenas, com inquéritos clínicos e bioquímicos escassos e resultados contraditórios. Contudo, constataram que o consumo de vitamina A era baixo nas classes sociais pobres e que o nível de ingestão recomendado pela OMS não era alcançado pela maioria das crianças (Souza, Vilas Boas, 2002).

A terceira revisão de literatura, intitulada "Hipovitaminose A no Brasil: um problema de saúde pública" analisou 73 artigos publicados em periódicos nacionais e internacionais no período de 1982 a 2002. Os resultados evidenciaram que a DVA era "um problema com magnitude de Saúde Pública em todo o país". A análise reiterou que os inquéritos alimentares indicavam baixo consumo de fontes naturais de vitamina $\mathrm{A}$, o que contribuía para a monotonia alimentar prevalente nas "diversas camadas da população", agravando a situação da DVA no País. Os inquéritos bioquímicos confirmaram-na como um problema de saúde pública nos estados de São Paulo, Minas Gerais, Pernambuco, Paraíba, Ceará, Bahia, Amazonas e na cidade do Rio de Janeiro. Os autores concluíram que "no Brasil, pensava-se que o problema estaria limitado às regiões mais pobres do Norte e Nordeste, mas dados da região Sudeste em nada diferem dos dados dessas 
regiões, tornando a DVA independente do mapa do país" (Ramalho, Flores, Saunders, 2002).

Na quarta revisão, intitulada "Distribuição da hipovitaminose A no Brasil nas últimas quatro décadas: ingestão alimentar, sinais clínicos e dados bioquímicos", foram analisados 84 trabalhos sobre alterações do estado nutricional relacionado com a vitamina $\mathrm{A}$ em grupos populacionais, publicados sob a forma de artigos originais em periódicos de circulação nacional ou internacional, de capítulos de livro e de documentos, estes últimos por instituições governamentais ou resultantes de parcerias firmadas entre instituições universitárias e governamentais. As avaliações do estado nutricional relacionado à vitamina A descritas na revisão dos trabalhos foram feitas com diferentes métodos, que incluíram avaliação da ingestão alimentar, exame clínico, níveis séricos de retinol e concentração hepática de retinol. A DVA foi registrada em grupos populacionais de vários estados brasileiros (Amazonas, Rio Grande do Norte, Paraíba, Pernambuco, Bahia, Minas Gerais e São Paulo), em várias capitais de estados, em cidades grandes, como Ribeirão Preto e Campinas, e em cidades menores. Em algumas dessas regiões, essa deficiência foi reconhecida como um problema de saúde pública. A maioria dos estudos foi conduzida com populações de baixa renda, mas mesmo nos poucos estudos realizados com grupos populacionais mais favorecidos economicamente, foram encontrados baixos níveis de retinol. A maioria dos estudos realizados na Região Nordeste evidenciou proporção elevada de crianças com níveis bioquímicos inadequados, região onde também se observou maior frequência de manifestações clínicas da DVA (lesões oculares). Os autores destacaram que, para a época, ganhava importância a noção da deficiência subclínica da vitamina A, uma vez que mesmo essa forma de DVA se associa a elevados riscos de morbidade e mortalidade, principalmente em crianças (Geraldo et al., 2003).

A quinta revisão incluiu 93 referências bibliográficas, e basicamente analisou os mesmos artigos da revisão anterior, de forma que suas conclusões praticamente reiteraram as do trabalho anterior (Dolinsky, Ramalho, 2003).

A sexta revisão analisou 70 artigos, também revelando que a DVA estava presente em crianças de vários estados brasileiros, principalmente das regiões Sudeste e Nordeste. Em algumas regiões do estado de São Paulo, Minas Gerais e 
Sergipe, os limites de retinol sérico considerados baixos pela OMS alcançavam prevalências superiores a 20,0\%, sendo que, na Bahia, atingiram mais de 40,0\%. Para os autores, as evidências apresentadas foram suficientes para afirmar que a DVA era um problema de saúde pública no Brasil (Milagres, Nunes, PinheiroSant’ana, 2007).

A sétima e última revisão de literatura encontrada foi publicada em 2008 e analisou 27 estudos brasileiros que avaliaram a DVA por meio do indicador bioquímico retinol sérico no grupo materno-infantil, após a implantação do Programa de Suplementação de Vitamina A em 1994. Constatou-se que todos os estudos apontaram a DVA como um problema de proporção preocupante. Diante do número de crianças acometidas por essa deficiência em São Paulo e no Rio de Janeiro, regiões que se encontram fora do eixo tradicional da miséria no Brasil, confirma-se a hipótese de que a DVA não é um problema restrito apenas às regiões de extrema pobreza do País (Ramalho, Padilha, Saunders, 2008).

O Quadro 3 apresenta os principais estudos analisados em cada revisão por macrorregião, destacando autoria e ano de publicação, tamanho da amostra e prevalência de DVA.

Quadro 3 -Estudos nacionais de prevalência de DVA infantil por macrorregião, analisado em sete Revisões de Literatura

\begin{tabular}{|l|c|c|}
\hline Estudos por Macrorregião & $\begin{array}{c}\text { Tamanho } \\
\text { amostral (n) }\end{array}$ & $\begin{array}{c}\text { Prevalência de DVA } \\
(\%)\end{array}$ \\
\hline NORTE & 476 & 15,5 \\
\hline Marinho, 2000 (Manaus, AM) & 90 & 32,4 \\
\hline Marinho, 2000 (Boa Vista, RR) & 145 & 32,4 \\
\hline Marinho, 2000 (Porto Velho, RO) & 48 & 25,0 \\
\hline Alencar et al., 2002 (Nhamundá, AM) & 124 & 60,6 \\
\hline REGIÃO CENTRO-OESTE & \\
\hline $\begin{array}{l}\text { Muniz-Junqueira, Queiroz, 2002 (Brasília, } \\
\text { DF) }\end{array}$ & 271 & 39,9 \\
\hline NORDESTE & 244 & 31,1 \\
\hline McAuliffe et al., 1991 (Fortaleza, CE) & 2.619 & 34,0 \\
\hline McAuliffe et al., 1991 (outras regiões do CE) & 203 & 17,7 \\
\hline McAuliffe et al., 1991 (Recife, PE) & 236 & 16,1 \\
\hline McAuliffe et al., 1991 (João Pessoa, PB) & 61 & 55,0 \\
\hline McAuliffe et al., 1991 (semiárido da PB) & 563 & 44,7 \\
\hline McAuliffe et al., 1991 (estado da BA) & Não informa \\
\hline Prado et al., 1995 (área rural, estado da BA) & 161 & 15,3 \\
\hline Santos et al., 1996 (semiárido da BA) & \multicolumn{1}{|}{} \\
\hline Assis et al., 1997 (semiárido da BA) & \multicolumn{1}{|l|}{} \\
\hline
\end{tabular}




\begin{tabular}{|c|c|c|}
\hline Estudos por Macrorregião & $\begin{array}{c}\text { Tamanho } \\
\operatorname{amostral}(\mathbf{n})\end{array}$ & $\begin{array}{c}\text { Prevalência de DVA } \\
(\%)\end{array}$ \\
\hline \multicolumn{3}{|l|}{ NORDESTE } \\
\hline $\begin{array}{l}\text { Instituto Nacional de Alimentação e Nutrição } \\
\text { (INAN). Instituto Materno Infantil de } \\
\text { Pernambuco (IMIP), } 1998 \text { (outras regiões do } \\
\text { estado de Pernambuco) }\end{array}$ & 669 & 19,3 \\
\hline Martins, Santos, Assis, 2004 (Sergipe, SE) & 607 & 22,5 \\
\hline Fernandes et al., 2005 (Recife, PE) & 311 & 7,0 \\
\hline Paiva et al., 2006 (Teresina, PI) & 631 & 15,4 \\
\hline \multicolumn{3}{|l|}{ SUDESTE } \\
\hline Roncada et al., 1978 (São Paulo, SP) & 109 & 51,4 \\
\hline Wilson et al., 1981 (São Paulo, SP) & 142 & 73,9 \\
\hline $\begin{array}{l}\text { Roncada et al., } 1981 \text { (regiões do estado de } \\
\text { São Paulo) }\end{array}$ & Não informa & 49,0 \\
\hline $\begin{array}{l}\text { Roncada et al., } 1984 \text { (regiões do estado de } \\
\text { São Paulo) }\end{array}$ & 362 & 30,2 \\
\hline $\begin{array}{l}\text { Araújo et al., } 1986 \text { (Vale do Jequitinhonha, } \\
\text { MG) }\end{array}$ & 264 & 34,0 \\
\hline $\begin{array}{l}\text { Gonçalves-Carvalho et al., } 1995 \text { (Campinas, } \\
\text { SP) }\end{array}$ & 56 & 6,9 \\
\hline $\begin{array}{l}\text { Ferraz, Daneluzzi, Vannucchi, } 2000 \text { (Ribeirão } \\
\text { Preto, SP) }\end{array}$ & 103 & 21,4 \\
\hline $\begin{array}{l}\text { Rondo, Abbott R, Tomkins, } 2001 \text { (outras } \\
\text { regiões do estado de São Paulo) }\end{array}$ & 711 & 23,0 \\
\hline $\begin{array}{l}\text { Magalhães, Ramalho, Colli, } 2001 \text { (Viçosa, } \\
\text { MG) }\end{array}$ & 135 & 15,0 \\
\hline Ferraz et al., 2005 (Ribeirão Preto, SP) & 179 & 75,4 \\
\hline $\begin{array}{l}\text { Ramalho, Anjos, Flores, } 1998 \text { (Rio de } \\
\text { Janeiro, RJ) }\end{array}$ & 253 & 55,7 \\
\hline $\begin{array}{l}\text { Ramalho, Anjos, Flores, } 2001 \text { (Rio de } \\
\text { Janeiro, RJ)) }\end{array}$ & 175 & 34,3 \\
\hline Ramalho et al., 2006 (Rio de Janeiro, RJ) & 291 & 54,2 \\
\hline
\end{tabular}

Fonte: Adaptado de Diniz e Santos (2000), Dolinsky e Ramalho (2003), Geraldo et al. (2003), Milagres, Nunes e Pinheiro-Sant'ana (2007), Ramalho, Flores, Saunders (2002), Ramalho, Padilha, Saunders (2008) e Souza e Vilas Boas (2002)

Observa-se que os estudos concentram-se nas regiões Sudeste e Nordeste, com ausência na região Sul e apenas um no Centro-Oeste, e revelam-se pesquisas isoladas, com amostras pequenas, excetuando-se um, que avaliou mais de 2.500 crianças. Considerando-se todos os estudos apresentados no Quadro 3, a prevalência mediana de DVA foi de 32,4\%, com variação de 6,9\% a 75,4\%. Nas regiões Nordeste e Sudeste a prevalência mediana foi de 22,5\% e 34,3\%, respectivamente. Conforme a classificação da OMS e as medianas observadas por macrorregião, constata-se que a DVA em crianças brasileiras representavam problema grave de saúde pública.

Outros estudos não incluídos nas revisões analisadas foram publicados posteriormente, e seus autores são devidamente apresentados no Quadro 4. Esses 
estudos, com mediana de 17,7\%, evidenciam uma tendência de diminuição na prevalência de DVA, sinalizando que as políticas públicas efetivadas têm contribuído positivamente para a erradicação dessa deficiência, porém, a DVA continua como problema moderado de saúde pública, que acomete tanto as macrorregiões socioeconomicamente menos desenvolvidas, quanto as mais desenvolvidas do País. A PNDS/2006 reiterou a tendência de redução na prevalência de DVA (17,4\%) (Brasil, 2009).

Quadro 4 - Estudos nacionais de prevalência de DVA infantil por macrorregião

\begin{tabular}{|l|c|c|}
\hline Estudos por Macrorregião & Tamanho amostral (n) & Prevalência da DVA (\%) \\
\hline NORDESTE & 135 & 8,9 \\
\hline Pereira et al., 2008 & 652 & 44,8 \\
\hline Vasconcelos, Ferreira, 2009 & 344 & 7,7 \\
\hline Azevedo et al., 2010 & 1.108 & 21,4 \\
\hline Gondim et al., 2012a & 790 & 16,1 \\
\hline Miglioli et al., 2013 & 1.211 & 21,8 \\
\hline Queiroz et al., 2013 & 563 & 16,0 \\
\hline Paula et al., 2013 & 173 & 17,7 \\
\hline SUDESTE & 101 & 39,6 \\
\hline Barros et al., 2010 & \multicolumn{2}{|l}{} \\
\hline Netto et al., 2012 &
\end{tabular}




\subsection{Interações entre anemia e deficiência de vitamina $A$}

É importante ressaltar que a anemia, a deficiência de vitamina A (DVA) e outras deficiências nutricionais, na maioria das vezes, não ocorrem isoladamente no indivíduo, e sim simultaneamente, apresentando ou não associação umas com as outras (Palafox et al., 2003; Ferraz et al., 2005; Netto, Priore, Franceschini, 2007).

No que diz respeito à interação entre anemia e DVA, existem fortes evidências de que a DVA contribui para o desenvolvimento da anemia. A deficiência de ferro, por sua vez, pode influenciar no metabolismo da vitamina A, inibindo a liberação plasmática da proteína carreadora de retinol (Semba, Bloem, 2002; Willows, Gray-Donald, 2003; Silva et al., 2008; Gondim et al., 2012a; Sales et al., 2013).

Nesse âmbito, há indícios de que o aumento dos níveis séricos de vitamina A conduz ao aumento dos níveis de hemoglobina, de forma que, para alguns estudiosos, a vitamina A tem papel importante no combate da deficiência de ferro (Semba, Bloem, 2002; Ahmed et al., 2006; Jimenez et al., 2010).

Semba e Bloem (2002), em revisão de pesquisas epidemiológicas para analisar a epidemiologia e a patogênese da anemia causada pela DVA, constataram que a prevalência de anemia é alta em populações afetadas pela DVA nos países em desenvolvimento. Os estudos analisados mostraram que a melhora do estado nutricional de vitamina A tende a diminuir a prevalência de anemia, estando o real impacto dessa redução bem estabelecido em nível de saúde pública. Para os autores, o envolvimento da vitamina A na patogênese da anemia pode ser explicado por meio de diversos mecanismos biológicos, tais como sua participação no crescimento e diferenciação de células progenitoras de eritrócitos; na melhora da imunidade à infecção e, por conseguinte, na redução da anemia decorrente da infecção; e na mobilização de reservas de ferro a partir dos tecidos. Entretanto, não obstante a DVA seja reconhecida como causa da anemia, a "anemia da DVA" carece de uma caracterização como uma entidade clínica distinta.

A associação entre vitamina A e ferro tem sido sugerida por pesquisas que mostram correlação entre os indicadores do estado nutricional de ferro e de 
vitamina A em crianças. No estudo de Willows e Gray-Donald (2003), a concentração de retinol sérico correlacionou-se significativamente com a concentração de hemoglobina e de ferro sérico. Além disso, os autores constataram que as crianças anêmicas apresentavam concentração de retinol sérico mais baixa que as não anêmicas. Entre crianças que receberam suplementação com vitamina A, C e D (em protocolo clínico), observaram maior concentração de hemoglobina e menor prevalência de anemia.

Efetivamente, Mwanri, Worsley e Ryan (2000) e Semba e Bloem (2002) concluíram que a suplementação concomitante de vitamina A e ferro melhorava a resposta do organismo no aumento da taxa de hemoglobina, se comparada à suplementação isolada desses dois nutrientes. Também Zimmerman, Biebinger e Rohner (2006) evidenciaram aumento nos níveis de eritropoietina e redução na prevalência de anemia com a suplementação de vitamina A em crianças com baixa concentração de hemoglobina. Referida interação foi reiterada por Netto, Priore e Franceschini (2007) em revisão de literatura, principalmente nas crianças, pois os estudos comprovaram que a suplementação com vitamina A melhorava o estado nutricional de ferro, com reduções significativas nas prevalências de anemia.

Mais recentemente, Jimenez et al. (2010) constataram, por sua vez, aumento significativo no nível de retinol e na concentração de hemoglobina após 30 dias de suplementação com dose única de vitamina A [200.000 UI (60 mg)], com consequente redução nas prevalências de anemia e DVA.

Apesar das evidências de benefícios da suplementação de vitamina A na redução da anemia, há poucos estudos que encontram correlação significativa entre os níveis de hemoglobina e de retinol sérico em crianças brasileiras. Silva et al. (2008) encontraram associação positiva e estatisticamente significante entre níveis de retinol sérico e concentração de hemoglobina. Esse efeito manteve-se no modelo final, ajustado para as variáveis demográficas, ambientais, domiciliares, bem como para as variáveis infecções parasitárias e consumo de ferro biodisponível, com elevação de $0,033 \mathrm{~g} / \mathrm{dL}$ na concentração de hemoglobina a cada unidade a mais de retinol sérico $(\mu \mathrm{mol} / \mathrm{L})$. No Sul do Brasil, no entanto, constatou-se forte correlação apenas entre retinol sérico e ferro sérico, porém, não com concentração de hemoglobina ou hematócrito (Mariath et al., 2010). Sales et 
al. (2013), por sua vez, observaram que as crianças com DVA apresentaram níveis séricos de ferro significativamente menores quando comparadas às crianças sem DVA, enquanto Gondim et al. (2012a) verificaram que quanto menores os níveis de retinol sérico, maior a suscetibilidade das crianças à anemia, consolidando a hipótese de que o desenvolvimento da anemia é influenciado pelos níveis de retinol sérico, embora os indícios dessa associação ainda sejam obscuros.

Ferraz et al. (2005), no entanto, não encontraram associação estatisticamente significante entre DVA e carência de ferro, apesar da prevalência de $29,1 \%$ de carência de ferro e DVA concomitante. O estudo realizado por Pereira et al. (2007) também não observou diferença nas médias de $\mathrm{Hb}$ e na proporção de anêmicos ao suplementar escolares com sulfato ferroso e sulfato ferroso associado a vitamina A.

Diante do exposto, é pertinente aprofundar a análise da ocorrência concomitante de DVA e anemia infantil no Brasil, tendo em vista suas implicações para as políticas de alimentação e nutrição. 


\subsection{Determinantes da anemia e da deficiência de vitamina $\mathrm{A}$}

O grau das desigualdades sociais vivenciadas na atualidade e sua relação com o padrão de saúde da população faz parte da tendência dominante do pensamento em saúde coletiva. As condições sociais e econômicas, bem como as dimensões étnicas e de gênero das desigualdades são aquelas que mais importam para avaliar as condições de saúde nas populações (Breilh, Granda, 1989; Buss, Pellegrini Filho, 2007). Um dos desafios para a compreensão do processo saúde doença consiste em entender a forma como as desigualdades sociais influenciam a distribuição das doenças na sociedade (Lana, 2006; Buss, Pellegrini Filho, 2007; Almeida-Filho, 2009; Ferreira, Latorre, 2012).

Com vistas a promover a tomada de consciência sobre a importância dos determinantes sociais na situação de saúde, a OMS criou uma comissão específica para estudar os determinantes sociais da saúde. Nos primeiros anos da vida, devem ser abordados os mecanismos que provocam as iniquidades na saúde da criança, complexa e enredada trama de fatores responsáveis pelo crescimento e desenvolvimento infantil, que envolvem atributos familiares, escolares, comunitários e do contexto sociopolítico em que vive a criança e sua família (Whitehead, 2000).

Para esquematizar a trama de relações entre os vários níveis de determinantes sociais e as iniquidades em saúde adotam-se os modelos circulares. Nesse modelo, o indivíduo se posiciona no centro e suas características pessoais como idade, sexo e fatores genéticos devem ser consideradas. Os comportamentos e os estilos de vida que ele adota estão no patamar superior, sendo relevantes e sujeitos à interferência das informações veiculadas pela mídia. A camada circular seguinte refere-se às redes comunitárias e de apoio, que têm por finalidade contribuir para a coesão social. Em outro nível estão situados os fatores relacionados às condições de vida e de trabalho, à disponibilidade de acesso aos alimentos, à saúde e à educação. No último nível do modelo circular estão os macro determinantes econômicos, culturais e ambientais da sociedade, com destaque, no atual contexto, para o processo de globalização, determinantes esses que influenciam grandemente as demais camadas (CNDSS, 2008). 
Em relação ao contexto da determinação da anemia e da DVA, estas resultam da inter-relação de variáveis de distintas dimensões, de forma que seus determinantes são estudados por meio da proposição de modelos hierarquizados complexos (Silva, Giugliani, Aerts, 2001; Osório, 2002; Caminha, 2005; Oliveira et al., 2010; Miglioli et al., 2013).

Para Silva, Giugliani e Aerts (2001), no que se refere à anemia, os determinantes distais (representados pela dimensão dos processos estruturais da sociedade) influenciam os determinantes intermediários (retratados pela dimensão dos processos do ambiente imediato da criança), e estes os determinantes proximais (aqueles que agem de maneira mais direta sobre o desfecho, representados pela dimensão dos processos individuais da criança).

\section{Determinantes da anemia}

Importante revisão de literatura sobre os determinantes da anemia em crianças menores de 5 anos foi realizada por Osório (2002). Essa autora delineia um modelo teórico hierárquico que tem como base as condições socioeconômicas, que influenciam o consumo alimentar e as condições de assistência à saúde e nutrição da criança, os quais condicionam o estado nutricional e de morbidade, que determinam o quadro de anemia na criança, como pode ser visualizado na Figura 2.

Figura 2- Modelo hierárquico dos fatores determinantes da anemia

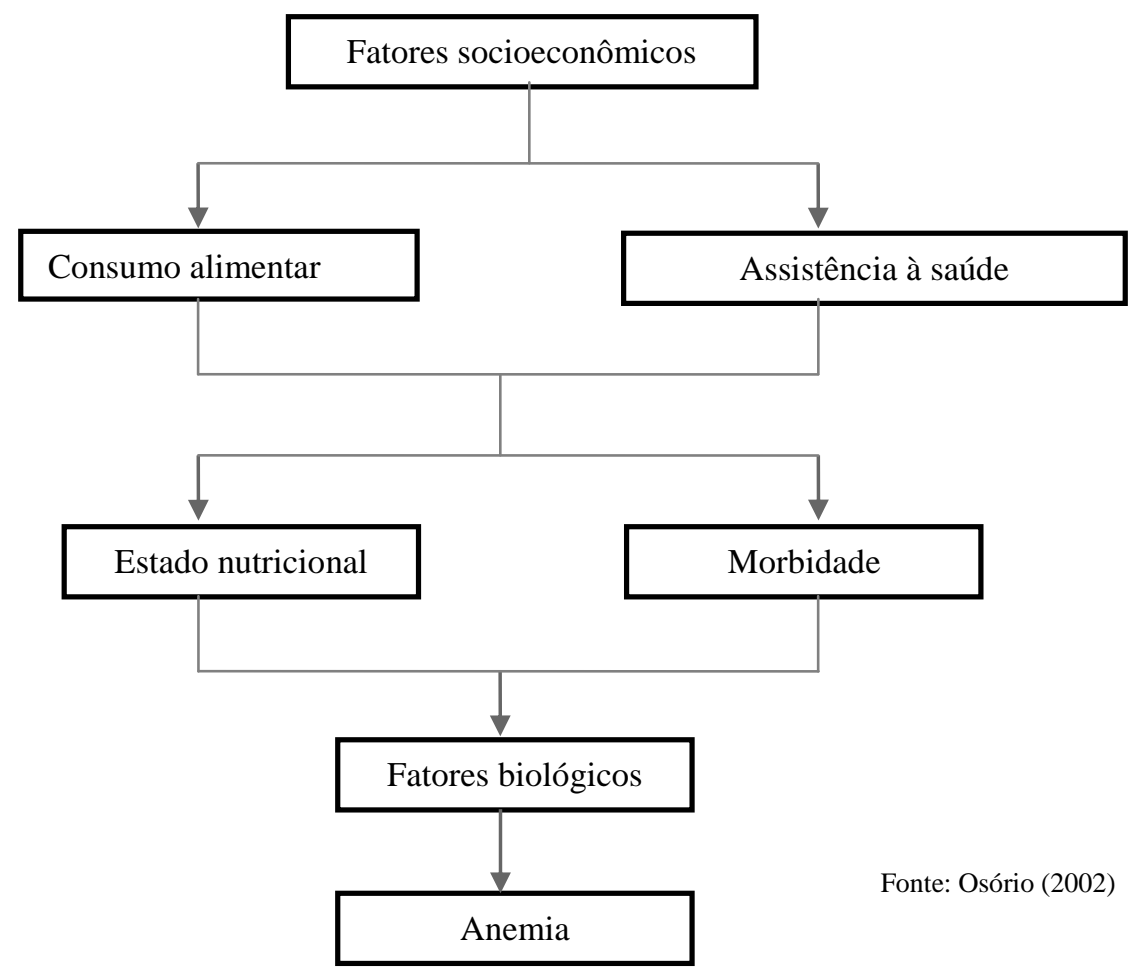


Revisão sistemática, que analisou estudos populacionais sobre ocorrência de anemia em crianças menores de 6 anos, constatou uma multiplicidade de fatores associados à anemia em diferentes contextos, sendo os mais citados: área geográfica; renda familiar; escolaridade materna; índice de riqueza do domicílio; densidade de ferro e calorias provenientes do leite de vaca; peso ao nascer; indicador altura/idade; indicador peso/altura; diarreia; idade; etnia; e sexo da criança (Leal, Osório, 2010).

Em um estudo sobre a tendência secular da anemia infantil na cidade de São Paulo, Monteiro Szarfarc e Mondini (2000) identificaram baixa renda familiar, menor escolaridade materna, aleitamento artificial, inadequação energética, menor consumo de ferro e baixa densidade de ferro dietético, além de menor idade, como fatores de risco para anemia.

Neuman et al. (2000), por sua vez, reiteraram a associação entre anemia e renda familiar, bem como com maior número de pessoas que dormem por cômodo e também entre anemia e idade da criança, com o maior risco na faixa etária de 12-18 meses. Estudos mais recentes desenvolvidos na região Norte continuam a apontar que a anemia afeta especialmente os menores de 24 meses, com menor crescimento estatural, afetados por diarreias e infestações por geohelmintos, além de ter como fator de proteção o trabalho materno fora de casa (Castro et al., 2011; Oliveira et al., 2011, Cardoso et al., 2012). Rocha et al. (2012) também confirmaram associação de anemia com idade menor ou igual a 24 meses e déficit do índice altura para idade entre crianças assistidas em creches de um Distrito Sanitário de Belo Horizonte.

Da mesma forma, estudos realizados na região Nordeste confirmaram associação de anemia em crianças menores de 24 meses de idade com menor renda familiar, precárias condições ambientais e sanitárias do domicilio, baixa escolaridade materna, menor densidade de ferro na dieta, baixo peso ao nascer, déficit do índice altura para idade e diarreia (Assis et al., 2004a; Osório, Lira, Ashworth, 2004; Oliveira, Osório, Raposo, 2007; Leal et al., 2012). Ainda no Nordeste, na área urbana, constatou-se que os fatores associados à anemia eram baixa classe econômica, falta de saneamento básico, mães com menor nível de escolaridade e idade inferior a 20 anos e crianças menores de 24 meses de idade. 
$\mathrm{Na}$ área rural, apenas a idade materna e a da criança se associaram significativamente com a ocorrência de anemia (Leal et al., 2011).

Spinelli et al. (2005), que conduziram estudo mais abrangente com 2.715 crianças entre 6 e 12 meses de idade, residentes em 12 municípios das cinco regiões do Brasil, também confirmaram associação da anemia com a idade materna inferior a 20 anos, baixo peso ao nascer e não receber leite materno ou estar em aleitamento misto, porém, identificaram também como fatores de risco morar na região Sudeste e a criança ser do sexo masculino.

Em estudo conduzido com 610 crianças de 6 a 59 meses de Rio Branco, no estado do Acre, constatou-se como determinantes da anemia os anos de estudo da mãe, consumir carnes e frutas menos de uma vez por semana e ter idade inferior a 24 meses (Souza et al., 2012a).

Em relação à anemia e alimentação, Levy-Costa e Monteiro (2004) evidenciaram associação positiva entre consumo de leite de vaca e anemia, além de um possível efeito inibidor do leite de vaca sobre a absorção do ferro presente em outros alimentos ingeridos pelas crianças, o que aumenta o risco para anemia.

De fato, a alimentação tem papel importante no desenvolvimento da anemia ferropriva, de forma que, segundo a OMS (2001), nas regiões com prevalências elevadas de anemia (acima de 40\%), a causa mais comum é a deficiência de ferro dietético.

No Brasil, dados da PNDS/2006, que permitiram analisar o consumo alimentar de crianças de 6-59 meses de idade, evidenciaram uma alimentação inadequada, em quantidade e qualidade. A comparação do consumo alimentar entre as macrorregiões mostrou que as crianças residentes no Sul, Sudeste e Centro-oeste consumiam com mais frequência arroz, pão, batata, feijão, verdura de folha, legumes e carne, porém, também ingeriam com maior frequência alimentos como doces e refrigerantes. Em relação à zona de residência, os dados revelaram que as crianças da área urbana tinham mais acesso a alimentos recomendados (arroz, pão, batata, feijão, verduras de folhas, legumes, frutas, carne, frango, peixe, suco natural de fruta e iogurte) e também aos não recomendados (doces, biscoito, salgadinhos e refrigerantes), quando comparadas às crianças que residiam na zona rural (Bortolini, Gubert, Santos, 2012). 
No município do Rio de Janeiro, estudo que avaliou a influência de práticas alimentares na incidência de anemia em 288 crianças de 12 a 24 meses revelou consumo inadequado de ferro biodisponível e baixa ingestão de carne e de vitamina $\mathrm{C}$, constatando associação significativa entre anemia severa e consumo inadequado de ferro (Lacerda, Cunha, 2001). Na cidade de São Paulo, também se constatou associação entre anemia e ingestão quantitativa e qualitativa pobre em ferro (Compri et al., 2007).

A alimentação é, pois, fundamental para a prevenção das deficiências nutricionais, porém, depende-se de sua disponibilidade no domicílio. $\mathrm{O}$ acesso à alimentação em quantidade e qualidade adequadas pode ser medido por uma escala que identifica a condição de segurança ou insegurança alimentar no domicílio. Entende-se por Segurança Alimentar e Nutricional (SAN) a realização do direito de todos ao acesso regular e permanente a alimentos de qualidade, em quantidade suficiente, sem comprometer o acesso a outras necessidades essenciais, tendo como base práticas alimentares promotoras da saúde, que respeitem a diversidade cultural e que sejam social, econômica e ambientalmente sustentáveis (Brasil, 2005b).

Considera-se que as condições socioeconômicas desfavoráveis produzem piores resultados na saúde da população e, em geral, que quanto menor a renda, menor o poder de compra e acesso a uma alimentação variada e nutricionalmente adequada. Vários estudos correlacionam insegurança alimentar e nutricional com pobreza e más condições ambientais e de vida (Panigassi et al., 2008; Sales-Costa et al., 2008). Dados da Pesquisa Nacional por Amostra de Domicílios (PNAD) de 2009 mostraram que 30,2\% dos domicílios brasileiros particulares apresentavam algum grau de insegurança alimentar (Brasil, 2010).

No presente estudo, entende-se insegurança alimentar como determinante da anemia, que pode conduzir à deficiência de ferro em decorrência de restrição alimentar, tanto no que se refere à quantidade como à qualidade dos alimentos. Os achados, contudo, são conflitantes, pois há estudos que evidenciam correlação positiva entre insegurança alimentar e ocorrência de anemia (Park et al., 2009; Campbell et al., 2011), enquanto outros encontram níveis de hemoglobina mais baixos entre crianças de famílias com insegurança alimentar moderada e grave, porém, não estatisticamente significativos (Oliveira et al., 2010). 


\section{Determinantes da DVA}

Em relação à DVA, Caminha (2005) e Miglioli et al. (2013) propõem um modelo hipotético-causal da DVA (Figura 3) para identificar prioridades em propostas de estratégias de intervenção e subsidiar programas governamentais, com vistas à melhora da saúde e nutrição de grupos vulneráveis, especialmente as crianças. Os autores apresentam um modelo que tem como base as condições socioeconômicas e ambientais, que condicionam as condições de assistência à saúde da criança, o consumo alimentar, o estado nutricional e de morbidade, que determinam o quadro de DVA na criança. Além disso, a DVA contribui para o surgimento de infecções (Figura 3).

Entre os estudos sobre os fatores de risco associados à DVA infantil, têm destaque a baixa renda familiar (Martins, Santos, Assis, 2004), as condições ambientais desfavoráveis (Queiroz et al., 2013; Paula et al., 2013), a baixa escolaridade materna (Paiva et al., 2006), o déficit do estado nutricional (Martins, Santos, Assis, 2004), o baixo peso ao nascer (Ramalho, Padilha, Saunders, 2008) e a menor idade das crianças (Santos et al., 1996; Vasconcelos, Ferreira, 2009; Sales et al., 2013). Destacam-se, ainda, a deficiência dietética de vitamina A, o deficiente aleitamento materno, as doenças infecciosas e parasitárias (McLaren, Frigg, 2001; Saunders et al., 2007; Miglioli et al., 2013; Queiroz et al., 2013; Paula et al., 2013), a sazonalidade da produção alimentar, o sexo masculino e a pobreza em geral (McLaren, Frigg, 2001, Sherwin et al., 2012).

Figura 3 - Modelo causal de determinação da deficiência de vitamina A em menores de 5 anos

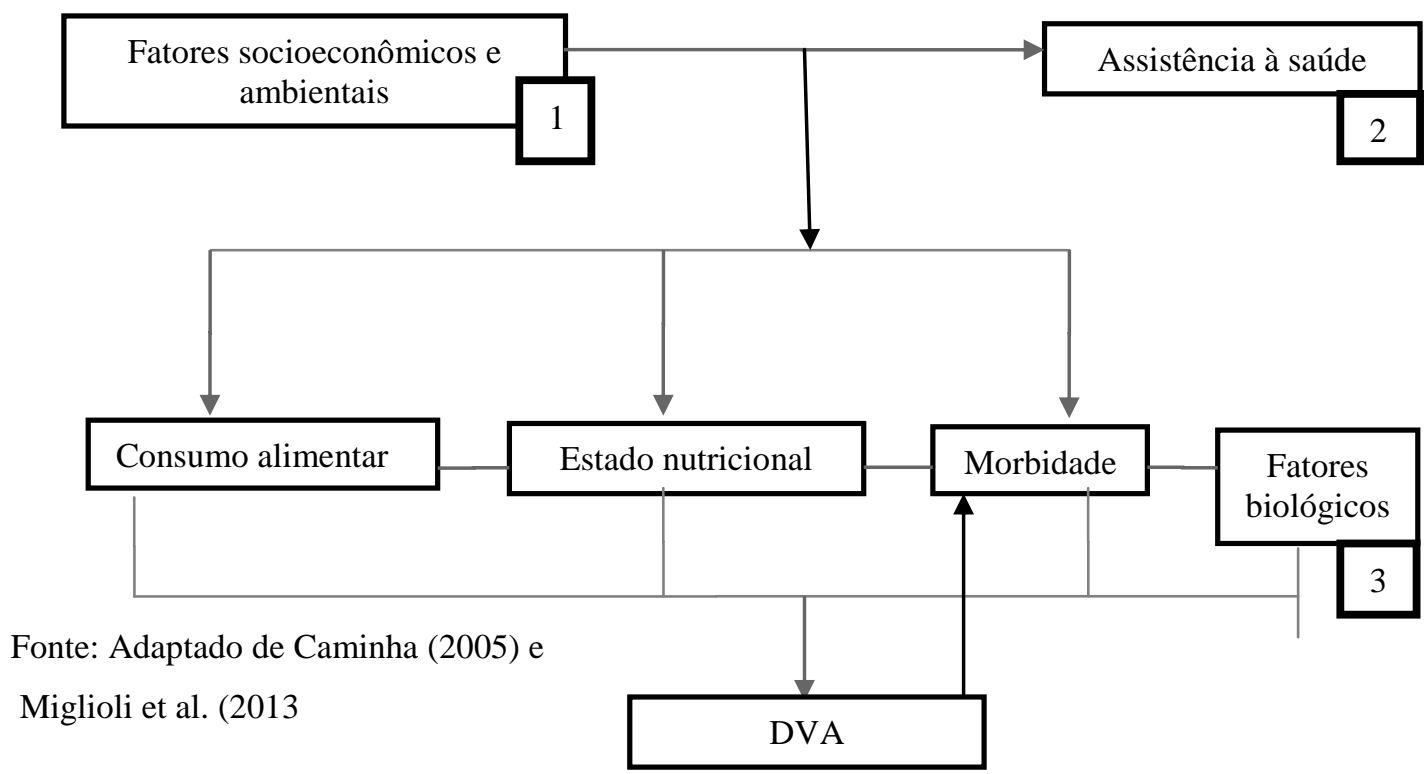


Pesquisa realizada no semiárido da Bahia, entretanto, não encontrou associação entre prevalência de DVA em pré-escolares e renda familiar per capita, nem com escolaridade materna (Santos et al., 1996). Da mesma forma, Ramalho et al. (2006) também não observaram associação entre os níveis de retinol sérico de mães e recém-nascidos e a renda familiar per capita, saneamento básico, índice de aglomeração da residência, tampouco com escolaridade e idade materna.

De fato, estudos mais recentes desenvolvidos na macrorregião Nordeste mostraram como fator de risco associado à DVA apenas a criança ter baixo peso. Entre as residentes na zona urbana, outro fator de risco foi ter mãe com idade menor que 20 anos, e entre as da zona rural, ter apresentado diarreia nos últimos 15 dias (Miglioli et al., 2013, Paula et al., 2013).

Outro determinante importante da DVA no Brasil é a inadequação do consumo alimentar, incluindo déficit da ingestão de alimentos fonte de vitamina A e também de alimentos que contém nutrientes importantes para o seu bioaproveitamento (Ramalho et al., 2006; Saunders et al., 2007; Ramalho, Padilha, Saunders, 2008; Pereira et al., 2008; Azevedo et al., 2010; Netto et al., 2012).

Por não ser capaz de sintetizar a vitamina A, o organismo humano precisa receber esse micronutriente de fontes alimentares, que se encontram sob duas formas: 1) vitamina A pré-formada, presente em alimentos de origem animal; 2) pró-vitamina A, sintetizada pelos vegetais na forma de carotenoides. Assim, a vitamina A pré-formada é encontrada no leite integral e seus derivados, gema de ovo, vísceras e peixes; e a pró-vitamina A tem como fontes alimentares as hortaliças e frutas de cor amarelo-alaranjadas e verde-escuras (McLaren, Frigg, 2001; El Beitune et al., 2003).

A população brasileira apresenta baixa adequação do consumo de vitamina A, que varia de $10 \%$ a $25 \%$ da recomendação (Ramalho, 2011). Em muitos países em desenvolvimento, as crianças pequenas também ingerem quantidades dietéticas inadequadas de vitamina A (Sherwin et al., 2012).

Para Bortolini, Gubert e Santos (2012), que analisaram o consumo alimentar de crianças de 6-59 meses de idade da PNDS/2006, a elevada ingestão de alimentos não recomendados pelas crianças brasileiras, tais como refrigerantes, 
alimentos fritos, salgadinhos e doces, como já referido, "poderia causar (e causa) as deficiências de micronutrientes", a exemplo da anemia e da DVA, bem como o excesso de peso. Para os autores, o fator que mais claramente poderia justificar essa situação seria a desigualdade social instalada entre as macrorregiões do Brasil.

De fato, o consumo alimentar atrela-se às condições sociais e econômicas, que determinam a capacidade de compra dos alimentos, porém, também sofrem influências de fatores culturais, que vão refletir na escolha dos alimentos e nos hábitos alimentares (Castro et al., 2005; Panigassi et al., 2008). Apesar disso, da mesma forma que em relação à anemia, também são poucos os estudos que associam insegurança alimentar e nutricional com DVA. 


\section{Questões de pesquisa, \\ hipóteses, objetivo}




\section{QUESTÕES DE PESQUISA}

Embora reconhecidos como problemas relevantes de saúde pública e bastante explorados, ainda há espectros de interesse epidemiológico a serem investigados no que se refere à ocorrência de anemia e DVA no Brasil e sua rede de determinantes.

Assim, este estudo buscou responder às seguintes questões:

- Anemia e deficiência de vitamina A (DVA) têm determinantes comuns nas crianças brasileiras?

- São deficiências nutricionais associadas? 


\section{HIPÓTESES}

Apesar de a anemia e a DVA serem deficiências nutricionais distintas, apresentam determinantes comuns referentes às variáveis que compõem a dimensão dos processos estruturais da sociedade, do ambiente imediato e individual da criança.

A anemia e a DVA ocorrem concomitantemente na mesma criança, considerando-se que a DVA contribui para o desenvolvimento da anemia. 


\section{OBJETIVO}

Analisar os determinantes da anemia, da deficiência de vitamina A e da carência concomitante de DVA e anemia em crianças brasileiras. 
Método 


\section{MÉTODO}

\subsection{Delineamento do estudo}

Trata-se de uma reanálise dos dados da Pesquisa Nacional de Demografia e Saúde da Criança e da Mulher de 2006 (PNDS/2006) ${ }^{1}$, disponíveis on-line no site do Ministério da Saúde e, portanto, de domínio público.

A PNDS é um estudo transversal, de representatividade nacional, que teve como propósito caracterizar a população feminina em idade fértil e as crianças menores de 5 anos nas macrorregiões geopolíticas do País. Foi aprovada pelo Conselho de Ética em Pesquisa do Centro de Referência e Treinamento DST/Aids da Secretaria de Estado da Saúde (SP) e realizada de acordo com os preceitos éticos recomendados (Brasil, 2009).

\subsection{Pesquisa Nacional de Demografia e Saúde da Mulher e da Criança}

Conduzida em escala global, a Pesquisa Nacional de Demografia e Saúde da Mulher e da Criança - PNDS/2006 (Brasil, 2009) é um projeto da Measure Demographic and Health Survey, desenvolvido com apoio da Agência dos Estados Unidos para o Desenvolvimento, em parceria com várias outras instituições internacionais e nacionais, com o intuito de prover dados e análises para um amplo conjunto de indicadores de planejamento, monitoramento e avaliação de impacto nas áreas de população, saúde e nutrição de mulheres e crianças nos países em desenvolvimento.

No Brasil, esse inquérito foi realizado nos anos de 1986, 1991, 1996 e 2006 sob a coordenação do Instituto Brasileiro de Geografia e Estatística (IBGE) e do Ministério da Saúde (MS).

Os principais objetivos da PNDS/2006 foram: caracterizar a população feminina em idade fértil e as crianças menores de 5 anos, segundo fatores demográficos, socioeconômicos e culturais; identificar padrões de conjugalidade,

\footnotetext{
${ }^{1}$ A metodologia da Pesquisa Nacional de Demografia e Saúde da Criança e da Mulher está disponível on line: http://bvsms.saude.gov.br/bvs/pnds/index.php.
} 
parentalidade e reprodutivos; identificar perfis de morbimortalidade na infância, de amamentação e a cobertura vacinal; avaliar o estado nutricional, a prevalência da deficiência de vitamina A e de anemia ferropriva nos dois grupos populacionais; avaliar a segurança/insegurança alimentar, o teor de iodo disponível em âmbito domiciliar e avaliar o acesso a serviços de saúde e a medicamentos.

\subsubsection{Amostragem da PNDS/2006}

Trata-se de uma pesquisa de caráter domiciliar, realizada por amostragem probabilística complexa, de representatividade nacional. O plano amostral foi desenhado para fornecer estimativas representativas da população brasileira residente em domicílios particulares em setores comuns ou não especiais (inclusive favelas), selecionadas em dez estratos amostrais que compõem uma combinação das cinco macrorregiões geográficas brasileiras e as áreas urbanas e rurais.

As unidades amostrais foram selecionadas em dois estágios: unidades primárias, compostas por setores censitários, e unidades secundárias, formadas pelas unidades domiciliares. O universo amostral elegível foi constituído por todas as mulheres em idade reprodutiva entre 15 a 49 anos residentes nos domicílios, e seus filhos naturais menores de 5 anos, nascidos a partir de janeiro de 2001.

A amostra de setores foi obtida de forma independente em 10 estratos, por amostragem aleatória simples por conglomerados. Dentro dos setores foram selecionados aleatoriamente 12 domicílios por setor, denominados domicílios elegíveis por conterem pelo menos uma mulher de 15 a 49 anos de idade para responder ao questionário completo.

O total de setores das cinco macrorregiões e da situação do domicílio, urbana e rural, foi obtido de forma a garantir um total de entrevistas que permitisse um número mínimo de coletas de sangue em crianças, segundo os percentuais de incidência de deficiência de vitamina A no sangue. 


\subsubsection{Processo de expansão da amostra da PNDS/2006}

A amostragem probabilística complexa requer cálculos específicos para sua expansão. Adicionalmente, por ter sido realizada com o procedimento de amostragem inversa, em que o número de entrevistas realizadas é fixo e o número de elementos visitados é aleatório, foi necessário proceder a uma etapa anterior de re-ponderação da amostra, antes da expansão. Em pesquisas por amostragem, cada unidade selecionada representa a si mesma e também outras unidades da população de referência, mas que não foram selecionadas para compor a amostra. Assim, a cada unidade da amostra atribui-se um fator de expansão denominado "peso", que permite estimar os resultados para toda a população.

A expansão da amostra foi elaborada com a determinação inicial dos pesos dos domicílios, que sofreram reajustes devido a perdas no setor. Posteriormente, foram determinados os pesos referentes às mulheres, com base nos pesos dos domicílios. Em seguida, foi aplicado um procedimento de calibração dos pesos, tomando como base os resultados da Pesquisa Nacional por Amostra de Domicílios (PNAD)/2006.

\subsubsection{Aspectos metodológicos da coleta de dados da PNDS/2006}

O trabalho de campo teve início no dia 3 de novembro de 2006 e foi finalizado em 3 de maio de 2007. Ao final, foram obtidas informações de 14.617 domicílios, dos quais 13.056 tinham pelo menos uma mulher elegível, totalizando 15.575 mulheres entrevistadas e 6.375 crianças.

As mulheres entrevistadas com 15 anos ou mais assinaram o Termo de Consentimento Livre e Esclarecido (TCLE). Das solteiras menores de 18 anos, além da assinatura desse termo, solicitou-se aprovação de um responsável, mediante assinatura de um termo de consentimento específico. $\mathrm{O}$ termo das crianças menores de 5 anos foi assinado pelas mães ou responsável legal.

Dois questionários foram utilizados para a obtenção de informações básicas sobre o domicílio e seus moradores habituais e informações detalhadas sobre o público-alvo - mulheres elegíveis e seus filhos menores de 5 anos. Em todos os domicílios selecionados na amostra, o questionário, denominado Ficha 
do Domicílio, foi aplicado a um dos moradores, preferencialmente o responsável pelo domicílio e, em sua ausência, a um morador maior de 15 anos de idade que soubesse fornecer informações sobre o domicílio e seus moradores. O Questionário da Mulher foi aplicado a mulheres de 15 a 49 anos de idade identificadas como moradoras habituais do domicílio.

A coleta de sangue em mulheres de 15 a 49 anos foi realizada em cerca de $40 \%$ dos domicílios que compuseram o estudo. Os domicílios foram sorteados aleatoriamente, a fim de se garantir a quantidade necessária de amostras para o projeto (5.000 exames). A coleta de sangue e a antropometria foram realizadas em todas as crianças nascidas a partir de janeiro de 2001, desde que filhos biológicos da entrevistada, independentemente de o domicílio ter sido sorteado para a participação da mulher na coleta de sangue. No total, foi colhido sangue de 5.698 mulheres e obtidas 3.499 amostras de sangue de crianças de 6 a 59 meses para determinação de vitamina A, e 3.455, para análise de hemoglobina.

Uma única amostra de sangue foi coletada para a análise de hemoglobina e retinol sérico (teor de vitamina A no sangue). De acordo com recomendações técnicas internacionais, o sangue foi coletado por meio de micro-lanceta (Becton Dickinson, Franklin Lakes, NJ), sendo aproximadamente $30 \mu \mathrm{L}$ de sangue depositado diretamente num papel de filtro (Schleicher and Schuell 903 specimen collection paper; Dassel, Germany) e subsequentemente posto para secar, por meia hora, em uma caixa escura. Os filtros foram acondicionados no escuro, com um dessecante, na temperatura ambiente e em sacos plásticos hermeticamente fechados e identificados. Na sequência, o papel de filtro foi envolto em papel alumínio para se proteger a amostra dos efeitos da luz. Por fim, essa amostra foi colocada em um pequeno saco plástico, com identificação completa e lacrado. $\mathrm{O}$ período de tempo máximo entre a coleta e a sua recepção pelo laboratório foi de uma semana. As amostras coletadas foram enviadas ao laboratório por intermédio do correio, utilizando-se o Sedex em embalagens apropriadas. 


\subsubsection{Dosagens de hemoglobina e retinol sérico}

As dosagens foram realizadas pela determinação de cianometahemoglobina e por meio de HPLC (sigla em inglês para Cromatografia Líquida de Alta Eficiência- Clae), utilizando-se a técnica da gota seca, como descrito a seguir.

Para análise das amostras foram retirados três discos de 4,75 $\mathrm{mm}$ de diâmetro da gota seca usando-se um picotador. Cada disco corresponde a um volume de $9 \mu \mathrm{L}$, totalizando $27 \mu \mathrm{L}$. Em seguida foi feita a eluição do material em $500 \mu \mathrm{L}$ de água miliQ por 16 horas à temperatura ambiente, com posterior uso de sonicador por 15 minutos. Retirou-se $20 \mu \mathrm{L}$ para determinação de hemoglobina, analisada com kit laboratorial (Labtest ${ }^{\circledR}$, Brasil).

Depois se adicionou $500 \mu \mathrm{L}$ de etanol para desproteinização, agitou-se brevemente e em seguida adicionou-se $500 \mu \mathrm{L}$ de hexano, com agitação de dois minutos, com posterior centrifugação a $3500 \mathrm{rpm}$ por 10 minutos.

Para dosagem do retinol sérico retirou-se $300 \mu \mathrm{L}$ do sobrenadante (nhexano), que foi secado sob atmosfera de nitrogênio. A amostra suspensa em 150 $\mu \mathrm{L}$ de metanol foi injetada no HPLC, com volume do injetor (loop) de $100 \mu \mathrm{L}$. O resultado da concentração de retinol sérico na gota foi calculado pela curva de calibração com padrão externo, de no mínimo três pontos, conferido diariamente.

\subsection{Amostra do presente estudo}

O banco de dados construído para o presente estudo incluiu 3.417 crianças com resultado de hemoglobina e retinol sérico. Foram excluídas 38 crianças que tiveram amostra de sangue inadequadas para análise da hemoglobina e 82 para vitamina A (Figura 4).

Figura 4 - Fluxograma para seleção da amostra de crianças com análise de retinol sérico e hemoglobina

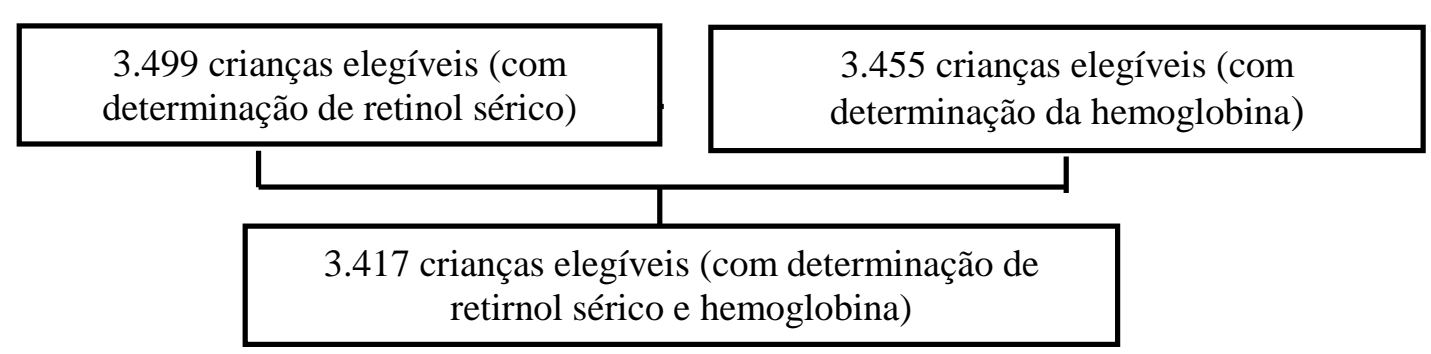


Com o objetivo de se avaliar a precisão e a validade dessa amostra, calculou-se o efeito do desenho (Deff), medida de comparação entre planos amostrais no estágio de planejamento de uma pesquisa (Brasil, 2009). O presente estudo considerou os pesos amostrais adotados pela PNDS/2006 para o cálculo das frequências absolutas, porcentagens, medidas de dispersão e ajustes de modelos, com uso do programa "R" para expansão (http://faculty.washington.edu/ tlumley/survey/), o que resultou em amostra expandida correspondente a 9 milhões e 206 mil crianças.

\subsection{Variáveis do estudo}

\subsubsection{Variáveis respostas}

No presente estudo, uma das variáveis resposta foi a presença de anemia, definida como concentrações de $\mathrm{Hb}$ inferior a 11,0 g/dL. O termo anemia foi utilizado para designar a anemia ferropriva e a dosagem de hemoglobina foi usada como proxy de anemia por deficiência de ferro, embora não diagnostique a deficiência do mineral. Para a sua classificação da anemia em relação ao seu nível de importância epidemiológica em saúde pública, utilizaram-se os critérios recomendados pela OMS (WHO, 2001), que definem os seguintes pontos de corte: nível leve para prevalências entre 5,0\% e 19,9\%; moderado, de 20,0\% a $39,9 \%$; e grave, para as de $40,0 \%$ ou mais.

Outra variável resposta estudada foi a presença de deficiência de vitamina A (DVA), definida como níveis séricos de retinol inferiores a 0,70 $\mu \mathrm{mol} / \mathrm{L}$ (20 $\mu \mathrm{g} / \mathrm{dL})$. Para a classificação da DVA em relação ao seu nível de importância epidemiológica em saúde pública utilizaram-se os critérios recomendados pela OMS (WHO, 1996), que definem os seguintes pontos de corte: nível leve para prevalências inferiores a 10,0\%, moderado de $10,0 \%$ a $19,9 \%$ e grave para prevalências de $20,0 \%$ ou mais. Por fim, analisou-se também como variável resposta a carência concomitante de DVA e anemia. 


\subsubsection{Variáveis explanatórias}

As variáveis explanatórias foram representadas pelas variáveis socioeconômicas e ambientais, maternas, de segurança e consumo alimentar e características biológicas da criança. Para a categorização de cada variável consideraram-se os critérios adotados pela PNDS/2006 (Brasil, 2009), bem como a especificidade de cada uma.

A população estudada foi categorizada em classes ou grupos socioeconômicos de acordo com o Critério de Classificação Econômica Brasil, medida baseada na posse de bens duráveis e em algumas características do chefe do domicílio (Associação Brasileira de Empresas de Pesquisa, 2008). Para caracterizar as condições socioeconômicas e ambientais, utilizaram-se as variáveis descritas no Quadro 5. Em relação à mãe, analisou-se também a idade ( $<20$ anos, 20 a 35 anos e $\geq 36$ anos).

Quadro 5- Caracterização da condição socioeconômica e ambiental do estudo

\begin{tabular}{|l|l|}
\hline \multicolumn{1}{|c|}{ Variável } & \multicolumn{1}{c|}{ Categoria } \\
\hline Macrorregião de residência & Norte, Nordeste, Sudeste, Sul e Centro-Oeste \\
\hline Zona de residência & Urbano e rural \\
\hline Abastecimento de água & Rede geral e outro \\
\hline Saneamento & Rede de esgoto, fossa séptica e outro \\
\hline Número de cômodos para dormir & 1,2 ou 3 e 4 ou mais \\
\hline Número de moradores & Até 4, 5 ou 6 e 7 ou mais \\
\hline Classe econômica* & A a E \\
\hline Renda familiar per capita** & $<0,5$ salário mínimo e $\geq 0,5$ salário mínimo \\
\hline Situação de trabalho materno & Remunerado e não remunerado \\
\hline Anos de estudo da mãe & $0-4$ anos, 5-8 anos e 9 e mais \\
\hline Estado civil da mãe & Casada/ união estável e solteira /separada/viúva \\
\hline
\end{tabular}

* Associação Brasileira de Empresas de Pesquisa (ABEP, 2008).

** Considerou-se o valor do salário mínimo em 2006 de $\mathrm{R} \$ 350,00$, ponto corte conforme Fujimori et al. (2008).

A segurança alimentar e os diferentes graus de insegurança foram avaliados mediante o uso da Escala Brasileira de Insegurança Alimentar (EBIA), nos parâmetros segurança alimentar, insegurança leve, insegurança moderada e insegurança grave (Segall-Corrêa et al., 2004). A segurança alimentar refere-se à garantia de acesso contínuo à quantidade suficiente de alimentos de qualidade, obtido por meio socialmente aceitável, de forma a assegurar o bem-estar e a saúde dos indivíduos. Insegurança alimentar leve refere-se ao receio ou medo de sofrer 
insegurança alimentar no futuro próximo (componente psicológico da família) e a problemas da qualidade da alimentação da família. Define-se insegurança alimentar moderada como a restrição na quantidade dos alimentos na família e insegurança alimentar grave como a fome entre adultos e/ou crianças da família.

O consumo alimentar dos últimos sete dias foi analisado considerando-se os grupos de alimentos: cereais/pães e massas; legumes/verduras; frutas; feijões; carnes; leite e derivados; e doces. Para cada grupo de alimentos utilizaram-se as seguintes categorias: não comeu; consumiu pelo menos 1 dia; 2 a 3 dias na semana; 4 a 6 dias; ou todos os dias da semana.

As variáveis biológicas da criança encontram-se descritas no Quadro 6.

Quadro 6- Descrição das variáveis biológicas das crianças do estudo

\begin{tabular}{|l|l|}
\hline \multicolumn{1}{|c|}{ Variável } & \multicolumn{1}{c|}{ Categoria } \\
\hline Idade da criança & $<2$ anos e $\geq 2$ anos \\
\hline Sexo & Feminino e masculino \\
\hline A criança foi amamentada alguma vez & Sim e não \\
\hline Tempo de aleitamento materno exclusivo- AME & $<30$ dias e $\geq 30$ dias \\
\hline Tempo de aleitamento materno- AM & $<6$ meses, 6-11 meses e $\geq 12$ meses \\
\hline Suplementação de vitamina A & Sim e não \\
\hline Suplementação de ferro & Sim e não \\
\hline Internação nos últimos 12 meses & Sim e não \\
\hline Estado nutricional & $\begin{array}{l}\text { Peso/Idade Altura/Idade, Peso/Altura e Índice } \\
\text { de Massa Corporal-IMC/Idade }\end{array}$ \\
\hline
\end{tabular}

A mensuração do peso e da altura das crianças foi realizada de acordo com as recomendações da OMS (WHO, 1995), coletadas por antropometristas treinados em duplicata, calculando-se a média aritmética de ambas. Em menores de 2 anos, a estatura foi estimada pela medida do comprimento, com a criança medida na posição deitada em um estadiômetro infantil. Nas crianças com idade igual ou superior a 2 anos, a estatura foi estimada pela medida da altura, com o indivíduo medido em pé, em aparelho denominado estadiômetro. Os aparelhos utilizados tiveram precisão de $1 \mathrm{~mm}$ e foram calibrados no início e no final de cada dia de trabalho.

O estado nutricional foi analisado pelos índices peso-para-idade (peso/idade); altura-para-idade (altura/idade); peso-para-altura (peso/altura); e índice de massa corporal-para-idade (IMC/Idade). A curva da OMS (WHO, 2006) foi utilizada como padrão de referência. 


\subsection{Processamento e análise dos dados}

Para o processamento dos dados, utilizaram-se os bancos de dados da Ficha do Domicílio e do Questionário da Mãe com dados da Criança para a construção de um novo banco que incluiu informações das 3.417 crianças com resultados de hemoglobina e retinol sérico.

O modelo teórico de determinação da anemia e da DVA foi estruturado com base na literatura e agrupado em três Blocos (Figura 5). O primeiro (Bloco 1) foi composto pelas variáveis determinadas pelas políticas sociais e econômicas que impactam diretamente nas condições ambientais e de vida da população (macrorregião e zona de residência, condição de moradia, classe econômica, renda, anos de estudo, trabalho e estado civil da mãe). O segundo bloco (Bloco 2) incluiu variáveis relativas ao ambiente imediato da criança (idade da mãe, segurança alimentar e consumo alimentar). O último bloco (Bloco 3) foi integrado por variáveis da criança. Analisou-se separadamente cada desfecho: anemia, DVA e ocorrência concomitante de DVA e anemia.

Figura 5- Modelo hierárquico proposto para a análise dos determinantes da anemia, DVA e ocorrência concomitante de DVA e anemia

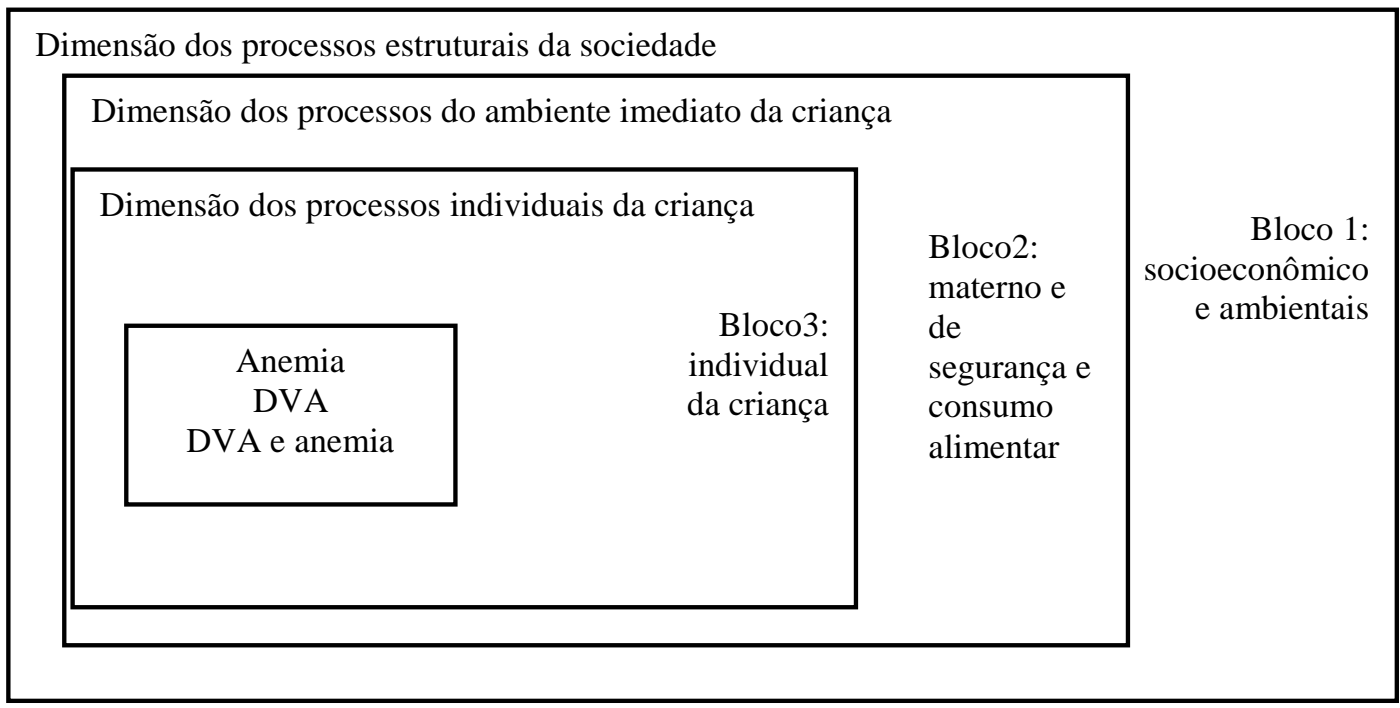

Fonte: Adaptado de Silva, Giugliani e Aerts (2001), Osório (2002), Caminha (2005), Oliveira et al. (2010) e Miglioli et al. (2013) 
Os parâmetros e os respectivos intervalos de confiança de 95\% (IC: 95\%) foram estimados para os dados expandidos considerando-se o efeito do desenho amostral. A força de associação entre as variáveis respostas e as explanatórias foi avaliada pelo odds ratio (OR), tanto na análise univariada (OR bruta) quanto na análise múltipla (OR ajustada). Utilizou-se o teste qui-quadrado com correção de segunda ordem de Rao-Scott (Rao, Scott, 1984) para se verificar a associação entre os níveis de retinol e as diferentes concentrações de hemoglobina, e também, entre anemia e DVA. Aplicou-se, ainda, o coeficiente de correlação de Pearson para se estudar a associação entre os níveis de retinol sérico e as concentrações de hemoglobina. Em todos os testes foi adotado o nível de significância de 5\%.

Para análise múltipla (regressão logística ponderada), empregou-se a abordagem hierárquica para a determinação da anemia, DVA e ocorrência concomitante de DVA e anemia, que consiste na entrada das variáveis explanatórias no modelo seguindo uma ordem previamente estabelecida pelo pesquisador, com base nas relações lógicas e teóricas de determinação, constituindo uma rede hipotética de causalidade (Silva, Giugliani, Aerts, 2001; Osório, 2002; Caminha, 2005; Oliveira et al., 2010; Miglioli et al., 2013). De acordo com essa estratégia, no presente estudo, a inclusão das variáveis seguiu a ordem dos Blocos, considerando o escalonamento hierárquico distal, intermediário e proximal, conforme apresentado na Figura 5. Assim, as variáveis dos níveis hierárquicos definidos a priori foram incluídas no modelo, nível por nível.

Em cada nível hierárquico, a seleção de variáveis para o modelo foi realizada com procedimento stepwise forward selection, utilizando-se como critério de exclusão, em cada passo, o valor de $p \geq 0,20$.

Assim, o processo de modelagem foi iniciado com as variáveis do primeiro nível hierárquico e com significância maior ou igual a $20 \%$ foram excluídas progressivamente. Em seguida, as variáveis do segundo nível hierárquico foram adicionadas ao modelo e procedeu-se da mesma maneira, com exclusão progressiva das variáveis desse nível com valor de $p \geq 0,20$. Dessa forma, todos os níveis hierárquicos foram analisados.

Contudo, no modelo final da anemia, as variáveis classe econômica, segurança alimentar, consumo do grupo das carnes e feijões, sexo e IMC/idade 
que não apresentaram significância nesse nível $(p>0,20)$ na análise univariada foram incluídas na análise múltipla, tendo em vista sua relevância como determinantes da anemia, de acordo com a literatura. Da mesma forma, as variáveis classe econômica; segurança alimentar; anos de estudo da mãe; consumo do grupo de legumes/verduras, frutas e feijões; idade; sexo; internação nos últimos 12 meses; e estado nutricional da criança que não apresentaram significância no nível de $\mathrm{p}<0,20$ na análise univariada também foram incluídas no modelo final de DVA. As variáveis classe econômica; sexo; suplementação com ferro; e IMC/idade, consideradas como determinantes da ocorrência concomitante de DVA e anemia, de acordo com a literatura, também foram incluídas na análise múltipla, embora não tenham apresentado significância no nível de p<0,20.

No entanto, no modelo final das deficiências estudadas, foram consideradas significantes aquelas variáveis de cada bloco referente a cada nível hierárquico que apresentaram um valor de $\mathrm{p}<0,05$.

Para as análises estatísticas utilizou-se o pacote estatístico " $R$ " versão 2.12.2., projeto colaborativo disponível gratuitamente na Internet (The $R$ Foundation for Statistical Computing: http://www.r-project.org). 


\section{Resultados}




\section{RESULTADOS}

Os resultados são apresentados em três tópicos: determinantes da anemia, determinantes da DVA e por último os determinantes da carência concomitante de DVA e anemia.

\subsection{Determinantes da anemia}

A prevalência de anemia nas crianças brasileiras de 6 a 59 meses de idade foi de $20,5 \%$ (IC95\%: 18,1; 23,2\%).

Apresenta-se, na Tabela 1, a análise univariada das variáveis referentes à dimensão dos processos estruturais da sociedade e do ambiente imediato da criança, relativas aos Blocos 1 e 2. Associaram-se estatisticamente $(\mathrm{p}<0,05)$ à ocorrência de anemia a macrorregião de residência, com maiores prevalências nas regiões Nordeste, Sudeste e Sul, morar na zona urbana e ter água encanada. Os resultados sugerem, como fator de proteção, a mãe ter mais anos de estudo [OR: 0,59; IC: $0,41-0,86]$.

Chamam atenção as maiores chances para ocorrência de anemia entre as classes econômicas $\mathrm{C}, \mathrm{D}$ e E, que apresentaram prevalências mais elevadas dessa condição, da mesma forma que as crianças de famílias com insegurança alimentar grave (Tabela 1). Assim, apesar de apresentarem p>0,20, as variáveis classe econômica e segurança alimentar foram incluídas na análise múltipla, considerando-se o referencial teórico adotado.

Tabela 1- Prevalência de anemia em crianças de 6 a 59 meses de idade, segundo as variáveis socioeconômicas, ambientais, maternas e de segurança alimentar (Blocos 1 e 2). Brasil, PNDS/2006

\begin{tabular}{lccccc}
\hline Variáveis & $\begin{array}{c}\text { Número de } \\
\text { crianças com } \\
\text { dados } \\
\text { disponíveis }\end{array}$ & $\begin{array}{c}\text { Prevalência de } \\
\text { anemia (\%) } \\
\text { Hb<11g/dL }\end{array}$ & OR Bruta & (IC 95\%) & p-valor \\
\hline BLOCO 1 & & & & \\
Macrorregião de residência & 667 & 10,7 & 1 & $<, 001$ \\
Centro-Oeste & 657 & 25,9 & 2,92 & $(1,99-4,29)$ & \\
Nordeste & 822 & 7,1 & 0,64 & $(0,40-10,03)$ \\
Norte & 672 & 22,6 & 2,43 & $(1,58-3,74)$ \\
Sudeste & 599 & 21,2 & 2,24 & $(1,46-3,43)$ \\
Sul & & & & $($ continuação)
\end{tabular}




\begin{tabular}{|c|c|c|c|c|c|}
\hline Variáveis & $\begin{array}{c}\text { Número de } \\
\text { crianças com } \\
\text { dados } \\
\text { disponíveis }\end{array}$ & $\begin{array}{c}\text { Prevalência de } \\
\text { anemia }(\%) \\
\mathrm{Hb}<11 \mathrm{~g} / \mathrm{dL}\end{array}$ & $\begin{array}{c}\text { OR } \\
\text { Bruta }\end{array}$ & $($ IC 95\%) & p-valor \\
\hline Zona da residência & & & & & $<0,001$ \\
\hline Rural & 1268 & 12,3 & 1 & & \\
\hline Urbano & 2149 & 22,7 & 2,10 & $(1,44-3,04)$ & \\
\hline $\begin{array}{l}\text { Abastecimento de } \\
\text { água }\end{array}$ & & & & & $<0,001$ \\
\hline Rede geral & 2118 & 22,9 & 2,00 & $(1,39-2,88)$ & \\
\hline Outro & 1297 & 12,9 & 1 & & \\
\hline Esgoto & & & & & $\mathbf{0 , 0 8 8}$ \\
\hline Rede geral & 1297 & 23,9 & 1 & & \\
\hline Séptica & 729 & 18,0 & 0,70 & $(0,46-1,06)$ & \\
\hline Outro & 930 & 16,9 & 0,65 & $(0,40-1,06)$ & \\
\hline $\begin{array}{l}\mathrm{N}^{\circ} \text { cômodos para } \\
\text { dormir }\end{array}$ & & & & & 0,319 \\
\hline 1 & 1039 & 23,6 & 1 & & \\
\hline 2 ou 3 & 2224 & 19,1 & 0,77 & $(0,54-1,08)$ & \\
\hline 4 ou mais & 152 & 16,5 & 0,64 & $(0,23-1,84)$ & \\
\hline $\mathbf{N}^{\circ}$ de moradores & & & & & 0,854 \\
\hline Até 4 & 1688 & 20,6 & 1 & & \\
\hline 5 ou 6 & 1084 & 21,0 & 1,02 & $(0,70-1,48)$ & \\
\hline 7 ou mais & 645 & 18,5 & 0,87 & $(0,54-1,42)$ & \\
\hline Classe econômica & & & & & 0,224 \\
\hline A & 26 & 4,9 & 1 & & \\
\hline B & 374 & 15,8 & 3,62 & $(0,88-14,88)$ & \\
\hline $\mathrm{C}$ & 1600 & 21,3 & 5,22 & $(1,33-20,52)$ & \\
\hline $\mathrm{D}$ & 877 & 22,7 & 5,68 & $(1,43-22,49)$ & \\
\hline $\mathrm{E}$ & 539 & 19,2 & 4,57 & $(1,12-18,67)$ & \\
\hline $\begin{array}{l}\text { Renda familiar per } \\
\text { capita }\end{array}$ & & & & & 0,194 \\
\hline $\begin{array}{l}<0,5 \text { salário } \\
\text { mínimo }\end{array}$ & 925 & 18,0 & 1 & & \\
\hline $\begin{array}{l}\geq 0,5 \text { salário } \\
\text { mínimo }\end{array}$ & 1889 & 21,8 & 1,27 & $(0,89-1,82)$ & \\
\hline $\begin{array}{l}\text { Anos de estudo da } \\
\text { mãe }\end{array}$ & & & & & 0,029 \\
\hline $0-4$ anos & 1476 & 24,1 & 1 & & \\
\hline 5-8 anos & 1021 & 15,8 & 0,59 & $(0,41-0,86)$ & \\
\hline 9 e mais & 823 & 20,8 & 0,83 & $(0,56-1,22)$ & \\
\hline $\begin{array}{l}\text { Situação do } \\
\text { trabalho }\end{array}$ & & & & & 0,249 \\
\hline Remunerado & 1196 & 22,5 & 1 & & \\
\hline Não remunerado & 2219 & 19,4 & 0,83 & $(0,60-1,14)$ & \\
\hline Estado civil da mãe & & & & & 0,218 \\
\hline $\begin{array}{l}\text { Casada/União } \\
\text { estável }\end{array}$ & 2897 & 19,6 & 1 & & \\
\hline $\begin{array}{l}\text { Solteira/Separada } \\
\text { /Viúva }\end{array}$ & 518 & 25,3 & 1,39 & $(0,82-2,37)$ & \\
\hline \multicolumn{6}{|l|}{ BLOCO 2} \\
\hline Idade da mãe & & & & & 0,661 \\
\hline$<20$ anos & 262 & 18,4 & 1 & & \\
\hline 20-35 anos & 2716 & 21,1 & 1,19 & $(0,68-2,07)$ & \\
\hline$\geq 36$ anos & 439 & 18,5 & 1,00 & $(0,52-1,93)$ & \\
\hline
\end{tabular}




\begin{tabular}{lccccc}
\hline Variáveis & $\begin{array}{c}\text { Número de } \\
\text { crianças com } \\
\text { dados } \\
\text { disponíveis }\end{array}$ & $\begin{array}{c}\text { Prevalência de } \\
\text { anemia (\%) } \\
\mathbf{H b}<\mathbf{1 1 g} / \mathbf{d L}\end{array}$ & $\begin{array}{c}\text { OR } \\
\text { Bruta }\end{array}$ & (IC 95\%) & p-valor \\
\hline $\begin{array}{l}\text { Segurança alimentar } \\
\quad \begin{array}{l}\text { Segurança } \\
\text { alimentar }\end{array}\end{array}$ & 1556 & 19,4 & 1 & & $\mathbf{0 , 5 8 3}$ \\
$\quad \begin{array}{l}\text { Insegurança leve } \\
\begin{array}{l}\text { Insegurança } \\
\text { moderada }\end{array}\end{array}$ & 913 & 21,9 & 1,16 & $(0,78-1,75)$ & \\
$\begin{array}{l}\text { Insegurança } \\
\text { grave }\end{array}$ & 398 & 20,3 & 1,06 & $(0,69-1,63)$ & \\
\hline
\end{tabular}

Ainda na análise univariada, o consumo alimentar dos últimos sete dias (Bloco 2) não se associou estatisticamente $(\mathrm{p}<0,05)$ com a ocorrência de anemia. Observou-se que a base da alimentação dessas crianças era representada pelo grupo de cereais/pães e massas $(n=2630)$ e feijões $(n=2193)$ consumidos "todos os dias". Em relação aos demais grupos, verificou-se que quase um terço $(n=1035)$ não consumiu o grupo de legumes/verduras, nem de leites e derivados $(n=1165)$ nos últimos sete dias. Destaca-se também o número de crianças que não consumiam o grupo das carnes (Tabela 2). Mesmo sem associação estatística no nível de $\mathrm{p}<0,20$, as variáveis consumo de carnes e do grupo de feijões foram incluídas no modelo múltiplo, por constituírem as principais fontes de ferro.

Tabela 2- Proporção de crianças com 6 a 59 meses de idade com anemia, segundo o consumo alimentar dos grupos de alimentos nos últimos sete dias (Bloco 2). Brasil, PNDS/2006

\begin{tabular}{|c|c|c|c|c|c|}
\hline Grupo de alimentos & $\begin{array}{l}\text { Número de } \\
\text { crianças } \\
\text { com dados } \\
\text { disponíveis }\end{array}$ & $\begin{array}{c}\text { Prevalência } \\
\text { de anemia } \\
(\%) \\
\text { Hb }<11 \text { g/dL }\end{array}$ & $\begin{array}{c}\text { OR } \\
\text { Bruta }\end{array}$ & $(\mathrm{IC} \mathrm{95 \% )}$ & p-valor \\
\hline \multicolumn{6}{|l|}{$\overline{B L O C O ~} 2$} \\
\hline $\begin{array}{l}\text { Cereais/ pães e } \\
\text { massas }\end{array}$ & & & & & 0,341 \\
\hline Não comeu & 113 & 23,5 & 1 & & \\
\hline $1 \mathrm{dia}$ & 99 & 26,8 & 1,19 & $(0,43-3,31)$ & \\
\hline 2 a 3 dias & 326 & 25,5 & 1,12 & $(0,50-2,49)$ & \\
\hline 4 a 6 dias & 223 & 15,7 & 0,61 & $(0,25-1,48)$ & \\
\hline Todos os dias & 2630 & 20,1 & 0,82 & $(0,39-1,69)$ & \\
\hline Legumes/ verduras & & & & & $\mathbf{0 , 3 8 0}$ \\
\hline Não comeu & 1035 & 21,2 & 1 & & \\
\hline $1 \mathrm{dia}$ & 354 & 19,5 & 0,90 & $(0,51-1,59)$ & \\
\hline 2 a 3 dias & 885 & 22,1 & 1,05 & $(0,68-1,63)$ & \\
\hline 4 a 6 dias & 472 & 14,2 & 0,62 & $(0,37-1,04)$ & \\
\hline Todos os dias & 637 & 21,5 & 1,02 & $(0,65-1,61)$ & \\
\hline
\end{tabular}




\begin{tabular}{|c|c|c|c|c|c|}
\hline Grupo de alimentos & $\begin{array}{l}\text { Número de } \\
\text { crianças } \\
\text { com dados } \\
\text { disponíveis }\end{array}$ & $\begin{array}{c}\begin{array}{c}\text { Prevalência } \\
\text { de anemia } \\
(\%) \\
\mathrm{Hb}<11 \mathrm{~g} / \mathrm{dL}\end{array} \\
\end{array}$ & $\begin{array}{c}\text { OR } \\
\text { Bruta }\end{array}$ & (IC 95\%) & p-valor \\
\hline Frutas & & & & & 0,092 \\
\hline Não comeu & 503 & 14,0 & 1 & & \\
\hline $1 \mathrm{dia}$ & 289 & 19,9 & 1,53 & $(0,75-3,10)$ & \\
\hline 2 a 3 dias & 844 & 25,6 & 2,12 & $(1,27-3,54)$ & \\
\hline 4 a 6 dias & 510 & 20,8 & 1,61 & $(0,92-2,83)$ & \\
\hline Todos os dias & 1242 & 19,6 & 1,50 & $(0,94-2,41)$ & \\
\hline Feijão & & & & & 0,232 \\
\hline Não comeu & 311 & 27,8 & 1 & & \\
\hline $1 \mathrm{dia}$ & 171 & 13,1 & 0,39 & $(0,18-0,87)$ & \\
\hline 2 a 3 dias & 435 & 20,5 & 0,67 & $(0,35-1,27)$ & \\
\hline 4 a 6 dias & 271 & 22,7 & 0,76 & $(0,39-1,47)$ & \\
\hline Todos os dias & 2193 & 20,1 & 0,65 & $(0,40-1,07)$ & \\
\hline Carne & & & & & 0,438 \\
\hline Não comeu & 608 & 21,4 & 1 & & \\
\hline $1 \mathrm{dia}$ & 326 & 13,8 & 0,59 & $(0,31-1,09)$ & \\
\hline 2 a 3 dias & 994 & 21,4 & 1,00 & $(0,65-1,54)$ & \\
\hline 4 a 6 dias & 572 & 19,0 & 0,86 & $(0,52-1,43)$ & \\
\hline Todos os dias & 881 & 21,9 & 1,03 & $(0,63-1,68)$ & \\
\hline Leite e derivados & & & & & 0,396 \\
\hline Não comeu & 1165 & 19,6 & 1 & & \\
\hline $1 \mathrm{dia}$ & 393 & 17,8 & 0,89 & $(0,56-1,41)$ & \\
\hline 2 a 3 dias & 741 & 22,6 & 1,20 & $(0,81-1,78)$ & \\
\hline 4 a 6 dias & 466 & 16,5 & 0,81 & $(0,50-1,31)$ & \\
\hline Todos os dias & 619 & 23,3 & 1,25 & $(0,79-1,98)$ & \\
\hline Doces & & & & & 0,774 \\
\hline Não comeu & 1042 & 19,6 & 1 & & \\
\hline $1 \mathrm{dia}$ & 490 & 23,8 & 1,28 & $(0,80-2,05)$ & \\
\hline 2 a 3 dias & 728 & 21,5 & 1,12 & $(0,75-1,68)$ & \\
\hline 4 a 6 dias & 453 & 19,3 & 0,98 & $(0,58-1,65)$ & \\
\hline Todos os dias & 658 & 18,7 & 0,94 & $(0,60-1,49)$ & \\
\hline
\end{tabular}

A Tabela 3 apresenta a análise univariada das características individuais das crianças (Bloco3). Constatou-se que apenas a variável internação nos últimos 12 meses associou-se estatisticamente $(p<0,05)$ com a ocorrência de anemia. Contudo, as crianças menores de 2 anos de idade e aquelas amamentadas por menos de 6 meses com leite materno apresentaram as maiores frequências de anemia. A despeito de apresentarem p $>0,20$, as variáveis sexo e estado nutricional classificado pelo índice IMC/idade, foram incluídas na análise múltipla.

A ocorrência de anemia também se mostrou elevada $(20,7 \%)$ entre as crianças que faziam uso da suplementação profilática com ferro (dado não apresentado em tabela). 
Tabela 3- Prevalência da anemia em crianças de 6 a 59 meses de idade, segundo as variáveis biológicas (Bloco 3). Brasil, PNDS/2006

\begin{tabular}{|c|c|c|c|c|c|}
\hline Variáveis & $\begin{array}{l}\text { Número de } \\
\text { crianças com } \\
\text { dados } \\
\text { disponíveis }\end{array}$ & 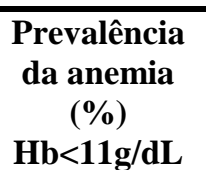 & $\begin{array}{c}\text { OR } \\
\text { Bruta }\end{array}$ & (CI 95\%) & p-valor \\
\hline \multicolumn{6}{|l|}{ BLOCO 3} \\
\hline Idade da criança & & & & & 0,064 \\
\hline$<2$ anos & 1070 & 23,7 & 1 & & \\
\hline$\geq 2$ anos & 2347 & 19,1 & 0,76 & $(0,57-1,02)$ & \\
\hline Sexo & & & & & 0,745 \\
\hline Feminino & 1627 & 20,1 & 1 & & \\
\hline Masculino & 1790 & 20,9 & 1,05 & $(0,77-1,44)$ & \\
\hline $\begin{array}{l}\text { A criança amamentada } \\
\text { alguma vez }\end{array}$ & & & & & 0,871 \\
\hline Não & 118 & 19,7 & 1 & & \\
\hline Sim & 3295 & 20,6 & 1,06 & $(0,55-2,02)$ & \\
\hline Tempo AME & & & & & 0,140 \\
\hline$<30$ dias & 689 & 15,5 & 1 & & \\
\hline$\geq 30$ dias & 2529 & 21,5 & 1,50 & $(0,87-2,58)$ & \\
\hline Tempo AM & & & & & 0,956 \\
\hline$<6$ meses & 862 & 19,5 & 1 & & \\
\hline 6-11 meses & 638 & 18,9 & 0,96 & $(0,60-155)$ & \\
\hline 12 meses e mais & 1036 & 18,6 & 0,94 & $(0,64-1,39)$ & \\
\hline $\begin{array}{l}\text { Internação nos } \\
\text { últimos } 12 \text { meses }\end{array}$ & & & & & $\mathbf{0 , 0 3 0}$ \\
\hline Não & 2994 & 19,5 & 1 & & \\
\hline Sim & 422 & 27,7 & 1,58 & $(1,04-2,41)$ & \\
\hline \multicolumn{6}{|l|}{ Estado nutricional } \\
\hline Peso/Idade & & & & & 0,135 \\
\hline Normal & 3156 & 20,9 & 1 & & \\
\hline$<-2$ escores $\mathrm{z}$ & 75 & 15,2 & 0,48 & $(0,12-1,97)$ & \\
\hline$>2$ escores z & 143 & 11,6 & 1,52 & $(0,89-2,62)$ & \\
\hline Altura/Idade & & & & & 0,993 \\
\hline Normal & 2987 & 20,4 & 1 & & \\
\hline$<-2$ escores $\mathrm{z}$ & 267 & 20,8 & 0,48 & $(0,12-1,97)$ & \\
\hline$>2$ escores $\mathrm{z}$ & 92 & 20,9 & 1,52 & $(0,89-2,62)$ & \\
\hline Peso/Altura & & & & & 0,124 \\
\hline Normal & 3075 & 20,0 & 1 & & \\
\hline$<-2$ escores z & 42 & 41,4 & 0,48 & $(0,12-1,97)$ & \\
\hline$>2$ escores $\mathrm{Z}$ & 219 & 23,0 & 1,52 & $(0,89-2,62)$ & \\
\hline IMC/Idade & & & & & 0,286 \\
\hline Normal & 3033 & 19,9 & 1 & & \\
\hline$<-2$ escores z & 64 & 32,1 & 0,48 & $(0,12-1,97)$ & \\
\hline$>2$ escores $\mathrm{z}$ & 249 & 24,3 & 1,52 & $(0,89-2,62)$ & \\
\hline
\end{tabular}

A Tabela 4 apresenta as variáveis que permaneceram no modelo de análise múltipla, após ajuste. Associaram-se à anemia, residir no Nordeste [OR: 3,45; IC: 2,21-5,40], Sudeste [OR: 2,55; IC: 1,60-4,06] e Sul [OR: 2,22; IC: 1,39-3,55]; na zona urbana [OR: 2,01; IC: 1,35-3,00]; e ter insegurança alimentar grave 
[OR:1,78; IC:1,00-3,16], destacando-se como proteção, ter mãe com 5 a 8 anos de estudo [OR: 0,62; IC: 0,41-0,92] (Bloco 1) e consumir carne pelo menos uma vez na semana [OR: 0,45; IC: 0,22-0,93] (Bloco 2).

Tabela 4- Modelo múltiplo final dos determinantes associados à anemia em crianças de 6 a 59 meses de idade. Brasil, PNDS/2006

\begin{tabular}{|c|c|c|c|c|c|c|}
\hline Variáveis & $\begin{array}{c}\text { Número de } \\
\text { crianças com } \\
\text { dados } \\
\text { disponíveis }\end{array}$ & $\begin{array}{c}\text { Prevalência da } \\
\text { anemia }(\%) \\
\text { Hb }<11 \text { g/dL }\end{array}$ & $\begin{array}{c}\text { OR } \\
\text { Ajustada }\end{array}$ & (IC 95\%) & p-valor & Deff* \\
\hline \multicolumn{7}{|l|}{$\overline{\text { BLOCO } 1}$} \\
\hline Macrorregião & & & & & $<0,001$ & 2,01 \\
\hline Centro-Oeste & 667 & 10,7 & 1 & & & \\
\hline Nordeste & 657 & 25,9 & 3,45 & $(2,21-5,40)$ & & \\
\hline Norte & 822 & 7,1 & 0,65 & $(0,37-1,12)$ & & \\
\hline Sudeste & 672 & 22,6 & 2,55 & $(1,60-4,06)$ & & \\
\hline Sul & 599 & 21,2 & 2,22 & $(1,39-3,55)$ & & \\
\hline Zona da residência & & & & & $<0,001$ & 2,12 \\
\hline Rural & 1268 & 12,3 & 1 & & & \\
\hline Urbano & 2149 & 22,7 & 2,01 & $(1,35-3,00)$ & & \\
\hline Anos de estudo da mãe & & & & & $<0,001$ & 3,13 \\
\hline 0-4 anos & 1476 & 24,1 & 1 & & & \\
\hline $5-8$ anos & 1021 & 15,8 & 0,62 & $(0,41-0,92)$ & & \\
\hline 9 e mais & 823 & 20,8 & 0,86 & $(0,57-1,32)$ & & \\
\hline \multicolumn{7}{|l|}{ BLOCO 2} \\
\hline Segurança alimentar & & & & & $<0,001$ & 3,08 \\
\hline Segurança alimentar & 1556 & 19,4 & 1 & & & \\
\hline Insegurança leve & 913 & 21,9 & 1,22 & $(0,81-1,85)$ & & \\
\hline Insegurança moderada & 498 & 20,3 & 1,26 & $(0,77-2,06)$ & & \\
\hline Insegurança grave & 344 & 25,5 & 1,78 & $(1,00-3,16)$ & & \\
\hline Carnes & & & & & $<0,001$ & 3,37 \\
\hline Não comeu & 608 & 21,4 & 1 & & & \\
\hline $1 \mathrm{dia}$ & 326 & 13,8 & $\mathbf{0 , 4 5}$ & $(0,22-0,93)$ & & \\
\hline 2 a 3 dias & 994 & 21,4 & 0,86 & $(0,54-1,35)$ & & \\
\hline 4 a 6 dias & 572 & 19,0 & 0,85 & $(0,48-1,48)$ & & \\
\hline Todos os dias & 881 & 21,9 & 0,96 & $(0,57-1,63)$ & & \\
\hline
\end{tabular}

* Efeito do desenho 


\subsection{Determinantes da deficiência de vitamina $A$}

A prevalência de DVA nas crianças brasileiras de 6 a 59 meses de idade foi de $17,5 \%$ (IC95\%: 15,1; 20,2\%).

Resultados da análise univariada relativa às variáveis dos Blocos 1 e 2 que se associaram estatisticamente $(\mathrm{p}<0,05)$ à ocorrência de DVA foram macrorregião de residência, com maior prevalência no Sudeste e Nordeste; morar na zona urbana; ter água encanada e rede de esgoto; e idade materna maior que 35 anos. A variável anos de estudo da mãe não apresentou associação significativa com a ocorrência de DVA, porém observou-se que as crianças de mãe com menos de cinco anos de estudo tinham maior chance para DVA (Tabela 5). Apesar de apresentarem p>0,20, as variáveis classe econômica, anos de estudo da mãe e segurança alimentar foram incluídas na análise múltipla, atendendo-se o referencial teórico adotado.

Tabela 5- Prevalência de DVA em crianças de 6 a 59 meses de idade, segundo as variáveis socioeconômicas, ambientais, maternas e de segurança alimentar (Blocos 1 e 2). Brasil, PNDS/2006

\begin{tabular}{|c|c|c|c|c|c|}
\hline Variáveis & $\begin{array}{c}\text { Número de } \\
\text { crianças com } \\
\text { dados } \\
\text { disponíveis } \\
\end{array}$ & $\begin{array}{c}\text { Prevalência de } \\
\text { DVA }(\%) \\
\text { Retinol }(<0,7 \\
\mu \mathrm{mol} / \mathrm{L}) \\
\end{array}$ & $\begin{array}{c}\text { OR } \\
\text { Bruta }\end{array}$ & (IC 95\%) & p-valor \\
\hline \multicolumn{6}{|l|}{ BLOCO 1} \\
\hline Macrorregião & & & & & $<0,001$ \\
\hline Centro-Oeste & 667 & 12,1 & 1 & & \\
\hline Nordeste & 657 & 19,3 & 1,73 & $(1,16-2,59)$ & \\
\hline Norte & 822 & 9,8 & 0,79 & $(0,52-1,20)$ & \\
\hline Sudeste & 672 & 22,1 & 2,05 & $(1,34-3,14)$ & \\
\hline Sul & 599 & 10,1 & 0,82 & $(0,52-1,28)$ & \\
\hline Zona de residência & & & & & $\mathbf{0 , 0 2 7}$ \\
\hline Rural & 1268 & 13,3 & 1 & & \\
\hline Urbano & 2149 & 18,7 & 1,50 & $(1,05-2,15)$ & \\
\hline $\begin{array}{l}\text { Abastecimento de } \\
\text { água }\end{array}$ & & & & & $<0,001$ \\
\hline Rede geral & 2118 & 19,4 & 1,82 & $(1,3-2,56)$ & \\
\hline Outro & 1297 & 11,6 & 1 & & \\
\hline Esgoto & & & & & $<0,001$ \\
\hline Rede geral & 1297 & 22,2 & 1 & & \\
\hline Séptica & 729 & 13,3 & 0,54 & $(0,35-0,83)$ & \\
\hline Outro & 930 & 12,5 & 0,50 & $(0,34-0,74)$ & \\
\hline
\end{tabular}

(continuação) 
(

\begin{tabular}{|c|c|c|c|c|c|}
\hline Variáveis & $\begin{array}{c}\text { Número de } \\
\text { crianças com } \\
\text { dados } \\
\text { disponíveis } \\
\end{array}$ & $\begin{array}{c}\text { Prevalência de } \\
\text { DVA }(\%) \\
\text { Retinol }(<0,7 \\
\mu \mathrm{mol} / \mathrm{L}) \\
\end{array}$ & $\begin{array}{c}\text { OR } \\
\text { Bruta }\end{array}$ & (IC 95\%) & p-valor \\
\hline $\begin{array}{l}\mathrm{N}^{\circ} \text { cômodos para } \\
\text { dormir }\end{array}$ & & & & & 0,068 \\
\hline 1 & 1039 & 17,5 & 1 & & \\
\hline 2 ou 3 & 2224 & 16,2 & 0,91 & $(0,65-1,28)$ & \\
\hline 4 ou mais & 152 & 36,0 & 2,65 & $(0,87-8,05)$ & \\
\hline $\mathbf{N}^{\circ}$ de moradores & & & & & 0,487 \\
\hline Até 4 & 1688 & 17,3 & 1 & & \\
\hline 5 ou 6 & 1084 & 19,2 & 1,14 & $(0,75-1,72)$ & \\
\hline 7 ou mais & 645 & 13,6 & 0,75 & $(0,41-1,38)$ & \\
\hline Classe econômica & & & & & 0,844 \\
\hline A & 26 & 29,0 & 1 & & \\
\hline B & 374 & 18,3 & 0,55 & $(0,14-2,15)$ & \\
\hline $\mathrm{C}$ & 1600 & 17,8 & 0,53 & $(0,16-1,79)$ & \\
\hline $\mathrm{D}$ & 877 & 17,3 & 0,51 & $(0,15-1,77)$ & \\
\hline $\mathrm{E}$ & 539 & 15,2 & 0,44 & $(0,12-1,55)$ & \\
\hline $\begin{array}{l}\text { Renda familiar per } \\
\text { capita }\end{array}$ & & & & & 0,167 \\
\hline $\begin{array}{l}<0,5 \text { salário } \\
\text { mínimo } \\
\geq 0,5 \text { salário }\end{array}$ & 1889 & 16,2 & 0,75 & $(0,51-1,13)$ & \\
\hline mínimo & 925 & 20,4 & 1 & & \\
\hline $\begin{array}{l}\text { Anos de estudo da } \\
\text { mãe }\end{array}$ & & & & & 0,406 \\
\hline $0-4$ anos & 1476 & 16,8 & 1 & & \\
\hline 5-8 anos & 1021 & 20,2 & 1,261 & $(0,81-1,97)$ & \\
\hline 9 e mais & 823 & 16,2 & 0,96 & $(0,65-1,42)$ & \\
\hline $\begin{array}{l}\text { Situação do } \\
\text { trabalho }\end{array}$ & & & & & 0,281 \\
\hline Remunerado & 1196 & 19,5 & 1 & & \\
\hline Não remunerado & 2219 & 16,4 & 0,81 & $(0,56-1,19)$ & \\
\hline $\begin{array}{l}\text { Estado civil da } \\
\text { mãe }\end{array}$ & & & & & 0,449 \\
\hline $\begin{array}{l}\text { Casada/União } \\
\text { estável } \\
\text { Solteira/Separada }\end{array}$ & 2897 & 17,1 & 1,21 & $(0,73-2,02)$ & \\
\hline /Viúva & 518 & 20,1 & 1 & & \\
\hline BLOCO 2 & & & & & \\
\hline Idade da mãe & & & & & $<0,001$ \\
\hline$<20$ anos & 262 & 11,7 & 1 & & \\
\hline $20-35$ anos & 2716 & 15,9 & 1,42 & $(0,79-2,59)$ & \\
\hline$\geq 36$ anos & 439 & 31,4 & 3,45 & $(1,63-7,32)$ & \\
\hline $\begin{array}{l}\text { Segurança } \\
\text { alimentar }\end{array}$ & & & & & $\mathbf{0 , 3 1 7}$ \\
\hline $\begin{array}{l}\text { Segurança } \\
\text { alimentar }\end{array}$ & 1556 & 16,8 & 1 & & \\
\hline $\begin{array}{l}\text { Insegurança leve } \\
\text { Insegurança }\end{array}$ & 913 & 19,1 & 1,17 & $(0,77-1,78)$ & \\
\hline $\begin{array}{l}\text { moderada } \\
\text { Insegurança }\end{array}$ & 498 & 14,0 & 0,81 & $(0,49-1,32)$ & \\
\hline grave & 344 & 22,6 & 1,44 & $(0,86-2,41)$ & \\
\hline
\end{tabular}


Em relação ao consumo alimentar dos últimos sete dias (Bloco 2), observou-se na análise univariada que a ocorrência de DVA se associou estatisticamente $(\mathrm{p}<0,05)$ apenas com o consumo do grupo de carnes como fator de proteção (Tabela 6). No entanto, o consumo do grupo de legumes/verduras, frutas e feijões, que não apresentou significância no nível de $\mathrm{p}<0,20$, também foi incluído no modelo final de DVA, tendo em vista esses alimentos constituírem importante fonte de vitamina A.

Tabela 6- Proporção de crianças com 6 a 59 meses de idade com DVA, segundo o consumo alimentar dos grupos de alimentos nos últimos sete dias (Bloco 2). Brasil, PNDS/2006

\begin{tabular}{|c|c|c|c|c|c|}
\hline Grupo de alimentos & $\begin{array}{c}\text { Número de } \\
\text { crianças com } \\
\text { dados } \\
\text { disponíveis }\end{array}$ & $\begin{array}{c}\text { Prevalência } \\
\text { de DVA }(\%) \\
\text { Retinol }(<0,7 \\
\mu \mathrm{mol} / \mathrm{L})\end{array}$ & $\begin{array}{c}\text { OR } \\
\text { Bruta }\end{array}$ & (IC 95\%) & p-valor \\
\hline \multicolumn{6}{|l|}{ BLOCO 2} \\
\hline $\begin{array}{l}\text { Pães/ cereais e } \\
\text { massas }\end{array}$ & & & & & $\mathbf{0 , 8 7 8}$ \\
\hline Não comeu & 113 & 23,5 & 1 & & \\
\hline $1 \mathrm{dia}$ & 99 & 21,0 & 0,87 & $(0,25-3,05)$ & \\
\hline 2 a 3 dias & 326 & 17,7 & 0,70 & $(0,32-1,55)$ & \\
\hline 4 a 6 dias & 223 & 18,5 & 0,74 & $(0,20-2,73)$ & \\
\hline Todos os dias & 2630 & 17,2 & 0,68 & $(0,34-1,33)$ & \\
\hline Legumes/ verduras & & & & & $\mathbf{0 , 7 5 3}$ \\
\hline Não comeu & 1035 & 17,7 & 1 & & \\
\hline $1 \mathrm{dia}$ & 354 & 16,0 & 0,89 & $(0,50-1,57)$ & \\
\hline 2 a 3 dias & 885 & 18,1 & 1,03 & $(0,62-1,73)$ & \\
\hline 4 a 6 dias & 472 & 14,7 & 0,80 & $(0,47-1,38)$ & \\
\hline Todos os dias & 637 & 20,1 & 1,18 & $(0,76-1,82)$ & \\
\hline Frutas & & & & & 0,405 \\
\hline Não comeu & 503 & 14,0 & 1 & & \\
\hline $1 \mathrm{dia}$ & 289 & 20,1 & 1,55 & $(0,81-2,94)$ & \\
\hline 2 a 3 dias & 844 & 16,3 & 1,20 & $(0,70-2,06)$ & \\
\hline 4 a 6 dias & 510 & 15,1 & 1,09 & $(0,61-1,96)$ & \\
\hline Todos os dias & 1242 & 19,5 & 1,50 & $0,90-2,48)$ & \\
\hline Feijão & & & & & 0,249 \\
\hline Não comeu & 311 & 15,1 & 1 & & \\
\hline 1 dia & 171 & 19,5 & 1,36 & $(0,59-3,13)$ & \\
\hline 2 a 3 dias & 435 & 14,7 & 0,97 & $(0,51-1,83)$ & \\
\hline 4 a 6 dias & 271 & 11,8 & 0,75 & $(0,35-1,60)$ & \\
\hline Todos os dias & 2193 & 19,1 & 1,33 & $\begin{array}{r}(0,76-2,32) \\
\text { (conti }\end{array}$ & \\
\hline
\end{tabular}




\begin{tabular}{|c|c|c|c|c|c|}
\hline Grupo de alimentos & $\begin{array}{c}\text { Número de } \\
\text { crianças com } \\
\text { dados } \\
\text { disponíveis }\end{array}$ & $\begin{array}{c}\text { Prevalência } \\
\text { de DVA }(\%) \\
\text { Retinol }(<0,7 \\
\mu \mathrm{mol} / \mathrm{L})\end{array}$ & $\begin{array}{c}\text { OR } \\
\text { Bruta }\end{array}$ & $($ IC 95\%) & p-valor \\
\hline Carne & & & & & $<0,001$ \\
\hline Não comeu & 608 & 25,1 & 1 & & \\
\hline $1 \mathrm{dia}$ & 326 & $.6,8$ & 0,22 & $(0,11-0,43)$ & \\
\hline 2 a 3 dias & 994 & 21,6 & 0,82 & $(0,51-1,33)$ & \\
\hline 4 a 6 dias & 572 & 13,2 & 0,45 & $(0,27-0,77)$ & \\
\hline Todos os dias & 881 & 15,0 & 0,53 & $(0,33-0,85)$ & \\
\hline Leite e derivados & & & & & 0,278 \\
\hline Não comeu & 1165 & 16,6 & 1 & & \\
\hline $1 \mathrm{dia}$ & 393 & 18,5 & 1,15 & $(0,66-2,00)$ & \\
\hline 2 a 3 dias & 741 & 14,0 & 0,82 & $(0,52-1,30)$ & \\
\hline 4 a 6 dias & 466 & 18,2 & 1,12 & $(0,69-1,82)$ & \\
\hline Todos os dias & 619 & 21,8 & 1,40 & $(0,84-2,33)$ & \\
\hline Doces & & & & & 0,154 \\
\hline Não comeu & 1042 & 18,4 & 1 & & \\
\hline $1 \mathrm{dia}$ & 490 & 14,8 & 0,77 & $(0,48-1,25)$ & \\
\hline 2 a 3 dias & 728 & 22,0 & 1,25 & $(0,77-2,00)$ & \\
\hline 4 a 6 dias & 453 & 11,8 & 0,59 & $(0,35-1,00)$ & \\
\hline Todos os dias & 658 & 17,7 & 0,95 & $(0,59-1,55)$ & \\
\hline
\end{tabular}

Não se observou associação estatística $(\mathrm{p}<0,05)$ entre DVA e características da criança na análise univariada (Bloco 3) (Tabela 7). A ocorrência de DVA também se mostrou elevada $(16,9 \%)$ entre as crianças que faziam uso da suplementação com vitamina A (dado não apresentado em tabela). Entretanto, as variáveis idade, sexo, internação nos últimos 12 meses e estado nutricional pelo índice Altura/Idade e IMC/Idade foram incluídas na análise múltipla apesar de apresentarem $\mathrm{p}>0,20$.

Tabela 7- Prevalência de DVA em crianças de 6 a 59 meses de idade, segundo as variáveis biológicas (Bloco 3). Brasil, PNDS/2006

\begin{tabular}{lccccc}
\hline Variáveis & $\begin{array}{c}\text { Número de } \\
\text { crianças com } \\
\text { dados } \\
\text { disponíveis }\end{array}$ & $\begin{array}{c}\text { Prevalência de } \\
\text { DVA (\%) } \\
\text { Retinol }(<\mathbf{0 , 7} \\
\boldsymbol{\mu m o l} / \mathbf{L})\end{array}$ & $\begin{array}{c}\text { OR } \\
\text { Bruta }\end{array}$ & (IC 95\%) & p-valor \\
\hline BLOCO 3 & & & & & \\
$\begin{array}{l}\text { Idade da criança } \\
\quad<2 \text { anos }\end{array}$ & 1070 & 16,9 & 1 & & $\mathbf{0 , 7 0 6}$ \\
$\quad>=2$ anos & 2347 & 17,8 & 1,07 & $(0,76-1,50)$ & \\
Sexo & 1627 & 16,4 & 1 & & $\mathbf{0 , 4 1 8}$ \\
$\quad$ Feminino & 1790 & 18,5 & 1,16 & $(0,81-1,65)$ & \\
$\quad$ Masculino & 689 & 15,1 & 1 & & \\
$\quad<30$ dias & 2529 & 17,7 & 1,21 & $(0,79-1,85)$ & \\
$\quad>=30$ dias & & & & & \\
\hline
\end{tabular}

(continuação) 


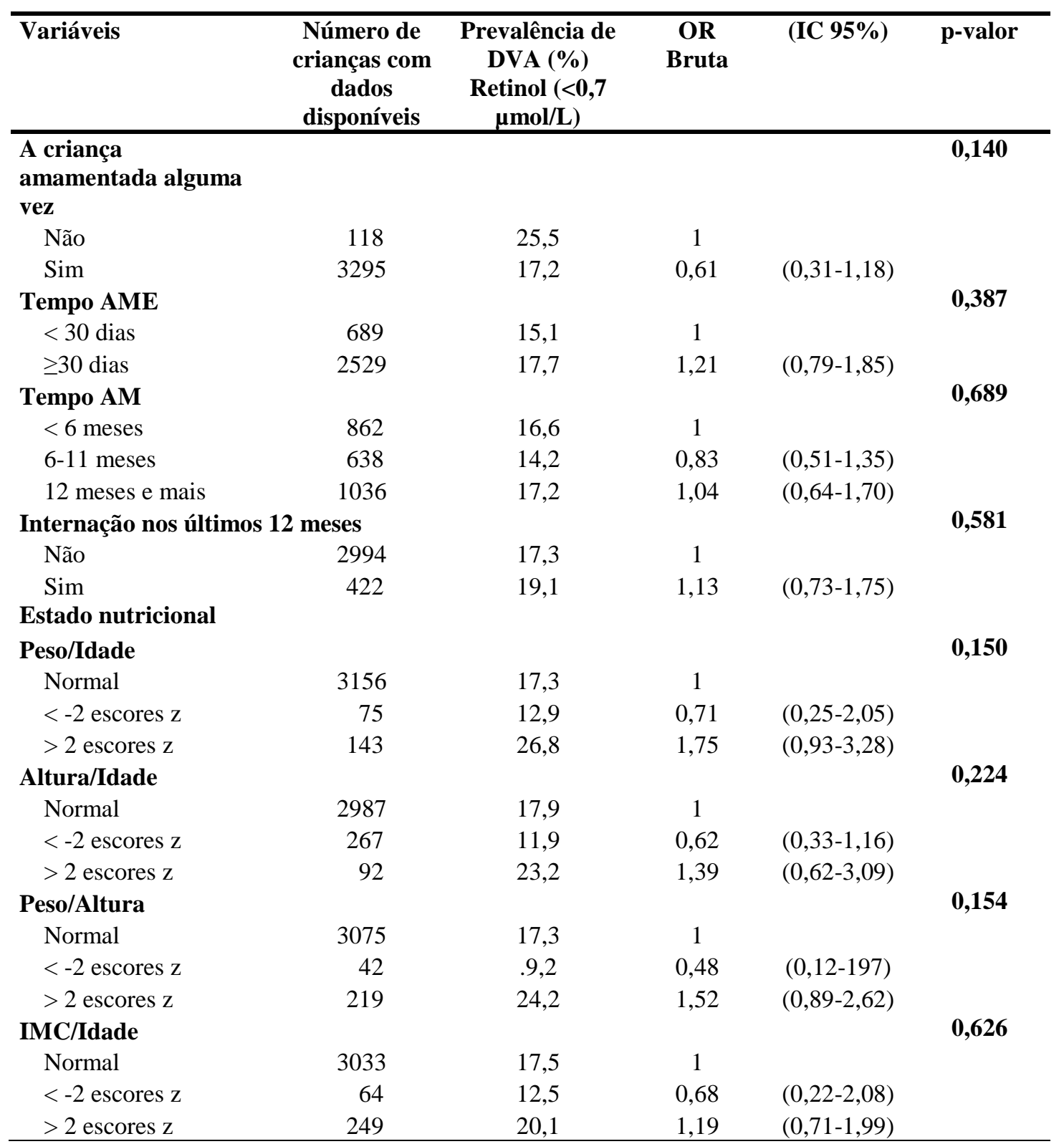

A Tabela 8 apresenta as variáveis que permaneceram associadas à DVA no modelo múltiplo. Após ajuste para as variáveis do mesmo nível hierárquico e dos níveis anteriores, permaneceram associadas à DVA, residir no Sudeste [OR: 1,83; IC: 1,22-2,84] e Nordeste [OR: 1,68; IC: 1,12-2,59]; na zona urbana [OR: 1,83; IC: 1,22-2,84] (Bloco 1); e ter mãe com idade $\geq 36$ anos [OR:3,09; IC:1,50-6,78], sendo proteção, consumir carne pelo menos uma vez na semana [OR: 0,18 ; IC:0,08-0,37] (Bloco 2). 
Tabela 8- Modelo múltiplo final dos determinantes associados à DVA em crianças de 6 a 59 meses de idade. Brasil, PNDS/2006

\begin{tabular}{|c|c|c|c|c|c|c|}
\hline Variáveis & $\begin{array}{c}\text { Número de } \\
\text { crianças com } \\
\text { dados } \\
\text { disponíveis } \\
\end{array}$ & $\begin{array}{c}\text { Prevalência de } \\
\text { DVA }(\%) \\
\text { Retinol }(<0,7 \\
\mu \mathrm{mol} / \mathrm{L}) \\
\end{array}$ & $\begin{array}{c}\text { OR } \\
\text { Ajustada }\end{array}$ & (IC 95\%) & p-valor & Deff: \\
\hline \multicolumn{7}{|l|}{ BLOCO 1} \\
\hline Macrorregião & & & & & $<0,001$ & 1,93 \\
\hline Centro-Oeste & 667 & 12,1 & 1 & & & \\
\hline Nordeste & 657 & 19,3 & 1,68 & $(1,12-2,59)$ & & \\
\hline Norte & 822 & $.9,8$ & 0,75 & $(0,47-1,18)$ & & \\
\hline Sudeste & 672 & 22,1 & 1,83 & $(1,22-2,84)$ & & \\
\hline Sul & 599 & 10,1 & 0,75 & $(0,47-1,21)$ & & \\
\hline Zona da residência & & & & & 0,040 & 1,97 \\
\hline Rural & 1268 & 12,3 & 1 & & & \\
\hline Urbano & 2149 & 22,7 & 1,43 & $(1,01-2,06)$ & & \\
\hline \multicolumn{7}{|l|}{ BLOCO 2} \\
\hline Idade da mãe & & & & & $<0,001$ & 3,26 \\
\hline 15-20 anos & 262 & 11,7 & 1 & & & \\
\hline $20-36$ anos & 2716 & 15,9 & 1,40 & $(0,77-2,77)$ & & \\
\hline $36-50$ anos & 439 & 31,4 & 3,09 & $(1,50-6,78)$ & & \\
\hline Carnes & & & & & 0,002 & 2,97 \\
\hline Não comeu & 608 & 25,1 & 1 & & & \\
\hline $1 \mathrm{dia}$ & 326 & $.6,8$ & 0,18 & $(0,08-0,37)$ & & \\
\hline 2 a 3 dias & 994 & 21,6 & 0,71 & $(0,45-1,15)$ & & \\
\hline 4 a 6 dias & 572 & 13,2 & 0,46 & $(0,26-0,79)$ & & \\
\hline Todos os dias & 881 & 15,0 & $\mathbf{0 , 5 2}$ & $(0,30-0,87)$ & & \\
\hline
\end{tabular}

* Efeito do desenho 


\subsection{Determinantes da ocorrência concomitante de deficiência de vitamina A e anemia}

A prevalência concomitante de DVA e anemia em crianças brasileiras de 6 a 59 meses de idade foi de 3,9\% (IC95\%: 2,9; 5,2\%), sem associação estatística significativa $(\mathrm{p}=0,48)$. A Figura 6 apresenta as prevalências de DVA e anemia e a ocorrência concomitante dessas deficiências nutricionais. Observa-se que as crianças que residem na macrorregião Sudeste apresentaram maior prevalência de DVA e ocorrência concomitante de DVA e anemia, enquanto as prevalências isoladas de anemia e DVA foram maior entre as crianças que residiam nas macrorregiões Nordeste e Sudeste, respectivamente.

Figura 6- Prevalência de DVA, anemia e DVA e anemia concomitantes em crianças de 6 a 59 meses de idade por macrorregiões de residência. Brasil, PNDS/2006

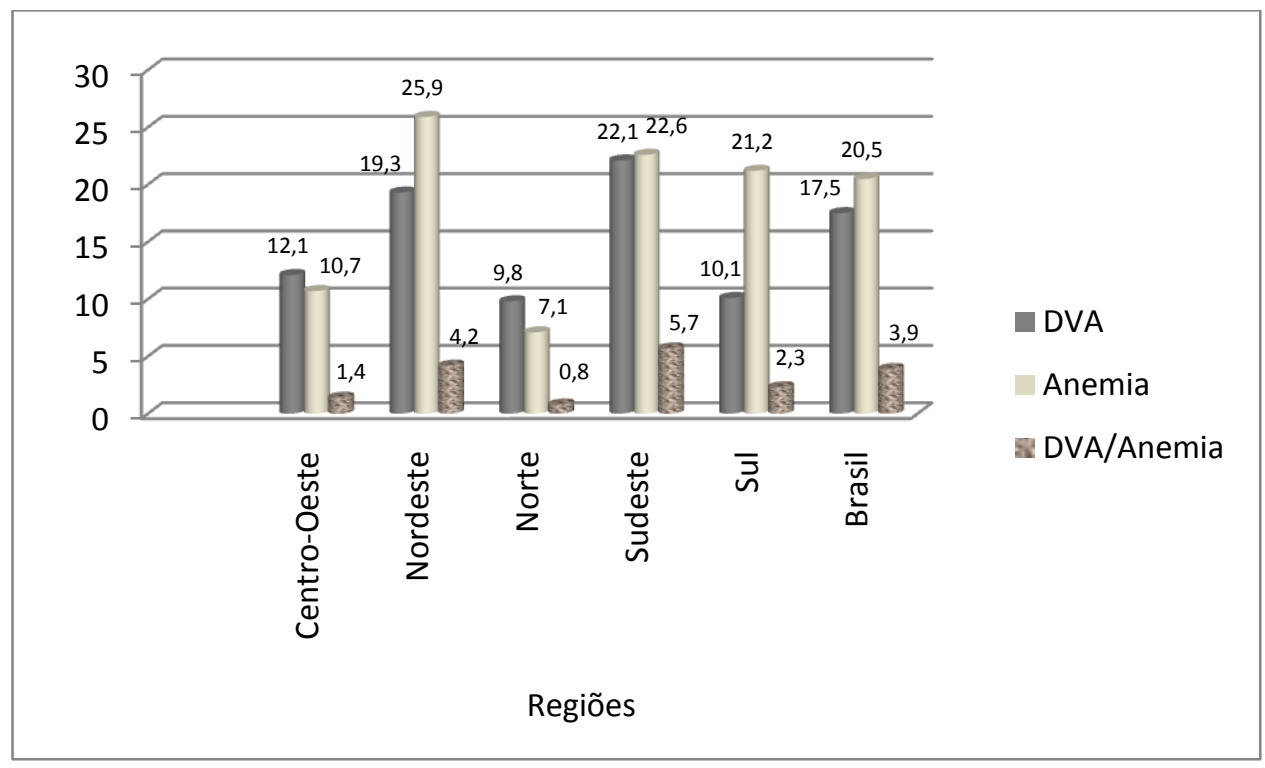

A análise entre níveis de retinol sérico e diferentes concentrações de hemoglobina não evidenciou associação estatisticamente significativa $(\mathrm{p}=0,129)$ (Tabela 9). Da mesma forma, a correlação de Pearson ( $\mathrm{r}=-0,033 ; \mathrm{p}=0,053)$, confirma que não há correlação entre os níveis de retinol sérico e as concentrações de hemoglobina (Figura 7). Constata-se também que não há anemia grave $(\mathrm{Hb}<7 \mathrm{~g} / \mathrm{dl})$. 
Tabela 9- Associação entre níveis de retinol sérico e diferentes concentrações de hemoglobina em crianças de 6 a 59 meses de idade. Brasil, PNDS/2006

\begin{tabular}{|c|c|c|c|c|c|c|c|c|}
\hline \multirow{3}{*}{$\begin{array}{c}\text { Retinol sérico } \\
(\mu \mathrm{mol} / \mathrm{L})\end{array}$} & \multicolumn{8}{|c|}{ Hemoglobina $(\mathrm{g} / \mathrm{dl}) *$} \\
\hline & \multicolumn{2}{|c|}{$7 \vdash 10$} & \multicolumn{2}{|c|}{$10 \vdash 11$} & \multicolumn{2}{|c|}{$\geq 11$} & \multicolumn{2}{|c|}{ Total } \\
\hline & $\mathbf{N}$ & $\%$ & $\mathbf{N}$ & $\%$ & $\mathbf{N}$ & $\%$ & $\mathbf{N}$ & $\%$ \\
\hline$<0,35$ & 7 & 2,3 & 2 & 0,8 & 31 & 1,1 & 40 & 1,2 \\
\hline $\mathbf{0 , 3 5} \vdash \mathbf{0 , 7 0}$ & 47 & 15,5 & 36 & 14,3 & 352 & 12,3 & 435 & 12,7 \\
\hline$\geq 0,70$ & 250 & 82,2 & 214 & 84,9 & 2478 & 86,6 & 2942 & 86,1 \\
\hline Total & 304 & 100,0 & 252 & 100,0 & 2861 & 100,0 & 3417 & 100,0 \\
\hline
\end{tabular}

Valor p do teste Qui-quadrado com correção de Rao \& Scott $=0,129$

(*) Não houve nenhum caso de Anemia grave $(<7 \mathrm{~g} / \mathrm{dl})$

Figura 7- Correlação entre os níveis de retinol sérico e as concentrações de hemoglobina em crianças de 6 a 59 meses de idade. Brasil, PNDS/2006

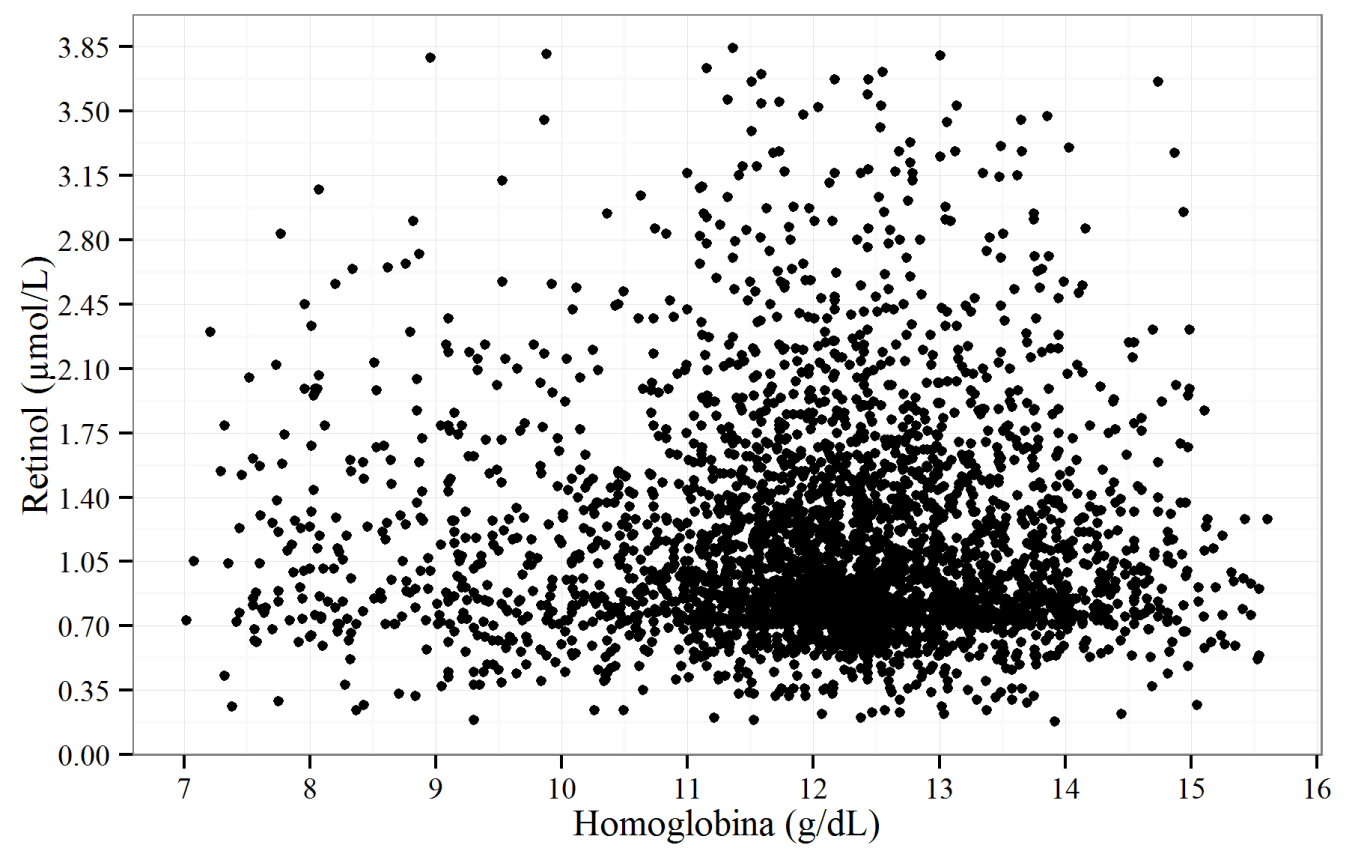

$\mathrm{Na}$ análise univariada das variáveis referentes à dimensão dos processos estruturais da sociedade e do ambiente imediato da criança, relativas aos Blocos 1 e 2, associaram-se estatisticamente $(\mathrm{p}<0,05)$ à ocorrência concomitante de DVA e anemia, a macrorregião de residência, com maiores prevalências no Sudeste e Nordeste, residir na zona urbana, ter água encanada, esgoto e insegurança alimentar grave. Chama atenção a maior chance de ocorrência das deficiências entre as crianças das classes econômicas C e D. Crianças de mães que não 
possuíam trabalho remunerado apresentaram maior risco para ocorrência concomitante de DVA e anemia, bem como filhos de mulheres solteiras, separadas ou viúvas (Tabela 10). Apesar de apresentar p>0,20, a variável classe econômica foi incluída na análise múltipla.

Tabela 10- Prevalência concomitante de DVA e anemia em crianças de 6 a 59 meses de idade, segundo variáveis socioeconômicas, ambientais, maternas e de segurança alimentar (Blocos 1 e 2). Brasil, PNDS/2006

\begin{tabular}{lccccc}
\hline Variáveis & $\begin{array}{c}\text { Número de } \\
\text { crianças com } \\
\text { dados } \\
\text { disponíveis }\end{array}$ & $\begin{array}{c}\text { Prevalência } \\
\text { DVA e } \\
\text { anemia }(\%)\end{array}$ & $\begin{array}{c}\text { OR } \\
\text { Bruta }\end{array}$ & (IC 95\%) & p-valor \\
\hline BLOCO 1 & & & & & \\
Macrorregião & 667 & 1,4 & 1 & & $\mathbf{0 , 0 0 2}$ \\
$\quad$ Centro-Oeste & 657 & 4,2 & 3,06 & $(1,35-6,91)$ & \\
$\quad$ Nordeste & 822 & 0,8 & 0,577 & $(0,20-1,65)$ & \\
$\quad$ Norte & 672 & 5,7 & 4,252 & $(1,87-9,68)$ & \\
Sudeste & 599 & 2,3 & 1,657 & $(0,59-4,69)$ & \\
$\quad$ Sul & 1268 & 1,3 & 1 & & $\mathbf{0 , 0 0 2}$ \\
Zona de residência & 2149 & 4,6 & 3,81 & $(1,51-9,62)$ & \\
$\quad$ Rural & & & & & $<0,001$ \\
$\quad$ Urbano & 2118 & 4,7 & 3,24 & $(1,65-6,35)$ & \\
Abastecimento de água & 1297 & 1,5 & 1 & & \\
$\quad$ Rede geral & & & & & \\
$\quad$ Outro & 1297 & 5,3 & 1 & & $\mathbf{0 , 0 0 6}$ \\
Esgoto & 729 & 1,9 & 0,35 & $(0,12-1,02)$ & \\
$\quad$ Rede geral & 930 & 3,0 & 0,56 & $(0,26-1,19)$ & \\
$\quad$ Séptica & & & & & $\mathbf{0 , 0 9 8}$ \\
$\quad$ Outro & 1084 & 3,7 & 0,96 & $(0,51-1,79)$ & \\
$\mathbf{N}^{\circ}$ cômodos para \\
dormir
\end{tabular}




\begin{tabular}{|c|c|c|c|c|c|}
\hline Variáveis & $\begin{array}{c}\text { Número de } \\
\text { crianças com } \\
\text { dados } \\
\text { disponíveis }\end{array}$ & $\begin{array}{c}\text { Prevalência } \\
\text { DVA e } \\
\text { anemia (\%) }\end{array}$ & $\begin{array}{c}\text { OR } \\
\text { Bruta }\end{array}$ & (IC 95\%) & p-valor \\
\hline Classe econômica & & & & & 0,664 \\
\hline A & 26 & 0,6 & & & \\
\hline B & 374 & 3,3 & 5,45 & $(0,61-48,57)$ & \\
\hline $\mathrm{C}$ & 1600 & 3,7 & 6,17 & $(0,78-48,69)$ & \\
\hline $\mathrm{D}$ & 877 & 5,0 & 8,44 & $(1,01-70,27)$ & \\
\hline $\mathrm{E}$ & 539 & 3,5 & 5,71 & $(0,66-49,65)$ & \\
\hline $\begin{array}{l}\text { Renda familiar per } \\
\text { capita }\end{array}$ & & & & & 0,580 \\
\hline$<0,5$ salário mínimo & 925 & 3,2 & & & \\
\hline 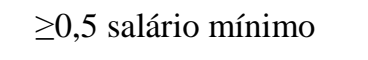 & 1889 & 3,8 & 1,21 & $(0,62-2,34)$ & \\
\hline Anos de estudo da mãe & & & & & 0,682 \\
\hline $0-4$ anos & 1476 & 3,9 & 1 & & \\
\hline $5-8$ anos & 1021 & 3,2 & 0,82 & $(0,38-1,75)$ & \\
\hline 9 e mais & 823 & 4,5 & 1,16 & $(0,55-2,43)$ & \\
\hline Situação do trabalho & & & & & 0,274 \\
\hline Remunerado & 1196 & 3,2 & 1 & & \\
\hline Não remunerado & 2219 & 4,4 & 1,40 & $(0,76-2,57)$ & \\
\hline Estado civil da mãe & & & & & $\mathbf{0 , 2 3 7}$ \\
\hline Casada/União estável & 2897 & 3,6 & 1 & & \\
\hline $\begin{array}{l}\text { Solteira/Separada/Viú } \\
\text { va }\end{array}$ & 518 & 6,0 & 1,71 & $(0,70-4,22)$ & \\
\hline \multicolumn{6}{|l|}{ BLOCO 2} \\
\hline Idade da mãe & & & & & 0,709 \\
\hline 15-20 anos & 262 & 3,2 & 1 & & \\
\hline $20-36$ anos & 2716 & 3,8 & 1,20 & $(0,40-3,61)$ & \\
\hline $36-50$ anos & 439 & 5,0 & 1,59 & $(0,46-5,55)$ & \\
\hline Segurança alimentar & & & & & 0,021 \\
\hline Segurança alimentar & 1556 & 3,4 & 1 & & \\
\hline Insegurança leve & 913 & 4,3 & 1,27 & $(0,61-2,66)$ & \\
\hline Insegurança moderada & 498 & 2,2 & 0,65 & $(0,26-1,65)$ & \\
\hline Insegurança grave & 344 & 9,3 & 2,91 & $(1,32-6,45)$ & \\
\hline
\end{tabular}

Quanto ao consumo dos grupos alimentares nos últimos sete dias, constatou-se associação significativa entre ocorrência concomitante de DVA e anemia e ingestão de carne uma vez na semana em crianças maiores de 6 meses, que atuou como fator de proteção. Em relação aos demais grupos, verificou-se que quase um terço não consumiu o grupo de legumes/verduras, frutas e leites e derivados nos últimos sete dias (Tabela 11). 
Tabela 11- Prevalência concomitante de DVA e anemia em crianças de 6 a 59 meses de idade, segundo o consumo alimentar dos grupos de alimentos nos últimos sete dias (Bloco 2). Brasil, PNDS/2006

\begin{tabular}{|c|c|c|c|c|c|}
\hline Grupo de alimentos & $\begin{array}{l}\text { Número de } \\
\text { crianças com } \\
\text { dados } \\
\text { disponíveis }\end{array}$ & $\begin{array}{c}\text { Prevalência } \\
\text { DVA e } \\
\text { anemia (\%) }\end{array}$ & $\begin{array}{c}\text { OR } \\
\text { Bruta }\end{array}$ & $($ IC 95\%) & p-valor \\
\hline \multicolumn{6}{|l|}{ BLOCO 2} \\
\hline Pães/ cereais e massas & & & & & 0,349 \\
\hline Não comeu & 113 & 8,0 & 1 & & \\
\hline 1 dia & 99 & 2,5 & 0,29 & $(0,03-2,91)$ & \\
\hline 2 a 3 dias & 326 & 5,0 & 0,61 & $(0,16-2,37)$ & \\
\hline 4 a 6 dias & 223 & 1,4 & 0,17 & $(0,03-0,84)$ & \\
\hline Todos os dias & 2630 & 4,0 & 0,47 & $(0,14-1,55)$ & \\
\hline Legumes/ verduras & & & & & 0,147 \\
\hline Não comeu & 1035 & 3,2 & 1 & & \\
\hline $1 \mathrm{dia}$ & 354 & 3,6 & 1,14 & $(0,42-3,12)$ & \\
\hline 2 a 3 dias & 885 & 4,1 & 1,31 & $(0,54-3,20)$ & \\
\hline 4 a 6 dias & 472 & 1,8 & 0,55 & $(0,18-1,69)$ & \\
\hline Todos os dias & 637 & 6,4 & 2,08 & $(0,95-4,56)$ & \\
\hline Frutas & & & & & 0,412 \\
\hline Não comeu & 503 & 3,0 & 1 & & \\
\hline $1 \mathrm{dia}$ & 289 & 6,8 & 2,41 & $(0,76-7,69)$ & \\
\hline 2 a 3 dias & 844 & 4,7 & 1,61 & $(0,53-4,85)$ & \\
\hline 4 a 6 dias & 510 & 2,4 & 0,81 & $(0,26-2,54)$ & \\
\hline Todos os dias & 1242 & 3,8 & 1,31 & $(0,51-3,38)$ & \\
\hline Feijão & & & & & 0,574 \\
\hline Não comeu & 311 & 3,9 & 1 & & \\
\hline 1 dia & 171 & 4,9 & 1,26 & $(0,31-5,10)$ & \\
\hline 2 a 3 dias & 435 & 2,6 & 0,67 & $(0,19-2,41)$ & \\
\hline 4 a 6 dias & 271 & 1,8 & 0,46 & $(0,10-2,19)$ & \\
\hline Todos os dias & 2193 & 4,4 & 1,14 & $(0,44-2,98)$ & \\
\hline Carne & & & & & $\mathbf{0 , 0 1 7}$ \\
\hline Não comeu & 608 & 7,5 & 1 & & \\
\hline $1 \mathrm{dia}$ & 326 & 0,4 & 0,05 & $(0,01-0,38)$ & \\
\hline 2 a 3 dias & 994 & 4,0 & 0,51 & $(0,23-1,13)$ & \\
\hline 4 a 6 dias & 572 & 3,6 & 0,46 & $(0,17-1,25)$ & \\
\hline Todos os dias & 881 & 3,3 & 0,42 & $(0,17-1,02)$ & \\
\hline Leite e derivados & & & & & $\mathbf{0 , 8 9 4}$ \\
\hline Não comeu & 1165 & 3,9 & 1 & & \\
\hline $1 \mathrm{dia}$ & 393 & 4,6 & 1,18 & $(0,50-2,79)$ & \\
\hline 2 a 3 dias & 741 & 3,3 & 0,84 & $(0,37-1,91)$ & \\
\hline 4 a 6 dias & 466 & 3,4 & 0,85 & $(0,31-2,31)$ & \\
\hline Todos os dias & 619 & 4,7 & 1,21 & $(0,51-2,86)$ & \\
\hline Doces & & & & & 0,599 \\
\hline Não comeu & 1042 & 4,8 & 1 & & \\
\hline $1 \mathrm{dia}$ & 490 & 4,1 & 0,84 & $(0,39-1,79)$ & \\
\hline 2 a 3 dias & 728 & 4,9 & 1,01 & $(0,48-2,11)$ & \\
\hline 4 a 6 dias & 453 & 2,7 & 0,56 & $(0,20-1,57)$ & \\
\hline Todos os dias & 658 & 2,7 & 0,55 & $(0,17-1,81)$ & \\
\hline
\end{tabular}


Em relação às variáveis do Bloco 3 , observou-se que a ocorrência concomitante de DVA e anemia associou-se estatisticamente $(\mathrm{p}<0,05)$ com a idade das crianças, sendo mais frequente naquelas com menos de 2 anos de idade e entre as internadas nos últimos 12 meses. Apesar de não estatisticamente significativa, chama atenção a elevada prevalência concomitante de DVA e anemia entre crianças que não receberam suplementação de vitamina A $(13,2 \%)$ (Tabela 12). Apesar de apresentarem p>0,20, as variáveis sexo, suplementação com ferro e estado nutricional classificado pelo índice IMC/Idade foram incluídas na análise múltipla.

Tabela 12- Prevalência concomitante de DVA e anemia em crianças de 6 a 59 meses de idade, segundo variáveis das crianças (Bloco 3). Brasil, PNDS/2006

\begin{tabular}{|c|c|c|c|c|c|}
\hline Variáveis & $\begin{array}{c}\text { Número de } \\
\text { crianças com } \\
\text { dados disponíveis }\end{array}$ & $\begin{array}{c}\text { Prevalência } \\
\text { DVA e } \\
\text { anemia }(\%)\end{array}$ & $\begin{array}{c}\text { OR } \\
\text { Bruta }\end{array}$ & $($ IC 95\%) & p-valor \\
\hline \multicolumn{6}{|l|}{ BLOCO 3} \\
\hline \multicolumn{5}{|l|}{ Idade da criança } & 0,021 \\
\hline$<2$ anos & 1070 & 5,8 & & & \\
\hline$\geq 2$ anos & 2347 & 3,1 & 0,51 & $(0,29-0,91)$ & \\
\hline \multicolumn{5}{|l|}{ Sexo } & 0,301 \\
\hline Feminino & 1627 & 3,3 & & & \\
\hline Masculino & 1790 & 4,4 & 1,35 & $(0,76-2,38)$ & \\
\hline \multicolumn{5}{|l|}{ Tempo AM } & $\mathbf{0 , 7 3 0}$ \\
\hline$<6$ meses & 862 & 3,6 & & & \\
\hline 6-11 meses & 638 & 2,5 & 0,71 & $(0,25-2,00)$ & \\
\hline 12 meses e mais & 1036 & 2,7 & 0,76 & $(0,35-1,69)$ & \\
\hline \multicolumn{5}{|c|}{ Suplementação de vitamina $\mathrm{A}$} & 0,123 \\
\hline Não & 50 & 13,2 & & & \\
\hline Sim & 813 & 4,6 & 0,31 & $(0,07-1,48)$ & \\
\hline \multicolumn{5}{|l|}{ Suplementação de } & 0,610 \\
\hline Não & 2326 & 3,7 & & & \\
\hline Sim & 1069 & 4,4 & 1,19 & $(0,61-2,31)$ & \\
\hline \multicolumn{5}{|c|}{ Internação nos últimos 12 meses } & 0,044 \\
\hline Não & 2994 & 3,5 & & & \\
\hline Sim & 422 & 6,7 & 1,94 & $(1,01-3,73)$ & \\
\hline
\end{tabular}

(continuação) 


\begin{tabular}{lccccc}
\hline Variáveis & $\begin{array}{c}\text { Número de } \\
\text { crianças com } \\
\text { dados disponíveis }\end{array}$ & $\begin{array}{c}\text { Prevalência } \\
\text { DVA e } \\
\text { anemia (\%) }\end{array}$ & $\begin{array}{c}\text { OR } \\
\text { Bruta }\end{array}$ & (IC 95\%) & p-valor \\
\hline Estado nutricional & & & & & $\mathbf{0 , 8 8 3}$ \\
Peso/Idade & 3156 & 3,9 & & & \\
$\quad$ Normal & 75 & 3,2 & 0,82 & $(0,12-5,65)$ & \\
$\quad$ <-2 escores z & 143 & 5,1 & 1,32 & $(0,32-5,43)$ & \\
$\quad$ > 2 escores z & & & & & $\mathbf{0 , 3 3 5}$ \\
Altura/Idade & 2987 & 4,1 & & & \\
$\quad$ Normal & 267 & 2,6 & 0,64 & $(0,16-2,64)$ & \\
$\quad$ <-2 escores z & 92 & 0,8 & 0,19 & $(0,04-0,94)$ & \\
> 2 escores z & & & & & $\mathbf{0 , 9 8 1}$ \\
Peso/Altura & 3075 & 3,9 & & & \\
$\quad$ Normal & 42 & 4,6 & 1,19 & $(0,18-7,93)$ & \\
$\quad$ <-2 escores z & 219 & 4,1 & 1,05 & $(0,29-3,75)$ & \\
$\quad$ > escores z & & & & & $\mathbf{0 , 8 8 9}$ \\
IMC/Idade & 3033 & 3,8 & & & \\
$\quad$ Normal & 64 & 3,4 & 0,89 & $(0,16-5,13)$ & \\
$\quad$ <-2 escores z & 249 & 4,7 & 1,23 & $(0,43-3,49)$ & \\
> 2 escores z & & & & & \\
\hline
\end{tabular}

A Tabela 13 apresenta a análise múltipla dos determinantes da ocorrência concomitante de DVA e anemia. As variáveis que se mantiveram no modelo final, após ajuste para as variáveis de confusão, foram: residir no Sudeste [OR: 4,28; IC: 1,96-11,68] e Nordeste [OR: 2,92; IC: 1,31-7,96]; na área urbana [OR: 3,66; IC: 1,46-12,30] (Bloco 1); e ter insegurança alimentar grave [OR: 3,64; IC: 1,41-8,84] (Bloco 2); constituindo proteção consumir carne pelo menos uma vez na semana [OR: 0,04; IC: 0,00-0,23] (Bloco 2) e ter idade $\geq 2$ anos [OR: 0,51; IC: 0,26-0,99] (Bloco 3). 
Tabela 13- Modelo múltiplo final dos determinantes associados à ocorrência concomitante de DVA e anemia em crianças de 6 a 59 meses de idade. Brasil, PNDS/2006

\begin{tabular}{|c|c|c|c|c|c|c|}
\hline Variáveis & $\begin{array}{c}\text { Número de } \\
\text { crianças com } \\
\text { dados disponíveis }\end{array}$ & $\begin{array}{c}\text { Prevalência } \\
\text { DVA e } \\
\text { anemia }(\%)\end{array}$ & $\begin{array}{c}\text { OR } \\
\text { Ajustada }\end{array}$ & (IC 95\%) & p-valor & Deff* \\
\hline \multicolumn{7}{|l|}{$\overline{\text { BLOCO } 1}$} \\
\hline Macrorregião & & & & & $<0,001$ & 3,4 \\
\hline Centro-Oeste & 667 & 1,4 & 1 & & & \\
\hline Nordeste & 657 & 4,2 & 2,92 & $(1,31-7,96)$ & & \\
\hline Norte & 822 & 0,8 & 0,38 & $(0,11-1,25)$ & & \\
\hline Sudeste & 672 & 5,7 & 4,28 & $(1,96-11,68)$ & & \\
\hline Sul & 599 & 2,3 & 1,62 & $(0,57-5,54)$ & & \\
\hline Zona da residência & & & & & $<0,001$ & 1,68 \\
\hline Rural & 1268 & 1,3 & 1 & & & \\
\hline Urbano & 2149 & 4,6 & 3,66 & $(1,46-12,30)$ & & \\
\hline \multicolumn{7}{|l|}{ BLOCO 2} \\
\hline Segurança alimentar & & & & & $<0,001$ & 2,53 \\
\hline Segurança alimentar & 1556 & 3,4 & 1 & & & \\
\hline Insegurança leve & 913 & 4,3 & 1,18 & $(0,54-2,50)$ & & \\
\hline $\begin{array}{l}\text { Insegurança } \\
\text { moderada }\end{array}$ & 498 & 2,2 & 0,69 & $(0,20-1,87)$ & & \\
\hline Insegurança grave & 344 & 9,3 & 3,64 & $(1,41-8,84)$ & & \\
\hline Carnes & & & & & $<0,001$ & 2,64 \\
\hline Não comeu & 608 & 7,5 & 1 & & & \\
\hline $1 \mathrm{dia}$ & 326 & 0,4 & 0,04 & $(0,00-0,23)$ & & \\
\hline 2 a 3 dias & 994 & 4,0 & 0,49 & $(0,19-1,25)$ & & \\
\hline 4 a 6 dias & 572 & 3,6 & 0,54 & $(0,16-1,57)$ & & \\
\hline Todos os dias & 881 & 3,3 & 0,52 & $(0,17-1,49)$ & & \\
\hline \multicolumn{7}{|l|}{ BLOCO 3} \\
\hline Idade da criança & & & & & 0,047 & 3,29 \\
\hline$<2$ anos & 1070 & 5,8 & & & & \\
\hline$\geq 2$ anos & 2347 & 3,1 & 0,51 & $(0,26-0,99)$ & & \\
\hline
\end{tabular}

* Efeito do desenho

Os resultados evidenciaram como determinantes comuns à ocorrência de anemia, DVA e ocorrência concomitante de DVA e anemia, as variáveis dos Blocos 1 e 2, relativas às dimensões dos processos estruturais da sociedade e do ambiente imediato da criança, destacando-se a macrorregião de residência (Sudeste e Nordeste) e a zona urbana, sendo fator de proteção, consumir o grupo das carnes pelo menos um dia nos últimos sete dias. Em relação à ocorrência concomitante de DVA e anemia entre as crianças brasileiras, constatou-se que são deficiências nutricionais não associadas. 
Discussão 


\section{DISCUSSÃO}

Os resultados foram apresentados para anemia, DVA e ocorrência concomitante de DVA e anemia separadamente, porém, considerando-se que muitos dos determinantes apresentaram-se comuns às deficiências estudadas, os mesmos foram discutidos conjuntamente.

A presente reanálise reiterou a redução na prevalência de anemia $(20,5 \%)$ e de DVA (17,5\%) já divulgada no relatório oficial da PNDS/2006, porém, permitiu que se avançasse nos aspectos concernentes aos determinantes dessas deficiências nutricionais entre as crianças brasileiras de 6 a 59 meses de idade, com representatividade para as áreas urbanas e rurais das cinco macrorregiões geográficas. Ademais, favoreceu a identificação da magnitude da ocorrência concomitante de DVA e anemia na população infantil do País $(3,9 \%)$.

A redução das deficiências nutricionais no Brasil pode ser justificada pelas marcantes modificações políticas, econômicas e sociais que o País sofreu ao longo das últimas décadas, elevando-o, da condição de um País de baixa renda, com uma larga parcela de população rural e um sistema de saúde múltiplo, para a de um País de renda média, urbanizado, com um sistema unificado de saúde, que certamente contribuíram para beneficiar o perfil nutricional da população infantil, bem como melhorar suas condições de saúde (Victora et al., 2011a,b).

De fato, de 1974 a 2007, a prevalência nacional de baixa estatura diminuiu de $37,1 \%$ para $7,1 \%$, atrelada ao desenvolvimento socioeconômico e aliada a políticas públicas efetivadas no período para diminuir a desigualdade social. Entretanto, o declínio foi mais acentuado no quintil mais rico da população, com queda de $27,0 \%$ de baixa estatura, em relação ao quintil mais pobre, que apresentou redução de 19,0\%, no período (Monteiro et al., 2013). Os padrões de amamentação também melhoraram substancialmente: no inquérito nutricional de 1974-75, a duração mediana da amamentação era de somente 2,5 meses, uma das mais curtas entre os países em desenvolvimento, que aumentou para 5,5 meses em 1990, para sete meses em 1996 e para 14 meses em 2006 (Brasil, 2009; Victora et al., 2011b).

Para Victora et al. (2011b), os principais fatores que contribuíram para esses avanços incluem as melhorias na educação materna, o aumento do poder 
aquisitivo da população mais pobre, a ampliação substancial da cobertura dos cuidados de saúde infantil e, em menor grau, a expansão da rede de abastecimento de água e de saneamento básico.

No que se refere à redução na prevalência de anemia, além da melhoria nas condições sociais e econômicas, as políticas públicas implementadas pelo governo, tais como o Programa Nacional de Suplementação de Ferro (Brasil, 2005a), a fortificação obrigatória de todas as farinhas de trigo e milho com ferro e ácido fólico (Brasil, 2002) e as intervenções propostas no âmbito da PNAN (Brasil, 2012b) podem ter contribuído para esse resultado.

O quadro observado torna a prevalência da anemia mais similar às constatadas na Europa (20\%), divergindo da estimativa da OMS para o Brasil (55\%) (WHO, 2008). Em termos de importância epidemiológica, a anemia passa a ser classificada como um problema moderado de saúde pública, segundo os critérios da OMS (WHO, 2001).

No presente estudo, apesar da redução, a anemia manteve-se associada à macrorregião de residência, mesmo após o controle para as variáveis de confusão, evidenciando que as crianças que residiam nas macrorregiões Nordeste, Sudeste e Sul tinham maior chance para desenvolver anemia. Tal resultado reitera o caráter trans-social da anemia, uma vez que afeta tanto a macrorregião menos desenvolvida como as mais desenvolvidas do País (Batista Filho, Souza, Bresani, 2008).

Embora as proporções de anemia encontradas confirmem as descritas na revisão sistemática que analisou 17 estudos brasileiros com amostras populacionais de crianças menores de 6 anos, publicados entre 1997 e 2010, os resultados dessa revisão mostraram que as maiores prevalências de anemia concentravam-se nas macrorregiões de residência menos desenvolvidas (Leal, Osório, 2010). Da mesma forma, Jordão, Bernardi e Barros Filho (2009) evidenciaram as maiores prevalências de anemia na macrorregião Nordeste. Também em nível internacional, constatam-se maior ocorrência de anemia em áreas menos desenvolvidas (Nguyen et al.,2006; Ngnie-Teta, Receveur, KuateDefo, 2007).

Tais resultados certamente podem ser explicados pelas diferenças sociais. Nesse aspecto, Batista Filho, Souza e Bresani (2008) destacam que a ocorrência 
da anemia é notadamente maior em regiões mais pobres e a associam com as condições socioambientais negativas.

Há que se considerar, no entanto, que o resultado obtido diverge, substancialmente, das elevadas prevalências de anemia encontradas nos estudos pontuais realizados no País, como evidenciam as revisões de literatura (Jordão Bernardi, Barros Filho, 2009; Vieira, Ferreira, 2010), bem como nos estudos de base populacional mais recentemente desenvolvidos. Na macrorregião Nordeste do País, análise da tendência temporal da anemia no estado de Pernambuco, nos anos de 1997 e 2006, apesar de constatar redução de 19,3\% (de 40,9\% para $33,0 \%$ ), ainda mostra que a prevalência continua elevada entre crianças menores de 5 anos de idade (Leal et al., 2012). Na Paraíba, outro estado do Nordeste, trabalho conduzido com 1.108 crianças menores de 5 anos também encontrou manutenção de elevada prevalência de anemia (36,5\%) (Gondim et al., 2012b). O mesmo se observa nas macrorregiões Norte, Sul e Sudeste do Brasil. No Norte, inquérito de base populacional realizado com 1.111 crianças de 6 meses a 10 anos confirmou elevada prevalência de anemia (45,4\%) (Cardoso et al., 2012). Estudos conduzidos em creches das macrorregiões Sul e Sudeste também continuam a evidenciar prevalências elevadas de anemia, 29,7\% e 30,8\%, respectivamente (Rocha et al., 2012; Rodrigues et al., 2011). Ainda na região Sul, constatou-se elevação de $41,1 \%(30,2 \%$ a 42,6\%) na prevalência de anemia no período de 2004 a 2008, com base em estudos populacionais desenvolvidos para avaliar o impacto da fortificação das farinhas com ferro, estratégia que, portanto, não mostrou efeito positivo no controle da anemia infantil (Assunção et al., 2012).

Contrariamente ao que se evidenciou em relação à anemia, a redução constatada na prevalência de DVA infantil no País se mostrou superior à estimativa da OMS para o Brasil (13,3\%) (WHO, 2009). Não obstante, esse resultado não impediu que a DVA, como a anemia, em termos de importância epidemiológica, passasse a ser classificada como um problema moderado de saúde pública (WHO, 1996).

Poder-se-ia conjecturar que a redução da DVA estaria também relacionada às estratégias de controle e combate a esse problema nutricional adotadas pelo governo, destacando-se, entre elas, o Programa Nacional de Suplementação de 
Vitamina A, que recomenda a distribuição de cápsulas de megadoses de vitamina A para crianças de 6 a 59 meses (Brasil, 2004, 2012a).

Apesar de esse Programa ter sido implantado desde os anos 1980, são escassos os estudos que avaliam o seu resultado. Dentre eles, um que o avaliou do ponto de vista dos gestores municipais mostrou que a efetividade do Programa era prejudicada por uma série de fatores políticos, administrativos, de planejamento, de organização, de gestão e de disponibilidade de recursos financeiros, materiais e humanos (Martins et al., 2007). Outro estudo de avaliação, realizado com os responsáveis pelas crianças, revelou que os mesmos não tinham conhecimento sobre vitamina A ou DVA, tampouco sobre o funcionamento do Programa (Almeida et al., 2010). Acrescente-se que em ambos os estudos, as recomendações de educação em saúde e incentivo a hábitos alimentares saudáveis preconizadas pelo Programa de Suplementação de Vitamina A não eram desenvolvidas (Martins et al., 2007; Almeida et al., 2010).

Esses resultados foram reiterados em recente avaliação do Programa Nacional de Suplementação de Vitamina A desenvolvida em nove municípios do estado da Paraíba, pois, de acordo com o relato de profissionais da Estratégia de Saúde da Família (ESF), constatam-se fragilidades, tais como: falta de material informativo para divulgar o Programa, irregularidade no fornecimento do suplemento, insuficiência de capacitações para os profissionais de saúde, preenchimento incorreto do instrumento de registro adotado pelo Programa e baixa cobertura (Paiva et al., 2011).

Há que se ressaltar, também, que a redução encontrada na prevalência de DVA diverge do verificado na maioria dos estudos realizados no País, como evidenciam as análises das várias revisões de literatura, que mostram uma mediana de 32,4\% de prevalência de DVA, com ampla variação $(6,9 \%$ a $75,4 \%)$ nas diversas regiões brasileiras, mas com maior prevalência nas macrorregiões Sudeste $(34,3 \%)$ e Nordeste (22,5\%) (Diniz, Santos, 2000; Souza, Vilas Boas, 2002; Ramalho, Flores, Saunders, 2002; Geraldo et al., 2003; Dolinsky, Ramalho, 2003; Milagres, Nunes, Pinheiro-Sant'ana, 2007; Ramalho, Padilha, Saunders, 2008).

O presente estudo confirma serem essas as macrorregiões mais afetadas, tendo em vista que, no modelo final, as crianças residentes no Sudeste, uma das 
regiões mais desenvolvidas do País, apresentavam chance quase duas vezes maior [OR: 1,83; IC: 1,22-2,84] de ter DVA, seguidas por crianças do Nordeste [OR: 1,68; IC: 1,12-2,59], uma das regiões mais pobres. Esse resultado mostra que a DVA afeta a macrorregião Sudeste como um todo, não se restringindo às microrregiões pobres como o Vale do Jequitinhonha em Minas Gerais e o Vale do Ribeira em São Paulo, como destacado por Milagres, Nunes e Pinheiro-Sant'ana, (2007).

Com base nesse resultado, poder-se-ia questionar se a DVA, também como a anemia, não teria um caráter trans-social, uma vez que afeta tanto as macrorregiões menos desenvolvidas como as mais desenvolvidas do País, onde têm sido documentado prevalências elevadas de DVA em cidades como Ribeirão Preto (75,4\%) (Ferraz et al., 2005); Rio de Janeiro (54,2\%) (Ramalho et al., 2006); e Viçosa (39,6\%) (Netto et al., 2012).

Estudos de base populacional mais recentemente conduzidos em áreas consideradas endêmicas no País também revelam um quadro ainda bastante diverso na macrorregião Nordeste: estudo de corte transversal realizado com 1.211 crianças de 6 a 59 meses de idade, procedentes da área urbana de nove cidades do estado da Paraíba, encontrou prevalência de DVA de 21,8\% (IC95\%: 19,6; 24,2\%) (Queiroz et al., 2013); outro estudo, também desenvolvido na Paraíba, reiterou tal resultado $(21,4 \%)$ (Gondim et al., 2012a); na região semiárida do estado de Alagoas, a prevalência verificada foi de 44,8\% (Vasconcelos, Ferreira, 2009); esses resultados mostram que a DVA ainda persiste como um grave problema de saúde pública, de acordo com os critérios da OMS (WHO, 1996). Em Pernambuco, também estado do Nordeste, evidencia-se, no entanto, uma tendência de redução na prevalência da DVA de 18,8\%, em 1997, para 16,0\%, em 2006 (Miglioli et al., 2013; Paula et al., 2013).

No que refere à manifestação concomitante de DVA e anemia, constatouse uma ocorrência bastante reduzida, praticamente inexistente como problema de saúde $(3,9 \%)$, evidenciando que, no Brasil, as crianças afetadas pela anemia não são as mesmas que apresentam DVA $(\mathrm{p}=0,48)$. Apesar disso, a carência concomitante manteve-se associada à macrorregião de residência, mesmo após o controle para as variáveis de confusão, evidenciando maior chance de seu aparecimento entre as crianças residentes nas macrorregiões Sudeste e Nordeste. 
Certamente esse resultado deve-se às maiores prevalências isoladas de anemia e DVA verificadas nessas macrorregiões.

Também não se constatou correlação entre os níveis de retinol sérico e de hemoglobina $(r=-0,033)$, apesar das evidências de interação positiva identificadas em diversos estudos internacionais (Mwanri, Worsley, Ryan, 2000; Willows, Gray-Donald, 2003; Zimmerman, Biebinger, Rohner, 2006; Jimenez et al., 2010) e nacionais (Silva et al., 2008; Mariath et al., 2010; Gondim et al., 2012a; Sales et al., 2013). Uma das prováveis explicações para esse resultado é que não se identificou anemia grave entre as crianças estudadas.

No meio acadêmico destaca-se, no entanto, que Ferraz et al. (2005) também não identificaram associação entre carência de ferro e DVA em crianças de 24 a 72 meses, apesar das elevadas prevalências de DVA $(35,8 \%)$ e de deficiência de ferro $(75,4 \%)$.

Embora não se tenha observado essa associação, chama atenção a elevada prevalência de DVA e anemia concomitante entre crianças que não receberam suplementação de vitamina A (13,2\%). Isso parece indicar a importância da suplementação de vitamina A no combate à deficiência concomitante de anemia e DVA. Entretanto, o estudo desenvolvido por Pereira et al. (2007) também não observou diferença nas médias de $\mathrm{Hb}$ e na proporção de anêmicos entre escolares suplementados com sulfato ferroso associado à vitamina A.

Os resultados revelaram também que as ocorrências de anemia e DVA se mostraram elevadas entre crianças que faziam uso da suplementação profilática com ferro $(20,7 \%)$ e vitamina $\mathrm{A}(16,9 \%)$. Tal resultado pode estar relacionado à utilização do medicamento para tratamento de anemia e de DVA já instaladas e não como uso profilático. Assim, os achados deste trabalho consolidam cada vez mais a necessidade de melhorias na operacionalização dos Programas Nacionais de Suplementação de Ferro e Vitamina A, com vistas à prevenção dessas deficiências.

Há que se considerar, no entanto, que a suplementação com vitamina A é uma importante medida de redução da mortalidade e morbidade em crianças menores de 5 anos de idade, principalmente entre aquelas que apresentam essa deficiência pelo consumo inadequado de alimentos fontes de vitamina A (WHO, 2011). 
Por outro lado, também se aponta a existência de estudos com resultados positivos da suplementação com sulfato ferroso, indicando incremento significativo na concentração média de $\mathrm{Hb}$ (Brunken, Muniz, Silva, 2004; Engstrom et al., 2008) e queda na prevalência de anemia (Brunken, Muniz, Silva, 2004; Lima et al., 2006; Coutinho, Goloni-Bertollo, Pavarino-Bertelli, 2008; Engstrom et al., 2008; Azeredo et al., 2011).

Quanto à situação de residência, constatou-se que as deficiências nutricionais estudadas prevaleceram na zona urbana, situação contraditória, considerando-se que a população residente na zona rural tende a apresentar maior vulnerabilidade para deficiências nutricionais, pois o ambiente rural dificulta o acesso aos serviços de saúde e educação, bem como a aquisição de alimentos de melhor valor nutricional (WHO, 2008).

Entretanto, como referido, o País tem experimentado um intenso processo de urbanização e metropolização, que se articula com o grande ciclo de expansão das migrações internas, principalmente da zona rural para a urbana (Brito, Pinho, 2012; Ribeiro, 2013). A urbanização aumentou de 55,9\% em 1970 para 83,9\% em 2010, bem como as aglomerações metropolitanas que aumentaram em termos absolutos, passando de 27,2 milhões para 69,8 milhões, entre os anos de 1970 e 2010 (Pinho, Brito, 2013). Assim, o processo de urbanização passa a ser um determinante estrutural da moderna sociedade brasileira. Essa grande transformação deve ser entendida como a construção de um centro privilegiado para atividades econômicas, mas também como difusora de novos padrões de relações sociais e de estilos de vida (Brito, Pinho, 2012).

As grandes aglomerações urbanas tendem a exacerbar a desigualdade e as iniquidades, uma vez que a migração da região rural para as cidades resulta em pessoas que passam a viver, principalmente, na periferia, em condições precárias, situação com importante reflexo nas condições de vida e, consequentemente, na saúde, em razão da falta de oportunidades de trabalho, dos baixos salários e das condições insalubres de habitação que interferem, negativamente, no estado de saúde (Ribeiro, 2013; Pinho, Brito, 2013). Esse quadro poderia justificar a maior prevalência das carências nutricionais encontrada na área urbana, atrelada à desigualdade no acesso a serviços e alimentação, que favorece o surgimento de deficiências nutricionais como anemia e DVA (Assis et al., 2007). Destaca-se que 
Segall-Corrêa et al. (2008) encontram maior chance de insegurança alimentar na área urbana, resultado possivelmente relacionado à produção para o autoconsumo na área rural, onde os gastos são menores com vestuário e transporte, diferentemente do que ocorre na área metropolitana.

Assim, nos resultados aqui apresentados, confirma-se que residir no ambiente urbano constitui um determinante para o acometimento das deficiências nutricionais, uma vez que a saúde da criança é determinada basicamente pelas condições socioeconômicas em que nasce, cresce e vive, que, por sua vez, são determinadas pela distribuição de recursos financeiros.

Nesse sentido, aparentemente, o lócus de pobreza e subnutrição infantil vem mudando gradualmente das áreas rurais para as áreas urbanas, uma vez que o número de crianças pobres e subnutridas aumenta mais rapidamente em ambientes urbanos que no meio rural. Vale ressaltar que, ainda que aparentem estar bem alimentadas, recebendo calorias suficientes para manter suas atividades cotidianas, as crianças podem sofrer a "fome oculta", causada pela falta de micronutrientes como vitamina A, ferro ou zinco, essenciais ao crescimento e desenvolvimento infantil adequado (UNICEF, 2012).

Estudos conduzidos no Brasil mostram resultados ainda diversos. No Acre, macrorregião Norte do País, evidenciou-se maior prevalência de anemia entre as crianças residentes na zona rural $(62,1 \%)$, quando comparadas às da zona urbana $(51,1 \%)$. Assim, o fato de residir na zona rural comportou-se como determinante da anemia (Oliveira et al., 2011). Já em Pernambuco, apesar da maior prevalência de anemia na área rural [36,6\% (IC95\%: 33,0; 40,3\%)], não se constatou diferença estatística significante em relação à área urbana [31,5\% (IC95\%: 28,2; 35,1\%)] (Leal et al., 2011). Em estudo com crianças pernambucanas menores de 5 anos assistidas pela ESF, também não se encontrou associação significativa entre a zona de residência e as deficiências nutricionais (anemia e DVA) (Paula et al., 2013).

No que se refere às condições socioeconômicas e ambientais, as análises ajustadas para as deficiências nutricionais estudadas mostraram que apenas a variável "anos de estudo da mãe" comportou-se como fator de proteção para ocorrência de anemia. Esse resultado reforça a importância do nível de escolaridade materna na saúde e nutrição dos filhos, uma vez que a mãe é a 
principal provedora da alimentação durante os períodos mais importantes do crescimento e desenvolvimento da criança.

De fato, estudos da literatura evidenciam que a anemia nas crianças apresenta associação significativa com níveis mais baixos de escolaridade da mãe. Estudo que analisou a tendência secular da anemia infantil no município de São Paulo constatou maior elevação da concentração média da hemoglobina e redução da prevalência da anemia quanto maiores os anos de estudo da mãe (Monteiro, Szarfarc, Mondini, 2000). Em estudo com 746 crianças do Nordeste do País constatou-se, na análise múltipla, o baixo nível de escolaridade da mãe como determinante para anemia (Oliveira, Osório, Raposo, 2007). De forma similar, na pesquisa que avaliou tendências temporais e fatores associados à anemia em Pernambuco, verificou-se que tanto em 1997 como em 2006, a escolaridade materna comportou-se como determinante da anemia (Leal et al., 2012). No Acre, em Rio Branco, estudo com 610 crianças menores de 5 anos de idade constatou que as crianças cujas mães tinham oito anos ou menos de estudo apresentavam suscetibilidade ao acometimento de anemia aumentada em 1,36 vezes (Souza et al., 2012a).

Ao contrário dos resultados obtidos com esta pesquisa, estudos de base populacional conduzidos por vários autores não apontam a baixa escolaridade materna como determinante para a anemia infantil. Assunção et al. (2007), em uma amostra de 507 crianças da cidade de Pelotas, Rio Grande do Sul, observaram que na análise univariada, a anemia foi significativamente mais prevalente entre as crianças de mães com até quatro anos de escolaridade. No entanto, essa variável não se manteve no modelo final. Os autores Spinelli et al. (2005) constataram apenas associação da escolaridade materna com anemia na análise univariada, condição que não se manteve na análise múltipla em 2.715 lactentes residentes em 12 municípios das cinco macrorregiões do Brasil. Oliveira et al. (2011), ao estudarem a prevalência e os fatores associados à anemia numa amostra de 429 crianças de 6 a 59 meses do município de Jordão, estado do Acre, observaram maior risco de anemia entre as crianças de mães com quatro anos ou menos de estudo, porém, sem associação estatística significante no modelo final. Pesquisa com 1.108 crianças paraibanas constatou a ocorrência de anemia em crianças cujas mães tinham menos de quatro anos de estudo na análise univariada, 
porém, na análise ajustada, o baixo nível de escolaridade da mãe não se comportou como determinante para a anemia infantil (Gondim et al., 2012b).

Para Gubert, Benicio e Santos (2010) e Souza et al. (2012b), o nível de escolaridade da mãe é indicador social preditivo de insegurança alimentar, tendo em vista que, quanto mais anos de estudo, maiores as chances de inserção no mercado de trabalho e, consequentemente, maior a participação no orçamento familiar. Isso se reflete no poder de compra e, portanto, no melhor acesso a uma alimentação variada e nutricionalmente adequada. De fato, Souza et al. (2012b) constataram maior prevalência de insegurança alimentar nos domicílios de mães com escolaridade inferior a dez anos, entre 243 famílias com crianças de 2 a 6 anos beneficiárias do Programa Bolsa Família.

Panigassi et al. (2008) ao correlacionarem insegurança alimentar e nutricional com pobreza e más condições ambientais de vida concluíram que famílias em situação de insegurança alimentar tinham dieta monótona, basicamente composta por alimentos energéticos.

Dados da Pesquisa Nacional por Amostra de Domicílios (PNAD) de 2009 evidenciaram disparidades significativas de insegurança alimentar entre as macrorregiões, que se mostraram maiores no Norte $(40,0 \%)$ e Nordeste $(46,0 \%)$, em relação ao Sudeste (23,0\%) e Sul (18,7\%) (Brasil, 2010). Para Gubert, Benicio e Santos (2010), essa situação se deve à desigualdade social entre as macrorregiões, porém no presente estudo, anemia e DVA apresentaram prevalências elevadas no Nordeste, mas também no Sudeste.

Poucos estudos analisam a associação entre a segurança alimentar da família e a ocorrência de deficiências nutricionais específicas. No Brasil, destacase apenas um estudo conduzido no Nordeste, que analisou a associação entre insegurança alimentar e níveis de retinol sérico e hemoglobina em menores de 5 anos. Os resultados evidenciaram níveis de retinol e hemoglobina mais baixos entre as crianças de famílias com insegurança alimentar moderada e grave, porém, sem associação estatística significativa (Oliveira et al., 2010), da mesma forma que o observado na análise univariada do presente estudo. Entretanto, após ajuste para as variáveis de confusão, a insegurança alimentar grave mostrou-se como um determinante da ocorrência de anemia e da deficiência concomitante de DVA e anemia. Esse resultado sugere serem essas deficiências nutricionais socialmente 
determinadas, ou seja, a deficiência de micronutrientes (ferro e vitamina A) é uma resposta da exposição biológica às condições socioeconômicas desfavoráveis, que impedem o acesso a uma alimentação que supra as necessidades nutricionais do organismo (Assis et al., 2007; Panigassi et al., 2008).

A associação entre insegurança alimentar e anemia tem sido confirmada também por estudos internacionais. Skalicky et al. (2006) observaram que a presença de insegurança alimentar na família norte-americana aumentava a chance de a criança apresentar anemia por deficiência de ferro (OR: 2,4; IC: 1,1-5,2; $\mathrm{p}=0,02$ ). Estudo desenvolvido também com crianças norte-americanas, menores de 36 meses, residentes em domicílios com insegurança alimentar, revelou que essas crianças apresentavam duas vezes mais chances de ter anemia em relação àquelas residentes em domicílios com segurança alimentar (Park et al., 2009). Em 2011, estudo conduzido com 4.949 crianças da Indonésia também evidenciou associação entre anemia e insegurança alimentar (Campbell et al., 2011).

Embora neste estudo não se tenha constatado associação entre a DVA e as variáveis classe econômica e renda per capita, estudos populacionais nacionais e internacionais reiteram os resultados aqui obtidos (Oliveira et al., 2010; Midyat et al., 2011; Sachdeva et al., 2011) que poderiam ser explicado pelo fato de que, com exceção das situações de extrema pobreza, a renda parece não ter relação na determinação da DVA, reforçando a tese de que a ingestão inadequada de alimentos fontes talvez seja o principal fator de risco para a ocorrência da DVA. Contudo, destaca-se um estudo brasileiro desenvolvido no estado de Sergipe, macrorregião Nordeste, com 607 crianças de 6 a 60 meses de idade, que constatou associação entre renda e DVA (Martins, Santos, Assis, 2004).

Ao contrário do que ocorre no caso da DVA, vários estudos evidenciam a baixa renda familiar como fator de risco para anemia (Monteiro, Szarfarc, Mondini, 2000; Neuman et al., 2000; Oliveira, Osório, Raposo, 2006; Assunção et al., 2007). Em revisão sistemática de estudos populacionais em menores de 6 anos, Leal e Osório (2010) reiteram a renda familiar como um dos fatores sociais mais destacados nos estudos analisados. Contudo, no presente estudo, apesar da maior chance de ocorrência de anemia nas classes econômicas B, C, D e E, não se constatou associação entre a anemia e essa variável. Em Pernambuco, os autores Leal et al. (2011), ao estudarem 1.403 crianças das áreas urbana e rural, 
encontraram associação entre anemia e classe econômica somente em relação às crianças da área urbana. Na Paraíba, Gondim et al. (2012b) também não evidenciaram associação entre renda familiar e anemia. No presente estudo, a não associação da anemia com variáveis que traduzam o status socioeconômico poderia ser explicada pela distribuição da anemia, que extrapola os limites socioeconômicos, uma vez que ocorre em macrorregiões mais desenvolvidas, como Sudeste e Sul.

Vale ressaltar que a anemia associou-se à insegurança alimentar, que é uma resposta às condições socioeconômicas desfavoráveis que impedem o acesso à alimentação adequada. Contudo, poder-se-ia inferir que a insegurança alimentar e a anemia têm fatores causais em comum, especialmente ligados à renda familiar, à escolaridade e às condições de moradia, que tornam as crianças mais susceptíveis às duas situações.

Segundo Antunes, Sichieri e Salles-Costa (2010), o consumo de cereais, hortaliças, frutas, carnes e ovos é significativamente reduzido entre crianças em situação de insegurança alimentar moderada e grave. E quanto maior a pontuação de insegurança da família, menor o consumo de proteínas e ferro pela criança. Ademais, os autores observaram também que o consumo de doces e gordura era elevado entre as crianças com insegurança alimentar, justificando a transformação nos hábitos alimentares e, consequentemente, comprometendo a qualidade da dieta infantil.

A assertiva de que a alimentação inadequada é um importante determinante das deficiências nutricionais foi confirmada no presente estudo, uma vez que a análise do consumo alimentar por meio dos grupos de alimentos entre as crianças brasileiras de 6 a 59 meses mostrou-se preocupante, tendo em vista que não atingiu as recomendações de consumo das porções de alimentos, de acordo com as diretrizes estabelecidas no País sobre alimentação saudável (Brasil, 2012b), pois apenas o consumo do grupo de carnes manteve-se, no modelo final, como um protetor das deficiências nutricionais estudadas. Ademais, constatou-se que a base da alimentação das crianças era representada pelo grupo de cereais/pães e massas e feijões consumidos "todos os dias". Em relação aos demais grupos, verificou-se que quase um terço não consumiu o grupo de legumes/verduras, tampouco o de leites e derivados, evidenciando-se, ainda, baixo 
consumo de frutas nos últimos sete dias. Esse quadro poderia justificar a maior ocorrência das deficiências estudadas, visto que a qualidade proteica elevada da mistura arroz/feijão não é considerada boa fonte de ferro biodisponível, por conter os fatores inibitórios da absorção do ferro (Moura, Canniatti-Brazaca, 2006). Ademais, pela baixa ingestão de alimentos fontes de vitamina $\mathrm{A}$, representados pelo grupo de legumes/verduras e frutas. A anemia por carência de ferro depende não só da quantidade ingerida, mas também da sua biodisponibilidade, que está condicionada a fatores interferentes dietéticos, como o consumo de alimentos ricos em vitamina $\mathrm{C}$, encontrados nos grupos verduras/legumes e frutas (Queiroz, Torres, 2000; Osório, 2002).

Osório (2002), Ramalho et al. (2006) e Saunders et al. (2007) destacam o papel da dieta, no que diz respeito ao consumo e biodisponibilidade do ferro e da vitamina A, como principal determinante da anemia e da DVA. Dieta com baixa disponibilidade de ferro é composta principalmente de cereais, como milho e trigo integral, que inibem a absorção de ferro, além de raízes e/ou tubérculos e legumes, e pouca quantidade de carne e frutas fontes de ácido ascórbico (Queiroz, Torres, 2000; Osório, 2002; Moura, Canniatti-Brazaca, 2006; Brasil, 2012b). A ocorrência da DVA em nível epidemiológico, por sua vez, relaciona-se principalmente com o baixo consumo de alimentos fontes de vitamina A (Saunders et al., 2007; Ramalho, 2011).

No que se refere à biodisponibilidade do ferro dietético e à anemia em crianças de 12 a 16 meses, encontrou-se baixa biodisponibilidade do ferro ingerido em 40,8\% das crianças, sendo 47,3\% em crianças anêmicas e 29,3\% naquelas que não apresentavam anemia. Para que a carne se torne um fator de proteção e possibilite um maior aporte de ferro, ela deve ser disponibilizada em quantidades superiores a $70 \mathrm{~g}$ por dia e associada ao consumo de vitamina $\mathrm{C}$ em quantidades superiores a $25 \mathrm{mg}$ por dia (Vitolo, Bortolini, 2007).

Em relação, ainda, às deficiências nutricionais e alimentação, estudo conduzido no Rio de Janeiro observou que as crianças com anemia tinham dieta pobre em carnes em relação às crianças sem anemia (Lacerda, Cunha, 2001). Do mesmo modo, uma pesquisa de base populacional realizada no estado do Pernambuco pelos autores Oliveira, Osório e Raposo (2007), também evidenciou que o menor consumo de ferro heme proveniente do consumo do grupo das 
carnes, associava-se à ocorrência de anemia. Na cidade de Rio Branco, as crianças que foram expostas ao consumo de carnes por período inferior a uma vez por semana encontravam-se mais suscetíveis à anemia (Souza et al., 2012a). Silva, Priore e Franceschini (2007) também evidenciaram que crianças com consumo de frutas inferior à recomendação diária apresentavam chance duas vezes maior de desenvolver anemia. Portanto, a presença de carnes, além de frutas, sucos e vegetais ricos em vitamina $\mathrm{C}$ nas refeições, torna o ferro dietético mais disponível e aumenta os níveis de hemoglobina do organismo.

Estudos nacionais relacionados à caracterização do consumo alimentar de vitamina A reiteram os resultados obtidos nesta pesquisa, evidenciando que o baixo consumo de alimentos ricos em vitamina A, representados pelos grupos verduras/legumes e frutas, favorece a ocorrência de DVA (Pereira et al.,2008; Azevedo et al., 2010; Netto et al., 2012).

Os dados de consumo alimentar encontrados corroboram a análise específica do consumo alimentar de crianças de 6-59 meses de idade da PNDS/2006, que mostrou também o baixo consumo diário de verduras (12,7\%), legumes $(21,8 \%)$ e carnes $(24,6 \%)$; e o elevado consumo de refrigerantes $(40,5 \%)$, alimentos fritos $(39,4 \%)$, salgadinhos $(39,4 \%)$ e doces $(37,8 \%)$ (Bortolini, Gubert, Santos, 2012). As diretrizes para alimentação infantil saudável estabelecidas no País recomendam o consumo diário de carnes, frutas, verduras de folhas, legumes e leguminosas, bem como ressaltam a necessidade de se evitar refrigerantes, biscoitos, doces e salgadinhos nos primeiros anos de vida das crianças (Brasil, 2012b).

Cabe salientar que não existe um método ouro para a avaliação do consumo alimentar, especialmente na população infantil, no entanto, o valor nutricional da dieta é a chave explicativa de marcante importância para a análise do problema da anemia e da DVA. Ademais, observa-se que, proporcionalmente ao número de publicações encontradas, são poucas aquelas que abordam o problema a partir de amostras populacionais representativas, assim, os resultados aqui apresentados tornam-se relevantes para futuras comparações e investigações.

No que tange às características maternas, observou-se maior ocorrência de DVA em crianças de mães com idade mais avançada, contrariando os resultados de uma pesquisa realizada em Pernambuco, que evidenciou maior prevalência de 
DVA entre as crianças de mães mais jovens (Miglioli et al., 2013). Para os mesmos autores, a justificativa da presença da DVA entre as crianças cujas mães eram mais jovens provavelmente se deve à inexperiência materna nos cuidados com as crianças, que envolve maiores dificuldades de alimentar seus filhos, resultando na oferta de alimentação insuficiente em vitamina A. Entretanto, em Sergipe, apesar da maior ocorrência de DVA entres as crianças de mães com menos de 20 anos, não se encontrou significância estatística entre idade da mãe e DVA dos filhos (Martins, Santos, Assis, 2004). Ramalho et al. (2006) também não encontraram associação entre níveis de retinol sérico da criança e idade da mãe. Tal fato poderia, em parte, ser explicado também pelo número reduzido de mães adolescentes presente na amostra, contribuindo para a menor possibilidade de se fazer a associação entre a idade materna e a presença de DVA.

Por fim, quanto às variáveis envolvidas nos processos individuais da criança, em relação às deficiências nutricionais, somente a variável internação nos últimos 12 meses mostrou-se associada à anemia e à ocorrência concomitante de DVA e anemia. No entanto, essa associação não se manteve na análise múltipla. O resultado encontrado difere dos obtidos em estudos conduzidos no Brasil que apontam a internação como determinante da anemia (Castro et al., 2011; Rodrigues et al., 2011). Esse aspecto merece ser analisado de forma mais aprofundada, visto que, isoladamente, a deficiência de ferro deprime a função imune do organismo, oportunizando maior exposição a risco de infecções, consequentemente, possibilitando a internação.

Para os autores Osório (2002) e Konstantyner, Taddei e Palma (2007), as infecções, por sua vez, principalmente quando acarretam internações hospitalares, causam diminuição dos níveis hematológicos de ferro por redução na produção e na absorção de $\mathrm{Hb}$, predispondo à instalação de um quadro de anemia. Também podem comprometer, de forma marcante, o consumo de alimentos por redução do apetite, favorecendo o aparecimento de carências nutricionais. Assim, as altas taxas de infecções dos tratos digestório e respiratório, bem como outras doenças comuns na infância, são apontadas como principais responsáveis pela inadequação de ferro e vitamina A observada em crianças menores de 5 anos de idade (Ramalho, 2011). 
Vários estudos mostram que as crianças menores de 2 anos de idade apresentam maior suscetibilidade à anemia e à DVA (Santos et al., 1996; Monteiro, Szarfarc, Mondini, 2000; Neuman et al., 2000; Vasconcelos, Ferreira, 2009; Castro et al., 2011; Leal et al., 2011; Oliveira et al., 2011; Rocha et al., 2012; Souza et al., 2012a; Cardoso et al., 2012; Gondim et al., 2012b; Sales et al., 2013), porém, no presente estudo, a idade associou-se somente à ocorrência concomitante de DVA e anemia, agindo como determinante de proteção para crianças com idade $\geq 2$ anos. Essa vulnerabilidade das crianças menores de 2 anos de idade à ocorrência de anemia e de DVA poderia ser atribuída, principalmente, ao período, caracterizado por intensa velocidade de crescimento e, sobretudo, às práticas alimentares inadequadas nos primeiros anos de vida. Apesar de a variável idade da criança ter perdido sua força de associação estatística na análise múltipla para anemia, no presente estudo, crianças menores de 2 anos de idade apresentaram maior suscetibilidade à anemia.

A análise exclusiva dos fatores de risco para anemia em 1.382 crianças menores de 24 meses de idade da PNDS/2006 reitera esse resultado, uma vez que evidenciou prevalências de anemia leve e moderada de $25,0 \%$ e $10,0 \%$, respectivamente, com maior associação da ocorrência da anemia em crianças menores de 12 meses à anemia leve (Konstantyner, Oliveira, Taddei, 2012).

Por fim, a não associação da anemia e da DVA no modelo ajustado a outras variáveis que traduzam a dimensão dos processos individuais da criança, a exemplo da associação entre as práticas de aleitamento materno e a anemia e a DVA, corrobora também com os resultados de estudos que não encontraram tal associação (Silva, Giugliani, Aerts, 2001; Silva, Priore, Franceschini, 2007; Oliveira et al., 2011), contrapondo-se, porém, a outros que evidenciaram associação entre aleitamento materno e anemia e DVA (McLaren, Frigg, 2001; Konstantyner, Taddei, Palma, 2007). Tal resultado poderia ser fundamentado em função de a ação protetora do aleitamento ser mais evidente nos primeiros seis meses de vida, grupo normalmente não incluído em estudos sobre anemia e DVA (Silva, Giugliani, Aerts, 2001; Silva, Priore, Franceschini, 2007; Oliveira, Oliveira, Bergamaschi, 2009).

Embora neste estudo não se tenha constatado associação entre anemia infantil e estado nutricional, chama atenção o fato de o número de crianças com 
maiores IMC/Idade apresentar quase duas vezes mais chances de ter anemia que o daquelas crianças com IMC/Idade normal ou com déficit, porém, não estatisticamente significativas. Essa relação tem produzido resultados conflitantes também na literatura.

Contudo, a não associação da anemia também com déficits de estatura nas crianças do presente estudo corrobora os resultados de vários trabalhos (Neuman et al., 2000; Almeida et al., 2004; Leal et al., 2011). De fato, estudos mostram maior suscetibilidade à anemia em crianças com déficit nutricional, uma vez que a anemia afeta o crescimento e desenvolvimento físico de crianças, consequentemente, comprometendo seu estado nutricional (Castro et al., 2011; Rocha et al., 2012; Foote et al. 2013).

No entanto, estudos realizados em países desenvolvidos reiteram, em seus resultados, que, ao analisarem tendência secular da deficiência de ferro em crianças americanas de 1 a 3 anos de idade, utilizando dados de amostras populacionais, constataram associação entre sobrepeso e anemia (Brotanek et al., 2007). Uma hipótese para os resultados deste estudo seria a de que as práticas alimentares inadequadas vivenciadas pelas crianças com excesso de peso, a exemplo do consumo elevado de alimentos industrializados com alto valor calórico e do baixo consumo diário de frutas, verduras/legumes e leguminosas, poderiam refletir a chamada "fome oculta", definida pela deficiência de micronutrientes (Ferraz et al., 2005; UNICEF, 2012).

No que se refere à DVA, a desnutrição avaliada como déficit antropométrico tem sido também destacada como fator associado à DVA, embora uma relação causal nessa direção não tenha sido provada no presente estudo. Pode-se dizer que a desnutrição acompanha a DVA e tende a aumentar conforme a gravidade da deficiência (McLaren, Frigg, 2001). O resultado do presente estudo difere do obtido em estudo realizado em Sergipe, que constatou associação entre níveis inadequados de retinol sérico e déficit no índice peso para idade em préescolares (Martins, Santos, Assis, 2004), e na Turquia, que também encontrou associação positiva entre o déficit nutricional e a DVA (Midyat et al., 2011).

Vale ressaltar que as deficiências nutricionais, como outras doenças comuns na infância, são problemas de saúde com determinantes múltiplos e complexos, que interagem para o seu desenvolvimento, razão pela qual têm sido 
estudadas por meio de modelo com seleção hierarquizada. O presente trabalho partiu de um modelo conceitual que considera os determinantes distais, representados pelo contexto social e cultural em que se situa a criança, assim como os determinantes intermediários e proximais. Os resultados aqui apresentados confirmaram a determinação social do problema, visto que os determinantes sociais (macrorregião e zona de residência; escolaridade e idade da mãe; insegurança e consumo alimentar) foram identificados como importantes preditores das deficiências estudadas.

Isso significa que o estudo dos determinantes deve levar em conta não só a distribuição de renda e o poder aquisitivo na esfera individual, mas também as políticas sociais que garantam o atendimento dos indivíduos em relação à saúde, alimentação, educação, moradia, as quais dependem do grau de desenvolvimento socioeconômico do país, que têm como base os processos estruturais da sociedade (Lana, 2006; Ferreira, Latorre, 2012).

Considera-se que a presente reanálise dos dados da PNDS/2006 possibilitou, pela primeira vez, a compreensão dos determinantes das carências nutricionais mais prevalentes, com representatividade para as áreas urbanas e rurais das cinco macrorregiões geográficas do País, utilizando uma técnica de expansão de amostras complexas para todos os procedimentos estatísticos com o objetivo de garantir a legitimidade dos dados. Permite-se, pois, sugerir a adoção de um modelo hierárquico com os determinantes identificados (Figura 8) para melhor se compreender o processo saúde/doença das carências nutricionais e se oferecer subsídios para a formulação de políticas de saúde e nutrição destinadas à prevenção e controle efetivo desses problemas, reduzindo-se, consequentemente, os danos produzidos por essas deficiências na população infantil. 
Figura 8 - Modelo hierárquico para a análise dos determinantes das carências nutricionais

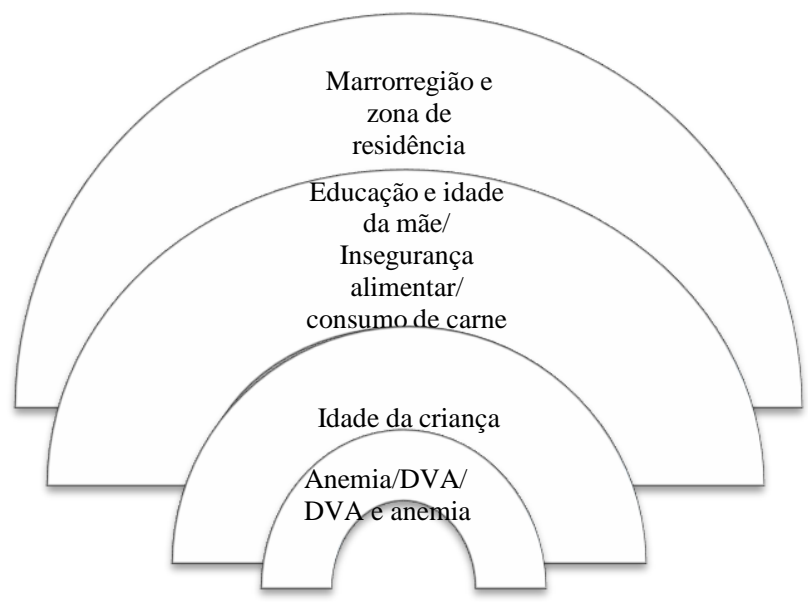


Considerações finais 


\section{CONSIDERAÇÕES FINAIS}

O presente estudo mostrou uma importante redução na prevalência de anemia e de DVA infantil no Brasil, embora ainda se caracterizem como problema moderado de saúde pública, de acordo com o critério de importância epidemiológica da Organização Mundial da Saúde.

Os resultados encontrados sugerem que as estratégias governamentais têm contribuído para a prevenção e controle dessas carências nutricionais no País. Contudo, sinaliza-se a necessidade de expansão da estratégia governamental de prevenção e controle da DVA, até então restrita às áreas de risco (região Nordeste e áreas pobres da região Sudeste).

Apesar das fortes evidências de que a DVA contribui para o desenvolvimento da anemia, constatou-se uma baixa prevalência dessas duas carências nutricionais conjuntas entre as crianças brasileiras, não havendo, portanto, associação entre elas.

Os determinantes comuns da anemia e da DVA, como residir em área urbana e em macrorregiões menos e mais desenvolvidas, reiteram o caráter transocial da anemia, bem como da DVA. Entretanto, o fato de terem como fator determinante a insegurança alimentar e como fator de proteção consumir carne pelo menos uma vez por semana reforça a determinação social dessas carências nutricionais, embora a insegurança alimentar não tenha se associado à DVA.

Reforça-se, por essas razões, a necessidade de que os governantes e a sociedade civil desenvolvam estratégias em diversos setores com a implementação de projetos intersetoriais, que visem à melhoria das condições de vida e saúde da população, especialmente a urbana.

Estratégias no âmbito da política nacional de nutrição e alimentação também devem ser aperfeiçoadas, para que venham a produzir melhorias nas condições de nutrição e saúde, com vistas a assegurar às famílias acesso universal à alimentação saudável e a orientações nutricionais voltadas para a prevenção e tratamento da anemia e da DVA, com informações sobre alimentos fontes de ferro e vitamina A e instruções educativas direcionadas que enfatizem a importância da suplementação medicamentosa desses nutrientes para as crianças menores de 5 anos. 
A interpretação dos resultados do presente estudo deve considerar a existência de uma série de variáveis intervenientes, que não puderam ser controladas por se tratar de uma reanálise de dados secundários. Vale destacar, também, que estudos transversais não permitem que se relacionem situações de causa e efeito, porém, esse tipo de delineamento é muito utilizado para se avaliar situações de saúde, por ser menos oneroso e mais facilmente realizado. Destacase, como mérito, a análise de um grande número de crianças com representatividade para as áreas urbanas e rurais das cinco macrorregiões geográficas do Brasil, que possibilitou caracterizar, de forma mais acurada, a situação nacional de anemia e da DVA no grupo infantil de 6 a 59 meses de idade. 


\section{Referências}




\section{REFERÊNCIAS}

Ahmed F, Rahman A, Noor AN, Akhtaruzzaman M, Hughes R. Anaemia and vitamin A status among adolescent schoolboys in Dhaka City, Bangladesh. Public Health Nutr. 2006;9(3):345-50.

Alencar FH, Castro JS, Yuyama LKO, Marinho HA, Nagahama D. Diagnóstico da realidade nutricional no estado do Amazonas, Brasil. I - Hipovitaminose A. Acta Amaz. 2002;32(4):613-23.

Almeida AP, Zandonade E, Abrantes MM, Lamounier JA. Deficiência de ferro e anemia em crianças de Vitória, ES. Pediatria. 2004; 26(3):140-50.

Almeida ER, Carvalho AT, Nilson EAF, Coutinho JG, Ubarana JA. Avaliação participativa do Programa Nacional de Suplementação de Vitamina A em um município da Região Nordeste do Brasil. Cad Saúde Pública. 2010;26(5):949-60.

Almeida-Filho N. A problemática teórica da determinação social da saúde (nota breve sobre desigualdades em saúde como objeto de conhecimento). Saúde debate. 2009;33(83):349-70.

Antunes MML, Sichieri R, Salles-Costa R. Consumo alimentar de crianças menores de três anos residentes em área de alta prevalência de insegurança alimentar domiciliar. Cad Saúde Publica. 2010;26(8):1642-50.

Araújo RL, Araújo MBDG, Sieiro RO, Machado RDP, Leite BV. Diagnóstico da situação de hipovitaminose A e da anemia nutricional na população do Vale do Jequitinhonha, Minas Gerais, Brasil. Arch Latinoam Nutr. 1986;36(4):642-52.

Assis AMO, Prado MS, Freitas MCS, Cruz MM. Deficiência de vitamina A e desnutrição energético proteica em crianças de localidades do semi-árido baiano. Rev Nutr. 1997;10(1):70-8.

Assis AM, Barreto ML, Gomes GS, Prado M da S, Santos NS, Santos LM et al. Childhood anemia prevalence and associated factors in Salvador, Bahia, Brazil. Cad Saúde Pública. 2004a;20(6):1633-41.

Assis AM, Gaudenzi EN, Gomes G, Ribeiro R de C, Szarfarc SS, Souza SB. Níveis de hemoglobina, aleitamento materno e regime alimentar no primeiro ano de vida. Rev Saúde Pública. 2004b;38(4):543-51.

Assis AMO, Barreto ML, Santos NS, Oliveira LPM, Santos SMC, Pinheiro SMC. Desigualdade, pobreza e condições de saúde e nutrição na infância no Nordeste brasileiro. Cad Saúde Publica. 2007;23(10):2337-50.

Associação Brasileira de Empresas de Pesquisa (ABEP). Critério padrão de classificação econômica Brasil 2008. [citado em 2011 dez. 09]. Disponível em: www.abep.org/codigosguias/Criterio_Brasil_2008.pdf. 
Assunção MCF, Santos IS, Barros AJD, Gigante DP, Victora CG. Efeito da fortificação de farinhas com ferro sobre anemia em pré-escolares. Rev Saúde Pública. 2007;41(4):539-48.

Assunção MCF, Santos IS, Barros AJD, Gigante DP, Victora CG. Flour fortification with iron has no impact on anaemia in urban Brazilian children. Public Health Nutr. 2012;15(10):1796-801.

Azeredo CM, Cotta RMM, Silva LS, Franceschini SCC, Sant'Ana LFR, Ribeiro RCL. Implantação e impacto do Programa Nacional de Suplementação de Ferro no município de Viçosa - MG. Ciênc saúde coletiva. 2011; 16(10): 4011-22.

Azevedo MMS, Cabral PC, Diniz AS, Fisberg M, Fisberg RM, Arruda IKG. Deficiência de vitamina A em pré-escolares da cidade do Recife, Nordeste do Brasil. Arch Latinoam Nutr. 2010;60(1):36-41.

Barros ALA, Soares ADN, Pessoa MC, Teixeira RA, Beinner MA. Deficiência de vitamina a em crianças residentes na região metropolitana de Belo Horizonte, Minas Gerais. Rev Min Enferm. 2010;14(3):386-93.

Batista Filho M, Souza AI, Bresani CC. Anemia como problema de saúde pública: uma realidade atual. Ciênc saúde coletiva. 2008;13(6):1917-22.

Bortolini GA, Gubert MB, Santos LMP. Consumo Alimentar entre crianças brasileiras com idade de 6 a 59 meses. Cad Saúde Pública. 2012;28(9):1759-71.

Bortolini GA, Vitolo MR. Relationship between iron deficiency and anemia in children younger than 4 years. J Pediatr. 2010;86(6):488-92.

Brasil. Ministério da Saúde. Resolução RDC nº 344, de 13 de dezembro de 2002. Aprova o regulamento técnico para a fortificação das farinhas de trigo e das farinhas de milho com ferro e ácido fólico. 2002 [acesso em 10 jan. de 2012]. Disponível em: http://www.anvisa.gov.br/legis/resol/ 2002/344_02rdc.html.

Brasil. Ministério da Saúde, Secretaria de Atenção à Saúde, Departamento de Atenção Básica. Vitamina A Mais: Programa Nacional de Suplementação de Vitamina A: Condutas Gerais. Brasília; 2004.

Brasil. Ministério da Saúde, Legislação em Vigilância Sanitária. Portaria nº 730 , de 13 de maio de 2005. In: Brasil. Ministério da Saúde. Programa Nacional de Suplementação de ferro. Diário Oficial da União, n. 92, 16 maio. Brasília; 2005a.

Brasil. Ministério do Desenvolvimento Social e Combate à Fome. Fome Zero: balanço dos programas e ações. Brasília; 2005b.

Brasil. Ministério da Saúde. Carências de micronutrientes. Brasília; 2007. 
Brasil. Ministério da Saúde. Pesquisa Nacional de Demografia e Saúde da Criança e da Mulher - PNDS 2006: Dimensões do processo reprodutivo e da saúde da criança. Brasília; 2009.

Brasil. Ministério do Planejamento, Ministério do Desenvolvimento Social e Combate a Fome, Instituto Brasileiro de Geografia e Estatística, Pesquisa Nacional por Amostra de Domicílios - PNAD. Segurança Alimentar 2004/2009. Rio de Janeiro; 2010.

Brasil. Ministério da Saúde, Secretaria de Atenção à Saúde, Departamento de Atenção Básica. Saúde da criança: crescimento e desenvolvimento. Brasília; 2012a.

Brasil. Ministério da Saúde, Secretaria de Atenção à Saúde, Departamento de Atenção Básica. Política Nacional de Alimentação e Nutrição. Brasília; 2012b.

Breilh J, Granda E. Investigação da saúde na sociedade: guia pedagógico sobre um novo enfoque do método epidemiológico. São Paulo: Cortez; 1989. Produção e distribuição da saúde-doença como fato coletivo; p. 35-52.

Brito FA, Pinho BATD. A dinâmica do processo de urbanização no Brasil, 19402010. Belo Horizonte: UFMG/CEDEPLAR; 2012.

Brotanek JM, Gosz J, Weitzman M, Flores G. Iron deficiency in early childhood in the United States: risk factors and racial/ethnic disparities. Pediatrics. 2007; 120(3):568-75.

Brunken GS, Guimarães LV, Fisberg M. Anemia em crianças menores de 3 anos que freqüentam creches públicas em período integral. J Pediatr. 2002;78(1):50-6.

Brunken GS, Muniz PT, Silva SM. Weekly iron supplementation reduces anemia prevalence by $1 / 3$ in preschool children. Rev bras epidemiol. 2004;7(2):210-9.

Bueno MB, Selem SSC, Áreas JAG, Fisberg RM. Prevalência e fatores associados à anemia entre crianças atendidas em creches públicas de São Paulo. Rev bras epidemiol. 2006;9(4):462-70.

Buss PM, Pellegrini Filho A. A saúde e seus determinantes sociais. Physis. 2007;17(1):77-93.

Caminha MFC. Concentração do retinol sérico em crianças desnutridas graves hospitalizadas no IMIP: um estudo tipo série de casos. [Dissertação]. Recife: Universidade Federal de Pernambuco; 2005.

Campbell AA, Akhter N, Sun K, De Pee S, Kraemer K, Moench-Pfanner R, Rah JH, Badham J, Bloem MW, Semba RD. Relationship of household food insecurity to anaemia in children aged 6-59 months among families in rural Indonesia. Ann Trop Paediatr. 2011; 31(4): 321-30. 
Cardoso MA, Scopel KK, Muniz PT, Villamor E, Ferreira MU. Underlying Factors Associated with Anemia in Amazonian Children: A Population-Based, Cross-Sectional Study. PLoS One. 2012;7(5):e36341.

Carvalho AGC, Lira PIC, Barros MFA, Aléssio MLM, Lima MC, Carbonneau MA et al. O diagnóstico de anemia ferropriva em crianças do Nordeste do Brasil. Rev Saúde Pública. 2010;44(3):513-9.

Castro TG, Campos FM, Priore SE, Coelho FM, Campos MT, Franceschini SC et al. Saúde e nutrição de crianças de 0 a 60 meses de um assentamento de reforma agrária, Vale do Rio Doce, MG, Brasil. Rev Nutr. 2004;17(2):167-76.

Castro TG, Novaes JF, Silva MR, Costa NM, Franceschini SC, Tinoco AL et al. Caracterização do consumo alimentar, ambiente socioeconômico e estado nutricional de pré-escolares de creches municipais. Rev Nutr. 2005;18(3):321-30.

Castro TG, Silva-Nunes M, Conde WL, Muniz PT, Cardoso MA. Anemia e deficiência de ferro em pré-escolares da Amazônia Ocidental brasileira: prevalência e fatores associados. Cad Saúde Pública. 2011;27(1):131-42.

Comissão Nacional sobre Determinantes Sociais da Saúde (CNDSS). As causas sociais das iniqüidades em saúde no Brasil. Relatório Final da Comissão Nacional sobre Determinantes Sociais da Saúde (CNDSS); 2008.

Compri PC, Cury MCFS, Novo NF, Juliano Y, Sigulem DM. Variáveis maternas e infantis associadas à ocorrência de anemia em crianças nos serviços de atenção básica em São Paulo. Rev paul pediatr. 2007;25(4):349-54.

Costa MJ, Terto AL, Santos LM, Rivera MA, Moura LS. Efeito da suplementação com acerola nos níveis sanguíneos de vitamina c e de hemoglobina em crianças pré-escolares. Rev Nutr. 2001;14(1):13-20.

Coutinho GGPL, Goloni-Bertollo EM, Pavarino-Bertelli EC. Effectiveness of two programs of intermittent ferrous supplementation for treating iron-deficiency anemia in infants: randomized clinical trial. São Paulo Med J. 2008;126(6):314-8.

Diniz AS, Santos LMP. Hipovitaminose A e xeroftalmia. J Pediatr. 2000;76(Supl 3):311-22.

Dolinsky M, Ramalho A. Deficiência de vitamina A: uma revisão atualizada. Compacta Nutrição 2003;4(2):3-18.

Duarte LS, Fujimori E, Minagawa AT, Schoeps FA, Montero RMJM. Aleitamento materno e níveis de hemoglobina em crianças menores de 2 anos em município do estado de São Paulo, Brasil. Rev Nutr. 2007;20(2):149-57.

El Beitune P, Duarte G, Quintana SM, Figueiró-Filho EA, Vannucchi H. Hipovitaminose A: cofator clínico deletério para o homem. Medicina. 2003;36(1): $5-15$. 
Engstrom EM, Castro IRR, Portela, M, Cardoso LO, Monteiro CA. Efetividade da suplementação diária ou semanal com ferro na prevenção da anemia em lactentes. Rev Saúde Pública. 2008;42(5):786-95.

Fernandes TF, Diniz AS, Cabral PC, Oliveira RS, Lola MM, Silva SM et al. Hipovitaminose A em pré-escolares de creches públicas do Recife: indicadores bioquímico e dietético. Rev Nutr. 2005;18(4):471-80.

Ferraz IS; Daneluzzi, JC, Vannucchi H. Vitamin A deficiency in children aged 6 to 24 months in São Paulo state, Brazil. Nutr Res. 2000;20(6):757-68.

Ferraz IS, Daneluzzi JC, Vannucchi H, Jordão AA Jr, Ricco RG, Del Ciampo LA et al. Prevalence of iron deficiency and its association with vitamin A deficiency in preschool children. J Pediatr. 2005;81(2):169-74.

Ferreira HS, Assunção ML, Vasconcelos VS, Melo FP, Oliveira CG, Santos TO. Saúde de populações marginalizadas: desnutrição, anemia e enteroparasitoses em crianças de uma favela do "Movimento dos Sem Teto", Maceió, Alagoas. Rev Bras Saúde Mater Infant. 2002;2(2):177-85.

Ferreira ML, Ferreira LO, Silva AA, Batista Filho M. Efetividade da aplicação do sulfato ferroso em doses semanais no Programa Saúde da Família em Caruaru, Pernambuco, Brasil. Cad Saúde Publica. 2003;19(2):375-81.

Ferreira MAF, Latorre MRDO. Desigualdade social e os estudos epidemiológicos. Ciênc saúde coletiva. 2012;7(9):2523-31.

Fisberg M, Ferreira AM, Silva JV, Kliamca PE, Cardoso R, Giorgini E et al. Nova fórmula láctea infantil: papel na prevenção da anemia carencial. Pediatria. 1999;21(1):48-59.

Foote EM, Sullivan KM, Ruth LJ, Oremo J, Sadumah I, Williams TN, Suchdev PS. Determinants of Anemia among Preschool Children in Rural, Western Kenya. Am J Trop Med Hyg. 2013;88(4):757-64.

Fujimori E, Duarte LS, Minagawa AT, Laurenti D, Montero RMJM. Reprodução social e anemia infantil. Rev Latino-Am Enfermagem. 2008;16(2):245-51.

Geraldo RRC, Paiva SAR, Pitas AMCS, Godoy I, Campana AO. Distribuição da hipovitaminose A no Brasil nas últimas quatro décadas: ingestão alimentar, sinais clínicos e dados bioquímicos. Rev Nutr. 2003;16(4):443-60.

Giorgini E, Fisberg M, de Paula RA, Ferreira AM, Valle J, Braga JA. The use of sweet rolls fortifed with iron bis-glycinate chelate in the prevention of iron deficiency anemia in preschool children. Arch Latinoam Nutr. 2001;51(Suppl 1):48-53. 
Gonçalves-Carvalho CMR, Amaya-Farfan J, Wilke BC, Vencovsky R. Prevalência de hipovitaminose A em crianças da periferia do município de Campinas, São Paulo, Brasil. Cad Saúde Publica. 1995;11(1):85-96.

Gondim SSR, Diniz AS, Cagliari MPP, Araújo ES, Queiroz D, Paiva AA. Relação entre níveis de hemoglobina, concentração de retinol sérico e estado nutricional em crianças de 6 a 59 meses do Estado da Paraíba. Rev Nutr. 2012a;25(4): 44149.

Gondim SSR, Diniz AS, Souto RA, Bezerra RGS, Albuquerque EC, Paiva AA. Magnitude, tendência temporal e fatores associados à anemia em crianças do Estado da Paraíba. Rev Saúde Pública. 2012b;46(4): 649-56.

Gubert MB, Benicio MHDA, Santos LMP. Estimativas de insegurança alimentar grave nos municípios brasileiros. Cad Saúde Pública. 2010;26(8):1595-1605.

Hadler MC, Juliano Y, Sigulem DM. Anemia do lactente: etiologia e prevalência. J Pediatr. 2002;78(4):321-6.

Hiratstuka MS, Ribeiro ZM. Diagnóstico de anemia em crianças de 0 a 3 anos: uma necessidade de recomendações. Rev saúde Dist Fed. 2002;13(1/2):7-14.

Imdad A, Herzer K, Wilson E, Yakoob MY, Bhutta AZl. Vitamin A supplementation for preventing morbidity and mortality in children from 6 months to 5 years of age. [Internet]. Cochrane Database Syst Rev. 2010;(12): CD008524 [cited 2013 May 30]. Available from: http://onlinelibrary.wiley.com/doi/10.1002/ 14651858. CD008524.pub2/pdf

Instituto Nacional de Alimentação e Nutrição (INAN). Instituto Materno Infantil de Pernambuco (IMIP). II Pesquisa Estadual de Saúde e Nutrição: saúde, nutrição, alimentação e condições sócio-econômicas no estado de Pernambuco. Recife: INAN/IMIP; 1998.

Iost C, Name JJ, Jeppsen RB, Ashmead HD. Repleting hemoglobin in iron defciency anemia in young children through liquid milk fortifcation with bioavailable iron amino acid chelate. J Am Coll Nutr. 1998;17(2):187-94.

Jimenez C, Leets I, Puche R, Anzola E, Montilla R, Parra C, Aguilera A, GarcíaCasal MN. A single dose of vitamin A improves haemoglobin concentration, retinol status and phagocytic function of neutrophils in preschool children. $\mathrm{Br} \mathbf{J}$ Nutr.2010; 103(6):798-802.

Jordão RE, Bernardi JLD, Barros Filho AA. Prevalência de anemia ferropriva no Brasil: uma revisão sistemática. Rev paul pediatr. 2009;27(1):90-8.

Konstantyner T, Taddei JAAC, Palma D. Fatores de risco de anemia em lactentes matriculados em creches públicas ou filantrópicas de São Paulo. Rev Nutr. 2007;20(4):349-59. 
Konstantyner T, Oliveira TCR, Taddei JAAC. Risk Factors for Anemia among Brazilian Infants from the 2006 National Demographic Health Survey. Anemia. 2012;(2012):1-7.

Lacerda E, Cunha AJ. Anemia ferropriva e alimentação no segundo ano de vida no Rio de Janeiro, Brasil. Rev Panam Salud Pública. 2001;9(5):294-301. Lana FCF. Saúde, doença e condições de vida (Editorial). Rev Min Enferm. 2006;10(2):106.

Leal LP, Osório MM. Validação e reprodutibilidade de sinais clínicos no diagnóstico de anemia em crianças. Cad Saúde Pública. 2005;21(2):565-72.

Leal LP, Osório MM. Fatores associados à ocorrência de anemia em crianças menores de seis anos: uma revisão sistemática dos estudos populacionais. Rev Bras Saúde Matern Infant. 2010;10(4):417-39.

Leal LP, Batista Filho M, Lira PIC, Figueiroa JN, Osório MM. Prevalência da anemia e fatores associados em crianças de seis a 59 meses de Pernambuco. Rev Saúde Pública. 2011;45(3):457-66.

Leal LP, Batista Filho M, Lira PI, Figueiroa JN, Osório MM. Temporal trends and anaemia-associated factors in 6- to 59-month-old children in Northeast Brazil. Nutr Public Health. 2012;15(9):1645-52.

Lessa AC, Devincenzi MU, Sigulem DM. Comparação da situação nutricional de crianças de baixa renda no segundo ano de vida, antes e após a implantação de programa de atenção primária à saúde. Cad Saúde Publica. 2003;19(2):505-14.

Levy-Costa RB, Monteiro CA. Consumo de leite de vaca e anemia na infância no Município de São Paulo. Rev Saúde Pública. 2004;38(6):797-803.

Lima AC, Lima MC, Guerra MQ, Romani SA, Eickmann SH, Lira PI. Impacto do tratamento semanal com sulfato ferroso sobre o nível de hemoglobina, morbidade e estado nutricional de lactentes anêmicos. J Pediatr. 2006;82(6):452-7.

Lynch SR. Why nutritional iron deficiency persists as a worldwide problem. J Nutr. 2011;141(4):763-8.

Magalhães P, Ramalho RA, Colli C. Deficiência de ferro e de vitamina A: avaliação nutricional de pré-escolares de Viçosa, MG, Brasil. Nutrire: Rev Soc Bras Aliment Nutr. 2001;21(1):41-56.

Marchi RP, Szarfarc SC, Rodrigues JE. Consumo de arroz fortificado com ferro na profilaxia da deficiência do mineral. Nutrire: Rev Soc Bras Aliment Nutr. 2004;28:53-64.

Mariath AB, Giachini RM, Lauda LG, Grillo LP. Estado de ferro e retinol sérico entre crianças e adolescentes atendidos por equipe da Estratégia de Saúde da Família de Itajaí, Santa Catarina. Ciênc saúde coletiva. 2010;15(2):509-16. 
Marinho HA. Prevalência de deficiência de vitamina A em pré-escolares de três capitais da Amazônia Ocidental Brasileira [tese]. São Paulo: Faculdade de Saúde Pública, Universidade de São Paulo; 2000.

Martins MC, Santos LMP, Assis AMO. Prevalência da hipovitaminose A em préescolares no estado de Sergipe. Rev Saúde Pública. 2004;38(4):537-42.

Martins MC, Oliveira YP, Coitinho DC, Santos LM. Panorama das ações de controle da deficiência de vitamina A no Brasil. Rev Nutr. 2007;20(1):5-18.

Matta IE, Veiga GV, Baião MR, Santos MM, Luiz RR. Anemia em crianças menores de cinco anos que freqüentam creches públicas do município do Rio de Janeiro, Brasil. Rev Bras Saúde Mater Infant. 2005;5(3):349-57.

Mayo-Wilson E, Imdad A, Herzer K, Yakoob MY, Bhutta ZA. Vitamin A supplements for preventing mortality, illness, and blindness in children aged under 5: systematic review and meta-analysis. BMJ. 2011;343:d5094.

McAuliffe J, Santos LM, Diniz AS, Batista Filho M, Barbosa RCC. A deficiência de vitamina A e estratégias para o seu controle: um guia para as Secretarias Municipais de Saúde. Fortaleza: Project HOPE; 1991.

McLaren DS, Frigg M. Sight and life manual on vitamin A deficiency disorders (VADD). $2^{\mathrm{a}}$ ed. Switzerland: Task Force Sight and Life; 2001.

Midyat L, Zafer Kurugöl N, Akşit S, Tanrıverdi M, Yağcı RV. Dietary vitamin A intake and serum retinol concentrations of preschool children from different socio-economical levels in Izmir, Turkey. Acta Paediatr. 2011;100(7):24-7.

Miglioli TC, Fonseca VM, Gomes Junior SC, Lira PIC, Batista Filho M. Deficiência de Vitamina A em mães e filhos. Ciênc saúde coletiva. 2013;18(5):1427-40.

Milagres RCRM, Nunes LC, Pinheiro-Sant'ana HM. A deficiência de vitamina A em crianças no Brasil e no mundo. Ciênc saúde coletiva. 2007;5(12):1253-66.

Miller HAE, Mason AC, Weaver CM, McCabe GP, Boushey CJ. Food insecurity is associated with iron deficiency anemia in US adolescents. Am J Clin Nutr. 2009;90(5):1358-71.

Miller JL. Iron deficiency anemia: a common and curable disease. Cold Spring Harb Perspect Med. 2013;3(7):a011866.

Miranda AS, Franceschini SC, Priori SE, Euclydes MP, Araújo RM, Ribeiro SM et al. Anemia ferropriva e estado nutricional de crianças com idade de 12 a 60 meses do município de Viçosa, MG. Rev Nutr. 2003;16(2):163-69. 
Monteiro CA, Szarfarc SC, Mondini L. Tendência secular da anemia na infância na cidade de São Paulo (1984-1996). Rev Saúde Pública. 2000;34(Suppl6):62-72.

Monteiro CA, Benicio MH D`A, Conde WL, Konno SC, Lima ALL; Barros AJD, Victora CG. Desigualdades socioeconômicas na baixa estatura infantil: a experiência brasileira, 1974-2007. Estud av. 2013;27(78), 38-49.

Mora JO, Gueri M, Mora OL. Vitamin A deficiency in Latin America and the Caribbean: An overview. Rev Panam Salud Pública. 1998;4(3):176-86.

Morais MB, Alves GM, Fagundes-Neto U. Nutritional status of Terena indian children from Mato Grosso do Sul, Brazil: follow up of weight and height and current prevalence of anemia. J Pediatr. 2005;81(5):383-9.

Moura NC, Canniatti-Brazaca SG. Avaliação da disponibilidade de ferro de feijão comum (Phaseolus vulgaris L.) em comparação com carne bovina. Ciênc Tecnol Aliment. 2006;26(2):270-6.

Muniz PT, Castro TG, Araújo TS, Nunes NB, Silva-Nunes M, Hoffmann EHE et al. Child health and nutrition in the Western Brazilian Amazon population-based surveys in two counties in Acre State. Cad Saúde Publica. 2007;23(6):1283-93.

Muniz-Junqueira MI, Queiroz EF. Relationship between protein-energy malnutrition, vitamin A, and parasitoses in children living in Brasília. Rev Soc Bras Med Trop. 2002;35(2):133-42.

Mwanri L, Worsley A, Ryan P. Supplemental vitamin A improves anemia and growth in anemic school children in Tanzania. J Nutr. 2000;130(11):2691-6.

Netto MP, Priore SE, Franceschini SCC. Interação entre vitamina A e ferro em diferentes grupos populacionais. Rev Bras Saúde Matern Infant. 2007;7(1):15-22.

Netto MP, Rocha DS, Franceschini SCC, Lamounier JA. Fatores associados à anemia em lactentes nascidos a termo e sem baixo peso. Rev Assoc Med Bras. 2011;57(5):550-8.

Netto MP, Priore SE, Sant'Ana HMP, Peluzio MCG, Sabarense CM, Franceschini SCC. Fatores associados à concentração de retinol sérico em lactentes. Rev paul pediatr. 2012;30(1):27-34.

Neuman NA, Tanaka OY, Szarfarc SC, Guimarães PR, Victora CG. Prevalência e fatores de risco para anemia no Sul do Brasil. Rev Saúde Pública. 2000;34(1):5663.

Neves MB, da Silva EM, de Morais MB. Prevalência e fatores associados à deficiência de ferro em lactentes atendidos em um centro de saúde-escola em Belém, Pará, Brasil. Cad Saúde Publica. 2005;21(6):1911-8. 
Ngnie-Teta I, Receveur O, Kuate-Defo B. Risk factors for moderate to severe anemia among children in Benin and Mali: Insights from a multilevel analysis. Food Nutr Bull. 2007;28(1):76-89.

Nguyen PH, Nguyen KC, Le Mai B, Nguyen TV, Ha KH, Bern C, Flores R, Martorell R. Risk factors for anemia in Vietnam. Southeast Asian J Trop Med Public Health. 2006; 37(6): 1213-23.

Nogueira-de-Almeida CA, Ricco RG, Del Ciampo LA, de Souza AM, Dutra-deOliveira JE. Growth and hematological studies on Brazilian children of low socioeconomic level. Arch Latinoam Nutr. 2001;51(3):230-5.

Oliveira RS, Diniz AS, Benigna MJ, Miranda-Silva SM, Lola MM, Gonçalves MG et al. Magnitude, distribuição espacial e tendência da anemia em préescolares da Paraíba. Rev Saúde Pública. 2002;36(1):26-32.

Oliveira MAA, Osório MM, Raposo MCF. Concentração de hemoglobina e anemia em crianças no Estado de Pernambuco, Brasil: fatores sócio-econômicos e de consumo alimentar associados. Cad Saúde Publica. 2006;22(10):2169-78.

Oliveira MAA, Osório MM, Raposo MCF. Fatores socioeconômicos e dietéticos de risco para a anemia em crianças de 6 a 59 meses de idade. J Pediatr. 2007;83(1):39-46.

Oliveira JM, Oliveira NS, Bergamaschi DP. Concentrações de vitamina A no leite humano e características socioeconômicas e nutricionais maternas: resultados de estudos brasileiros. Rev Bras Saúde Matern Infant. 2009;9(1):11-20.

Oliveira JS, Lira PIC, Osório MM, Sequeira LAS, Costa EC, Gonçalves FCLP et al. Anemia, hipovitaminose A e insegurança alimentar em crianças de municípios de Baixo Índice de Desenvolvimento Humano do Nordeste do Brasil. Rev bras epidemiol. 2010;13(4):651-64.

Oliveira CSM, Cardoso MA, Araújo TS, Muniz PT. Anemia em crianças de 6 a 59 meses e fatores associados no Município de Jordão, Estado do Acre, Brasil. Cad Saúde Pública. 2011;27(5):1008-20.

Orellana JD, Coimbra CE Jr, Lourenço AE, Santos RV. Nutritional status and anemia in Surui Indian children, Brazilian Amazon. J Pediatr. 2006;82(5):383-8.

Osório MM, Lira PI, Batista Filho M, Ashworth A. Prevalence of anemia in children 6-59 months old in the state of Pernambuco, Brazil. Rev Panam Salud Pública. 2001;10(2):101-7.

Osório MM. Fatores determinantes da anemia em crianças. J Pediatr. 2002;78(4): 269-78. 
Osório MM, Lira PIC, Ashworth A. Factors associated with Hb concentration in children aged 6 -59 months in the State of Pernambuco, Brazil. Br J Nutr. 2004; 91(2):307-14.

Paiva AA, Rondo PHC, Gonçalves-Carvalho CMR, Illison VK, Pereira JA, Vazde-Lima LRA et al. Prevalência de deficiência de vitamina A e fatores associados em pré-escolares de Teresina, Piauí, Brasil. Cad Saúde Pública. 2006;22(9): 1979-87.

Paiva AA, Cagliari MPP, Queiroz D, Souto RA, Brito VRS, França ISX. Programa Nacional de Suplementação de Vitamina A no Estado da Paraíba: uma análise a partir do relato de profissionais da Equipe de Saúde da Família. Epidemiol Serv Saúde. 2011; 20(3): 373-83.

Palafox NA, Gamble MV, Dancheck B, Ricks MO, Briand K, Semba RD. Vitamin A deficiency, iron deficiency, and anemia among preschool children in the Republic of the Marshall Islands. Nutrition. 2003;19(5):405-8.

Panigassi G, Segal-Corrêa AM, Marin-León L, Perez-Escamilla R, Sampaio MFA, Maranha LK. Insegurança alimentar como indicador de iniquidade: análise de inquérito populacional. Cad Saúde Pública. 2008;24(10):2376-84.

Park K, Kersey M, Geppert J, Story M, Cutts D, Himes JH. Household food insecurity is a risk factor for iron-deficiency anaemia in a multi-ethnic, lowincome sample of infants and toddlers. Public Health Nutr. 2009;12(11):2120-8.

Pasricha SR, Drakesmith H, Black J, Hipgrave D, Biggs BA. Control of iron deficiency anemia in low- and middle-income countries. Blood. 2013;121(14): 2607-17.

Paula RA, Fisberg M. The use of sugar fortified with iron tris-glycinate chelate in the prevention of iron deficiency anemia in preschool children. Arch Latinoam Nutr. 2001;51(Suppl 1):54-9.

Paula WKA, Caminha MFC, Figueirôa JN, Batista Filho M. Anemia e deficiência de vitamina A em crianças menores de cinco anos assistidas pela Estratégia Saúde da Família no Estado de Pernambuco, Brasil. [Internet]. Cienc Saude Colet 2013. [Citado 2013 maio 27]. Disponível em: http://www.cienciaesaudecoletiva.com.br

Pereira RC, Ferreira LOC, Diniz AS, Batista Filho M, Figueirôa JN. Eficácia da suplementação de ferro associado ou não à vitamina $\mathrm{A}$ no controle da anemia em escolares. Cad Saúde Pública. 2007;23(6):1415-21.

Pereira JA; Paiva AZ; Bergamaschi DP; Rondo PHC, Oliveira GC; Lopes IBM; Illison VK; Gonçalves- Carvalho CMR. Concentrações de retinol e de betacaroteno séricos e perfil nutricional de crianças em Teresina, Piauí, Brasil. Rev bras epidemiol. 2008; 11(2): 287-96. 
Pinho BATD, Brito FA. Fluxos migratórios intrametropolitanos: o caso da região metropolitana de Belo Horizonte, 1970-2010. Belo Horizonte: UFMG/CEDEPLAR; 2013.

Prado MS, Assis AM, Martins MC, Nazaré MP, Rezende IF, Conceição ME. Hipovitaminose A em crianças de áreas rurais do semi-árido baiano. Rev Saúde Pública. 1995;29(4):295-300.

Queiroz D, Paiva AA, Pedraza DF, Cunha MAL, Esteves GH, Luna JG et al. Deficiência de vitamina $A$ e fatores associados em crianças de áreas urbanas. Rev Saúde Pública. 2013;47(2):248-56.

Queiroz SS, Torres MAA. Anemia ferropriva na infância. J. Pediatr. 2000;76(3): 298-304.

$\mathrm{R}$ Core Team R: A language and environment for statistical computing. $\mathrm{R}$ Foundation for Statistical Computing, Vienna, Austria. 2012. ISBN 3-900051-070, URL: http://www.R-project.org/.

Ramalho RA, Anjos LA, Flores H. Hipovitaminose A em recém-nascidos em duas maternidades públicas no Rio de Janeiro, Brasil. Cad Saúde Pública. 1998;14(4): $821-7$.

Ramalho RA, Anjos LA, Flores H. Valores séricos de vitamina A e teste terapêutico em pré-escolares atendidos em uma unidade de saúde do Rio de Janeiro, Brasil. Rev Nutr. 2001;14(1):5-12.

Ramalho RA, Flores H, Saunders C. Hipovitaminose A no Brasil: um problema de saúde pública. Rev Panam Salud Pública. 2002;12(2):117-22.

Ramalho RA, Flores H, Accioly E, Saunders C. Associação entre deficiência de vitamina A e situação sociodemográfica de mães e recém-nascidos. Rev Assoc Med Bras. 2006;52(3):170-5.

Ramalho RA, Padilha P, Saunders C. Análise crítica de estudos brasileiros sobre deficiência de vitamina A no grupo materno-infantil. Rev paul pediatr. 2008; 26(4):392-9.

Ramalho RA. Hipovitaminose A. In: Nutrição em saúde Publica. Rio de Janeiro: Rubio; 2011. p. 211-20.

Rao JNK, Scott AJ. On chi-squared tests for multiway contingency tables with cell proportions estimated from survey data. Ann Stat. 1984;12(1):46-60.

Ribeiro H. Como produzir o comum no espaço urbano com equidade. Saúde soc. 2013;22(Suppl 1):33-6. 
Rocha DS, Capanema FD, Netto MP, Franceschini SCC, Lamounier JA. Prevalência e fatores determinantes da anemia em crianças assistidas em creches de Belo Horizonte - MG. Rev bras epidemiol. 2012;15(3):675-84.

Rodrigues CR, Motta SS, Cordeiro AA, Lacerda EM, Reichenheim ME. Prevalência de anemia ferropriva e marcadores de risco associados em crianças entre 12 e 18 meses de idade atendidas nos Ambulatórios do Instituto de Puericultura e Pediatria Martagäo Gesteira. J Pediatr. 1997;73(3):189-94.

Rodrigues VC, Mendes BD, Gozz A, Sandrini F, Santana RG, Matioli G. Deficiência de ferro, prevalência de anemia e fatores associados em crianças de creches públicas do oeste do Paraná, Brasil. Rev Nutr. 2011;24(3):407-20.

Roncada MJ, Wilson D, Netto AL, Netto OB, Nunes MF, Okani ET. Hipovitaminose A em filhos de migrantes nacionais em trânsito pela capital do estado de São Paulo, Brasil. Estudo clínico bioquímico. Rev Saúde Pública. 1978;12(3):345-50.

Roncada MJ, Wilson D, Mazzilli RN, Gandra YR. Hipovitaminose A em comunidades do Estado de São Paulo, Brasil. Rev Saúde Pública. 1981;15(3): $338-49$.

Roncada MJ, Wilson D, Okani ET, Aminos S. Prevalência da hipovitaminose A em pré-escolares do município de área metropolitana de São Paulo. Rev Saúde Pública. 1984;18(3):218-24.

Rondo PH, Abbott R, Tomkins AM. Vitamin A and neonatal anthropometry. J Trop Pediatr. 2001;47(5):307-10.

Sachdeva S, Alam S, Beig FK, Khan Z, Khalique N. Determinants of Vitamin A Deficiency amongst Children in Aligarh District, Uttar Pradesh. Indian Pediatrics. 2011;48(11):861-6.

Sales MC, Paiva AA, Queiroz D, Costa RAF, Cunha MAL, Pedraza DF. Nutritional status of iron in children from 6 to 59 months of age and its relation to vitamin A deficiency. Nutr Hosp. 2013;28(3):734-40.

Sales-Costa R, Pereira RA, Vasconcelos MTL, Veiga GV, Marins VMR, Jardim $\mathrm{BC}$ et al. Associação entre fatores socioeconômicos e insegurança alimentar: estudo de base populacional na região metropolitana do Rio de Janeiro, Brasil. Rev Nutr. 2008;21(Suppl ):99-109.

Santos LM, Assis AMO, Martins MC, Araújo MPN, Morris SS, Barreto ML. Situação alimentar e nutricional de pré-escolares no semiárido da Bahia: II. Hipovitaminose A. Rev Saúde Pública. 1996;30(1):67-74.

Santos I, César JA, Minten G, Valle N, Neumann NA, Cercato E. Prevalência e fatores associados à ocorrência de anemia entre menores de seis anos de idade em Pelotas, RS. Rev bras epidemiol. 2004;7(4):403-15. 
Saunders C, Ramalho A, Padilha PC, Barbosa CC, Leal MC. A investigação da cegueira noturna no grupo materno-infantil: uma revisão histórica. Rev Nutr. 2007;20(1):95-105.

Segall-Corrêa AM, Pérez-Escamilla R, Maranha LK, Sampaio MFA, Marin-Leon L, Panigassi $G$ et al. Acompanhamento e avaliação da segurança alimentar de famílias brasileiras: validação de metodologia e de instrumento de coleta de informação. Relatório técnico. Ministério da Saúde; 2004.

Segall-Corrêa AM, Marin-Leon L, Helito H, Pérez-Escamilla R, Santos LMP, Paes-Sousa R. Transferência de renda e segurança alimentar no Brasil: análise dos dados nacionais. Rev Nutr. 2008;21(Suppl):39-51.

Semba RD, Bloem MW. The anemia of vitamin A deficiency: epidemiology and pathogenesis. Eur J Clin Nutr. 2002;56(4):271-81.

Sherwin JC, Reacher MH, Dean WH, Ngondi J. Epidemiology of vitamin A deficiency and xerophthalmia in at-risk populations. Trans R Soc Trop Med Hyg. 2012;106(4):205-14.

Skalicky A, Meyers AF, Adams WG, Yang Z, Cook JT, Frank DA. Child food insecurity and iron-deficiency anemia in low-income infants and toddlers in the United States. Matern Child Health J. 2006;10(2):177-85.

Silva LSM, Giugliani ERJ, Aerts DRGC. Prevalência e determinantes de anemia em crianças de Porto Alegre, RS, Brasil. Rev Saúde Pública. 2001;35(1):66-73.

Silva MR, Castro TG, Costa NB, Ferreira CL, Franceschini SC, Leal PF et al. Efeito de uma bebida láctea fermentada e fortificada com ferro sobre o estado nutricional de ferro em pré-escolares.Viçosa-MG. Nutrire: Rev Soc Bras Aliment Nutr. 2002a;23:23-32.

Silva DG, Franceschini S do C, Priore SE, Ribeiro SM, Szarfarc SC, Souza SB et al. Anemia ferropriva em crianças de 6 a 12 meses atendidas na rede pública de saúde do município de Viçosa, Minas Gerais. Rev Nutr. 2002b;15(3):301-8.

Silva AP, Vitolo MR, Zara LF, Castro CF. Efeito da suplementação de zinco a crianças de 1 a 5 anos de idade. J Pediatr. 2006;82(3):227-31.

Silva DG, Priore SE, Franceschini SCC. Fatores de risco para anemia em lactentes atendidos nos serviços públicos de saúde: a importância das práticas alimentares e da suplementação com ferro. J Pediatr. 2007;83(2):149-56.

Silva RC, Assis AMO, Santana MLP, Barreto ML. Relação entre os níveis de vitamina A e os marcadores bioquímicos do estado nutricional de ferro em crianças e adolescentes. Rev Nutr. 2008;21(3):285-91.

Silva EB, Villani MS, Jahn AC, Coco M. Prevalência da anemia em crianças avaliadas pela palidez palmar. Esc Anna Nery. 2011;15(3):497-506. 
Soares NT, Guimarães AR, Sampaio HA, Almeida PC, Coelho RR. Estado nutricional de lactentes em áreas periféricas de Fortaleza. Rev Nutr. 2000;13(2): 99-106.

Souza SB, Szarfarc SC, de Souza JM. Anemia no primeiro ano de vida em relação ao aleitamento materno. Rev Saúde Pública. 1997;31(1):15-20.

Souza WA, Villas Boas OMGC. A deficiência de vitamina A no Brasil: um panorama. Rev Panam Salud Pública. 2002;12(3):173-9.

Souza OF, Macedo LF, Oliveira CSM, Araújo TS, Muniz PT. Anemia em crianças de Rio Branco, AC: prevalência e fatores associados. Rev bras crescimento desenvolv hum. 2012a;22(3):307-13.

Souza NN, Moura e Dias M, Sperandio N, Franceschini SCC, Priore SE. Perfil socioeconômico e insegurança alimentar e nutricional de famílias beneficiárias do Programa Bolsa Família no município de Viçosa, Estado de Minas Gerais, Brasil, em 2011: um estudo epidemiológico transversal. Epidemiol Serv Saúde. 2012b; 21(4):655-62.

Spinelli MGN, Souza JMP, Souza SB, Sesoko EH. Confiabilidade e validade da palidez palmar e de conjuntivas como triagem de anemia. Rev Saúde Pública. 2003;37(4):404-8.

Spinelli MGN, Marchioni DML, Souza JMP, Souza SB de, Szarfarc SC. Fatores de risco para anemia em crianças de 6 a 12 meses no Brasil. Rev Panam Salud Pública. 2005;17(2):84-91.

Szarfarc SC, Berg G, Santos AL, Souza SB, Monteiro CA. Prevenção de anemia no primeiro ano de vida em centros de saúde do município de Santo André, São Paulo. J Pediatr. 1996;72(5):329-34.

Terão SM, Puccini RF, Silva EM, Pedroso GC, Silva NN. Prevalência de anemia em crianças residentes no município do Embu (São Paulo), 1996-7. Rev paul pediatr. 2004;22(1):7-14.

Torres MA, Lobo NF, Sato K, Queiroz S de S. Fortificação do leite fluido na prevenção e tratamento da anemia carencial ferropriva em crianças menores de 4 anos. Rev Saúde Pública. 1996;30(4):350-7.

Torres MA, Braga JA, Taddei JA, Nóbrega FJ. Anemia em lactentes de baixa renda em aleitamento materno exclusivo. J Pediatr. 2006;82(4):284-7.

Tuma RB, Yuyama LK, Aguiar JP, Marques HO. Impacto da farinha de mandioca fortificada com ferro aminoácido quelato no nível de hemoglobina de pré-escolares. Rev Nutr. 2003;16(1):29-39. 
Uchimura TT, Szarfarc SC, Latorre MR, Uchimura NS, Souza SB. Anemia e peso ao nascer. Rev Saúde Pública. 2003;37(4):397-403.

Fundo das Nações Unidas para a Infância (UNICEF). Situação Mundial da Infância 2012. [citado em 2013 dez. 09]. Disponível em: <http://www.unicef.org/brazil/pt/PT-BR_SOWC_2012.pdf $>$.

Vasconcelos AMA, Ferreira HS. Prevalência de hipovitaminose A em crianças da região semi-árida de Alagoas (Brasil), 2007. Arch Latinoam Nutr. 2009;59(2): $152-8$.

Victora CG, Barreto ML, Leal MC, Monteiro CA, Schmidt MI, Paim J, et al. Health conditions and health-policy innovations in Brazil: the way forward. Lancet. 2011a; 377(9782):29-42.

Victora CG, Aquino EML, Leal MC, Monteiro CA, Barros FC, Szwarcwald CL. Maternal and child health in Brazil: progress and challenges. Lancet. 2011b; 377(9782):1863-76.

Vieira RCS, Ferreira HS. Prevalência de anemia em crianças brasileiras, segundo diferentes cenários epidemiológicos. Rev Nutr. 2010;23(3):433-44.

Vitolo MR, Aguirre AN, Kondo MR, Giuliano Y, Ferreira N, Lopez FA. Impacto do uso de cereal adicionado de ferro sobre os níveis de hemoglobina e a antropometria de pré-escolares. Rev Nutr. 1998;11(2):163-71.

Vitolo MR, Bortolini GA, Feldens CA, Drachler ML. Impactos da implementação dos dez passos da alimentação saudável para crianças: ensaio de campo randomizado. Cad Saúde Publica. 2005;21(5):1448-57.

Vitolo MR, Bortolini GA. Biodisponibilidade do ferro como fator de proteção contra anemia entre crianças de 12 a 16 meses. J Pediatr. 2007;83(1):33-8.

Whitehead M. The concepts and principles of equity and health. Copenhagen: World Health Organization; 2000.

World Health Organization (WHO). Physical status: the use and interpretation of anthropometry. Geneva; 1995.

World Health Organization (WHO). Indicators for assessing vitamin A deficiency and their application in monitoring and evaluating intervention programmes. Geneva; 1996.

World Health Organization (WHO). Nutrition for Health and Development: A global agenda for combating malnutrition. Progress Report. France; 2000.

World Health Organization (WHO). Iron deficiency anaemia: assessment, prevention, and control: a guide for programme managers. Geneva; 2001. 
World Health Organization (WHO). Assessing the iron status of populations: Report of a Joint World Health Organization/ Centers for Disease Control and Prevention Technical Consultation on the Assessment of Iron Status of population Level. Geneva; 2004.

World Health Organization (WHO). Multicentre Growth Reference Study Group. WHO child growth standards: length/height-for-age, weight-for-age, weightforlength, weight-for-height and body mass index-for-age: methods and development. Geneva; 2006.

World Health Organization (WHO). Conclusions and recommendations of the WHO consultation on prevention and control of iron deficiency in infants and young children in malaria-endemic areas. Food Nutr Bull. 2007;28(4):621-7.

World Health Organization (WHO). Worldwide prevalence of anaemia 19932005. WHO global database on anaemia. Geneva; 2008.

World Health Organization (WHO). Global prevalence of vitamin A deficiency in populations at risk 1995-2005. WHO Global Database on Vitamin A Deficiency. Geneva; 2009.

World Health Organization (WHO). Guideline: Vitamin A supplementation in infants and children 6-59 months of age. Geneva; 2011.

Willows ND, Gray-Donald K. Serum retinol is associates with hemoglobin concentration in infants who are not vitamin A deficient. Nutr Res. 2003;23(7): 891-900.

Wilson D, Roncada MJ, Lui Netto A, Berretta N O. Hipovitaminose A em préescolares internados em uma instituição na capital do Estado de São Paulo, Brasil. Rev Saúde Pública. 1981;15(4):395-400.

Zimmerman MB, Biebinger R, Rohner F. Vitamin A supplementation in children with poor vitamin $\mathrm{A}$ and iron status increases erythropoietin and hemoglobin concentrations without changing total body iron. Am J Clin Nutr. 2006;84(3):5806. 